\title{
Biosynthesis and heterologous production of argyrins
}

Domen Pogorevc $\star^{\mathrm{a}}$, Ying Tang ${ }^{\ddagger \mathrm{a}, \mathrm{b}, \mathrm{c}}$, Michael Hoffmann ${ }^{\mathrm{a}, \mathrm{d}}$, Gregor Zipf ${ }^{\mathrm{e}}$, Hubert S. Bernauer $^{\mathrm{e}}$, Alexander Popoff ${ }^{\text {a }}$, Heinrich Steinmetz $^{\mathrm{f}}$, Silke C. Wenzel ${ }^{\text {a* }}$

a Department of Microbial Natural Products, Helmholtz Institute for Pharmaceutical Research Saarland (HIPS) / Helmholtz Centre for Infection Research (HZI) and Department of Pharmaceutical Biot echnology, Saarland University, 66123 Saarbruecken, Germany

${ }^{\mathrm{b}}$ Hunan Provincial Key Laboratory of Microbial Molecular Biology, State Key Laboratory of Developmental Biology of Freshwater Fish, College of Life Science, Hunan Normal University, Changsha 410081, People's Republic of China

${ }^{\mathrm{c}}$ current address: School of Basic Medical Science, Changsha Medical University, Changsha, PR China

${ }^{\mathrm{d}}$ current address: BASF SE, 67056 Ludwigshafen am Rhein, Germany

e ATG:biosynthetics GmbH, 79249 Merzhausen, Germany

${ }^{\mathrm{f}}$ Microbial Strain Collection, Helmholtz Centre for Infection Research (HZI), 38124 Braunschweig, Germany

$\$$ These authors contributed equally.

* Corresponding author. Phone: +49 681 30270221. Email address: s.wenzel@mx.uni-saarland.de 


\section{Table of Contents}

1 Inactivation of the argyrin biosynthetic pathway in Cystobacter sp. SBCb004......................................5

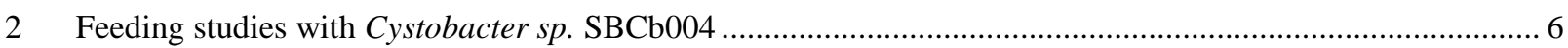

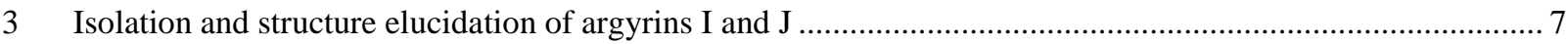

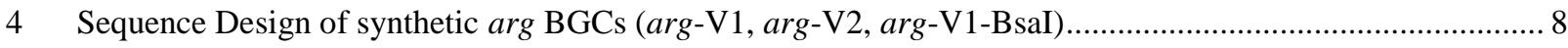

5 Construction of $M$. xanthus DK1622 AmchA-tet and arg BGC expression strains.................................... 9

$6 \quad$ Analysis of argyrin production in $M . x a n t h u s$ and valine feeding experiment ....................................... 11

$7 \quad$ Engineering of the A1 domain of the argyrin NRPS megasynthetase ................................................ 12

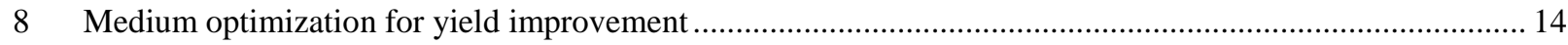

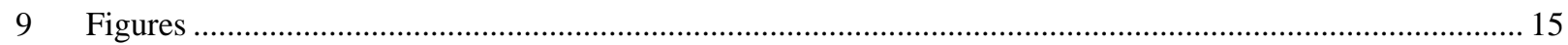

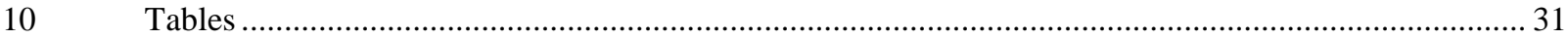

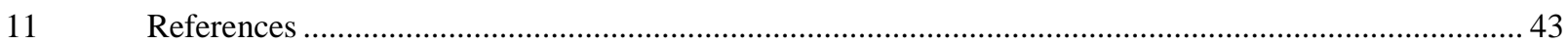




\section{List of Figures}

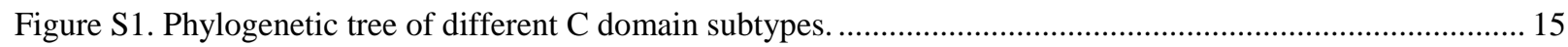

Figure S2. Inactivation of arg3 in Cystobacter sp. SBCb004 by insertional mutagenesis.................................... 16

Figure S3. Argyrin production analysis after arg3 inactivation in Cystobacter sp. SBCb004.............................. 16

Figure S4. Analysis of the incorporation $L$-serine-2,3,3-D3 during argyrin biosynthesis................................ 17

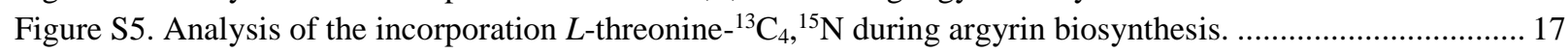

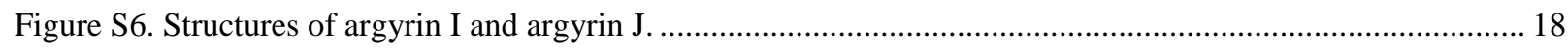

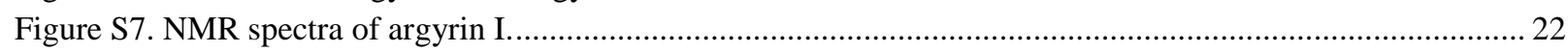

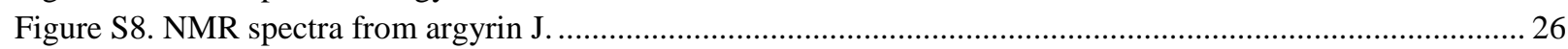

Figure S9. Effect of the $\arg$-V2 sequence modulation on selected features in comparison to $\arg$-native. .............27

Figure S10. Construction and verification of expression strains. ...............................................................2 28

Figure S11. Analysis of the incorporation $L$-valine-D8 during argyrin biosynthesis......................................... 29

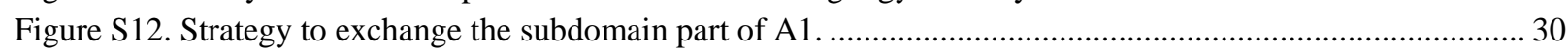

Figure S13. Modification strategy of the pArg2345-V1-BsaI expression construct. ........................................... 30 


\section{List of Tables}

Table S1. Genes, proteins, proposed function in the arg BGC from Cystobacter sp. SBCb004.......................... 31

Table S2. Substrate specificity analysis of A domains from the argyrin NRPS from Cystobacter sp. SBCb004.... 31

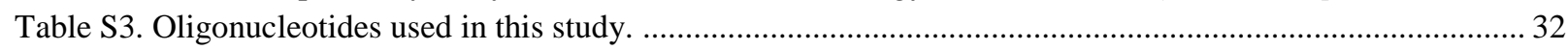

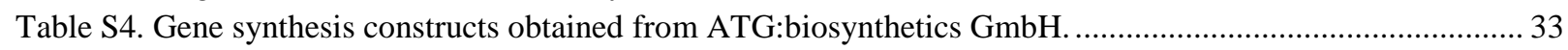

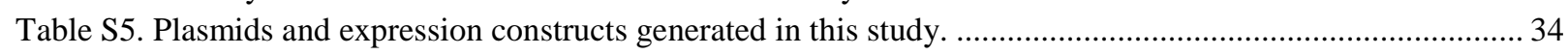

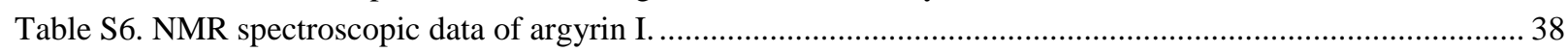

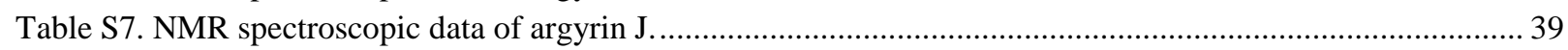

Table S8. Restriction sites (R-sites) engineered within the $\operatorname{arg~BGC~and~pSynBio3~sequence.............................40~}$

Table S9. Sequence features of synthetic arg BGC versions compared to the native sequence. ...........................40

Table S10. HPLC-MS data of argyrin derivatives detected in the heterologous expression strains. .....................41

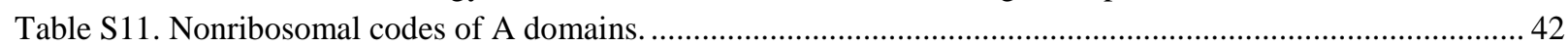




\section{Inactivation of the argyrin biosynthetic pathway in Cystobacter sp. SBCb004}

To verify that the identified BGC is indeed involved in argyrin production, one of the NRPS encoding genes ( $\arg 3)$ was inactivated by insertion of the suicide plasmid. For this purpose, the pArg1 plasmid was constructed and a conjugation protocol was established for transformation of Cystobacter sp. SBCb004. After genotypic verification of the obtained mutants secondary metabolite production was analyzed. In contrast to the wild type strain, all mutants were shown to lack production of argyrins. Experimental details are described below.

For the construction of pArg1 a $1.1 \mathrm{~kb}$ homologous fragment of arg3 was amplified from genomic DNA using the oligonucleotides Arg1/Arg2 (Table S3) and Taq DNA polymerase according to the manufacturer's protocol. PCR conditions were as follows: initial denaturation 3 min at $95{ }^{\circ} \mathrm{C}$; denaturation $30 \mathrm{~s}$ at $95{ }^{\circ} \mathrm{C}$; annealing $50 \mathrm{~s}$ at $56{ }^{\circ} \mathrm{C}$; extension $90 \mathrm{~s}$ at $72{ }^{\circ} \mathrm{C} ; 30$ cycles. The amplified fragment was ligated into the conjugable plasmid pSUP-Km, ${ }^{1}$ using the enzymes EcoRV/BamHI to generate the suicide plasmid pArg1.

To transform Cystobacter sp. SBCb004 with the suicide plasmid pArg1 a suitable conjugation procedure was established as follows: Cultures of the methylation-deficient strain E. coli SCS110 carrying pArg1 (SCS110/pArg1), E. coli HB101 carrying the helper plasmid pRK600² (HB101/pRK600) as well as Cystobacter sp. SBCb004 were grown in LB medium (amended with kanamycin for pArg1 or chloramphenicol for pRK600) or rather M medium until an OD 600 of 0.6 was reached. Cells from $2 \mathrm{ml}$ Cystobacter sp. SBCB004 culture were washed using 2 x 2 $\mathrm{ml}$ HEPES buffer ( $5 \mathrm{mM}$ HEPES [pH 7.2], $0.5 \mathrm{mM} \mathrm{CaCl}_{2}$ ) and cells from the E. coli cultures $(1 \mathrm{ml})$ were washed with LB medium $(2 \times 1 \mathrm{ml})$. After combining the cells in $1 \mathrm{ml} \mathrm{M}$ medium and shaking for $3 \mathrm{~h}$ at $30^{\circ} \mathrm{C}$, the cells were re-suspended in $250 \mu \mathrm{l}$ fresh M medium and plated out on an $\mathrm{M}$ agar plate, which was incubated at $30{ }^{\circ} \mathrm{C}$ for $2 \mathrm{~d}$. The cells were scraped from the plate, re-suspended in $\mathrm{M}$ medium and plated out on $\mathrm{M}$ agar amended with $100 \mu \mathrm{g} / \mathrm{ml}$ kanamycin and $120 \mu \mathrm{g} / \mathrm{ml}$ tobramycin. The plates were incubated at $30{ }^{\circ} \mathrm{C}$ until transconjugants appeared (about 3-4 d).

To verify the correct chromosomal integration of pArg1 the obtained transconjugants were analyzed by PCR (see Fig. S2). For this, the mutants were grown in M medium amended with kanamycin and genomic DNA was isolated using the Gentra PURGENE® DNA Purification Kit (Qiagen). Using the genomic DNA as template PCR analysis with different sets of oligonucleotides (Arg10/Arg11, Arg10/pSUP_B, Arg11/pSUP_E; see Table S3) and Taq DNA polymerase was performed according to the manufacturer's protocol. PCR conditions were as follows: initial denaturation $3 \mathrm{~min}$ at $95{ }^{\circ} \mathrm{C}$; denaturation $30 \mathrm{~s}$ at $95{ }^{\circ} \mathrm{C}$; annealing $50 \mathrm{~s}$ at $56{ }^{\circ} \mathrm{C}$; 
extension $90 \mathrm{~s}$ at $72{ }^{\circ} \mathrm{C} ; 30$ cycles. PCRs using oligonucleotides Arg10/pSUP_B and Arg11/pSUP_E produced DNA fragments of expected size in the Cystobacter sp. SBCb004::pArg1 mutants but not in Cystobacter sp. SBCb004 verifying that pArg1 was successfully integrated into gene $\arg 3$ on the chromosome (Fig. S2).

For phenotypic analysis the Cystobacter sp. SBCb004::pArg1 mutant strains as well as Cystobacter sp. SBCb004 wild-type were cultivated in $50 \mathrm{ml} \mathrm{M}$ liquid medium containing $2 \%$ XAD-16 for 4 days. The cells together with the XAD were harvested by centrifugation and extracted with methanol. To compare the spectrum of secondary metabolites produced by the mutant with that of the wild type strain, 50:1 concentrated methanol extracts were analysed by High performance liquid chromatography-mass spectrometry-diode array detection (HPLCMS-DAD). An Agilent 1100 series solvent delivery system coupled to Bruker HCTplus ion trap mass spectrometer was used. Chromatographic separation was carried out on an RP column Nucleodur C18 (125 by $2 \mathrm{~mm}, 3 \mu \mathrm{m}$ particle size; Macherey-Nagel) equipped with a precolumn C18 ( $8 \times 3 \mathrm{~mm}, 5 \mu \mathrm{m})$. The mobile phase gradient (solvent A: water $+0.1 \%$ formic acid and solvent B: acetonitrile $+0.1 \%$ formic acid) was linear from $5 \% \mathrm{~B}$ at 2 min to $95 \% \mathrm{~B}$ at $32 \mathrm{~min}$, followed by $4 \mathrm{~min}$ with $95 \% \mathrm{~B}$ at a flow rate of $0.4 \mathrm{ml} / \mathrm{min}$. Diode array detection was carried out at 200-600 $\mathrm{nm}$ and mass detection was performed in the positive and negative ionization mode within a range of 100-1100 amu. As shown in Fig. S3, the wild type culture produced $\operatorname{argyrin} \mathrm{A}, \operatorname{argyrin} \mathrm{B}, \operatorname{argyrin} \mathrm{D}$, and argyrins $\mathrm{E}$ to $\mathrm{H}$. On the contrary, the mutant did not produce any of these argyrins, demonstrating the involvement of enzyme encoded by arg3 in the argyrin biosynthesis.

\section{$2 \quad$ Feeding studies with Cystobacter sp. SBCb004}

To investigate the biosynthetic origin of the $L$ - $\alpha$-aminobutyrate (Abu) and dehydroalanine (Dha) units of argyrins, feeding studies with $L$-threonine- ${ }^{13} \mathrm{C}_{4},{ }^{15} \mathrm{~N}$ and $L$-serine-2,3,3-D3 were performed with the native producer Cystobacter sp. SBCb004. Experimental details and results are described below.

From a well-grown agar plate of Cystobacter sp. SBCb004 culture flasks with $50 \mathrm{ml} \mathrm{M}$ medium were inoculated and incubated on a rotary shaker $(200 \mathrm{rpm})$ at $30{ }^{\circ} \mathrm{C}$ for 4 days. Solutions of isotopically labelled precursors were prepared by dissolving $25 \mathrm{mg}$ of $L$-threonine${ }^{13} \mathrm{C}_{4},{ }^{15} \mathrm{~N}$ (Isotec) and $L$-serine-2,3,3-D3 (CIL) in $1.5 \mathrm{ml}$ water followed by sterile filtration. Equal aliquots $(300 \mu \mathrm{l})$ were fed to the production cultures after $24 \mathrm{~h}, 29 \mathrm{~h}, 32 \mathrm{~h}, 48 \mathrm{~h}$ and $56 \mathrm{~h}$ of incubation in parallel to a control experiment where no labelled precursor was added. 
Amberlite XAD-16 adsorber resin (2\%) was added after $72 \mathrm{~h}$ to all cultures. After $90 \mathrm{~h}$ of incubation the cultures were harvested by centrifugation and cells/XAD were extracted with $50 \mathrm{ml}$ of methanol. Concentrated methanol extracts from the feeding experiments and the respective controls without feeding were analyzed by HPLC-MS. Separation was performed on a Dionex UltiMate 3000 RSLC system equipped with a Waters BEH C18 $(100 \times 2.1 \mathrm{~mm}, 1.7$ $\mu \mathrm{m} \mathrm{dp}$ ) column using a linear gradient with solvent $\mathrm{A}$ (water $+0.1 \%$ formic acid) and $\mathrm{B}$ (acetonitrile $+0.1 \%$ formic acid) at a flow rate of $550 \mu \mathrm{l} / \mathrm{min}$ and $45{ }^{\circ} \mathrm{C}$. The gradient was initiated by a 0.39 min isocratic step with $5 \% \mathrm{~B}$ followed by an increase to $95 \% \mathrm{~B}$ within 18 min. HPLC was coupled to a Thermo Fisher Orbitrap via an Advion Triversa NanoMate nano-ESI system. Mass spectra were acquired in positive ionization mode with a range of 200$2000 \mathrm{~m} / \mathrm{z}$ at a resolution of $\mathrm{R}=30000$. Identities of the argyrins were confirmed by comparing with both retention time and $\mathrm{MS}^{2}$ fragmentation pattern of the authentic compounds. Results from the HPLC-MS analysis of the crude extracts are shown in Fig. S4/S5. Argyrin A and argyrin B exhibit in MS analysis three apparent isotopic signals with the monoisotopic signal $[\mathrm{M}+\mathrm{H}]^{+}$of $825.3143 \mathrm{~m} / \mathrm{z}$ (argyrin A) and $839.3300 \mathrm{~m} / \mathrm{z}$ (argyrin B). After feeding of the labelled precursors additional isotope signals appeared with a maximum intensity of a peak of $+2.0125 \mathrm{~m} / \mathrm{z}$ for $L$-serine-2,3,3-D3 (analyzed for $\operatorname{argyrin}$ A, Fig. S4) and $+4.0134 \mathrm{~m} / \mathrm{z}$ for

$L$-threonine- ${ }^{13} \mathrm{C}_{4},{ }^{15} \mathrm{~N}$ (analyzed for argyrin B; Fig. S5). These data indicate that the Dha unit indeed originates from serine and that the ethyl group of the peptide core from argyrin B (as well as from argyrins D and G) results from incorporation of an Abu unit. The latter is supplied by primary metabolism through conversion of $L$-threonine by threonine deaminase and aminotransferase enzymes as illustrated in Fig. S5C. ${ }^{3}$

\section{Isolation and structure elucidation of argyrins I and J}

During re-evaluation of extract fractions from large-scale fermentations of native argyrin producers, ${ }^{4}$ two novel argyrin derivatives (argyrin I and J, Fig. S6) were isolated (chromatographic data not shown). Structure elucidation was achieved using NMR spectroscopy and the high-resolution mass spectrometry (HR-MS). High resolution mass spectra were acquired on an UPLC coupled Bruker Daltonics maXis 4G qToF mass spectrometer in a range from $150-2500 \mathrm{~m} / \mathrm{z}$ in positive ionization mode. Separation was carried out on a Waters BEH C18 $100 \times 2.1 \mathrm{~mm}, 1.7 \mu \mathrm{m}$ dp column using $\mathrm{H}_{2} \mathrm{O}+0.1 \%$ formic acid as A and acetonitrile $+0.1 \%$ formic acid as B. Separation was carried out on a linear gradient from A to B over 16 minutes. HR-MS data of argyrin I yielded an $[\mathrm{M}+\mathrm{H}]^{+}$ion at $\mathrm{m} / z$, 809.3193 consistent with a molecular formula $\mathrm{C}_{40} \mathrm{H}_{44} \mathrm{~N}_{10} \mathrm{O}_{7} \mathrm{~S}\left(809.3188\right.$ calculated for $\left.\mathrm{C}_{40} \mathrm{H}_{45} \mathrm{~N}_{10} \mathrm{O}_{7} \mathrm{~S}\right)$. 
HR-MS data of argyrin J yielded an $[\mathrm{M}+\mathrm{H}]^{+}$ion at $\mathrm{m} / z 825.3204$ consistent with a molecular formula $\mathrm{C}_{40} \mathrm{H}_{44} \mathrm{~N}_{10} \mathrm{O}_{8} \mathrm{~S}$ (825.3137 calculated for $\mathrm{C}_{40} \mathrm{H}_{45} \mathrm{~N}_{10} \mathrm{O}_{8} \mathrm{~S}$ ). NMR spectra were acquired in $\mathrm{CDCl}_{3}$ at a Bruker Ascend $700 \mathrm{MHz}$ spectrometer. 1D ${ }^{1} \mathrm{H}$ as well as $2 \mathrm{D}{ }^{1} \mathrm{H}-{ }^{1} \mathrm{H}$ COSY, HSQC and HMBC spectra were recorded using standard pulse programs and are illustrated in Fig. S7/S8. Carbon chemical shifts were extracted from 2D NMR data. NMR spectroscopic data are listed in Tables S6/S7. The NMR data of argyrin I and J were in accordance with those of argyrin $\mathrm{E}$ and $\mathrm{H}$, which harbor a methyl group instead of an ethyl group in position $\mathrm{R}_{1}$. It is assumed that the absolute configuration of argyrin I and J corresponds to argyrin $\mathrm{A}-\mathrm{H}$ as the argyrin megasynthetase very likely applies the same stereochemistry control.

\section{Sequence Design of synthetic arg BGCs (arg-V1, $\arg -\mathrm{V} 2, \arg -\mathrm{V1}-\mathrm{BsaI})$}

To meet the constructive demands for arg BGC assembly based on synthetic building blocks and prospective modifications, endonuclease restriction sites ( $\mathrm{R}$-sites) were engineered as illustrated in Fig. 2A. This included the insertion of unique R-sites upstream and downstream of each gene, within the 5' end of $\arg 2$ as well as in NRPS intermodule linker regions of arg2 and arg3. Simultaneously, 59 interfering R-sites along the entire arg BGC sequence were eliminated. R-sites engineering was performed by point mutations (synonymous codon substitutions in coding regions) according to a list of 22 restriction enzymes selected for arg BGC and pSynBio3 vector backbone design (Table S8).

No further sequence modulation was performed in case of the arg-V1 BGC, whereat the argV2 sequence was additionally adapted by applying a similar strategy as previously reported for construction of a synthetic epothilone BGC. ${ }^{5}$ An artificial host codon usage table ("myxoPKS/NRPS") was used as basis for formal sequence optimization with particular emphasis on parameters affecting translational elongation. The relative adaptiveness scoring system implemented in the codon adaptation index $\left(\mathrm{CAI} ;{ }^{6}\right)$ was used to modulate the course of the local CAI in the four arg-V2 coding sequences (CDS). Due to the assumption that the translation rate of a single codon is to some degree correlated with its synonymous codon fraction, a slight gradient was engineered in the four arg-V2 CDSs (Fig. 2B), which theoretically should improve the ribosomal packing ratio along the whole message if the translation initiation rate is sufficiently high. The occurrence of internal Shine-Dalgarno (SD) sequences was strongly suppressed to avoid unfavorable duplex formation with the anti-SD sequence of the $16 \mathrm{~S}$ rRNA during translation. ${ }^{7}$ As illustrated in Fig. S9A, the $\arg ^{-V} 2 \mathrm{CDSs}$ show no strong signals indicating SD - ASD interactions in contrast to arg-native. In addition, the clustered occurrence of low frequency codons, which could cause ribosome stalling and 
abortion during translation, was avoided. The resulting $\arg$-V2 sequence lacks pronounced downward local CAI peaks according to a smaller 9 codon window ${ }^{8}$ (Fig. S9B). As it is assumed that "hidden" stop codons can have a positive impact on gene expression by preventing off-frame gene reading, ${ }^{9,10}$ the density of stop codons in neighbouring frames was increased in the $\arg$-V2 sequence (Fig. S9C). Furthermore, the emergence of homopolymeric stretches, which can cause transcriptional slippage, as well as DNA sequence repeats, was suppressed during arg-V2 optimization and the GC-content was kept within preselected limits.

Overall, sequence modifications were more extensive for $\arg -\mathrm{V} 2$ compared to $\arg -\mathrm{V} 1$, for which only R-sites engineering was applied. To facilitate future BGC engineering procedures, the $\arg$-V1 BGC sequence was later on further modified by eliminating all $32 \mathrm{BsaI}$ R-sites via synonymous codon substitutions ( $\operatorname{rrg}-\mathrm{V} 1-\mathrm{BsaI})$. Table S9 shows a comparison between argnative and the adapted gene sequences of $\arg -\mathrm{V} 1, \arg -\mathrm{V} 2$ and $\arg$-V1-BsaI.

\section{Construction of M. xanthus DK1622 AmchA-tet and arg BGC expression strains}

Prior to the transfer of the generated expression constructs into $M$. xanthus, the strain was engineered to delete the $m c h_{A} \mathrm{BGC}$, which is in charge for production of the lipopeptide family myxochromides A. ${ }^{11}$ A suitable suicide vector was constructed, which enables replacement of the $m c h_{A}$ BGC region with a tetracycline resistance gene $\left(t e t^{R}\right)$ via two successive homologous recombination events (Fig. S10). Two homologous fragments, each around $1 \mathrm{~kb}$, were amplified by PCR from chromosomal DNA of $M$. xanthus DK1622 wild-type using the oligonucleotide pairs Mch140/Mch141 and Mch165/Mch166, respectively (Table S3). PCR was carried out with Taq DNA polymerase according to general procedures (see Materials and methods section 4.3). After gel purification, the PCR products were hydrolyzed using the restriction enzymes $S a c \mathrm{I} / X b a \mathrm{I}$ for the Mch140/Mch141 amplicon and XbaI/BamHI for the Mch165/mch166 amplicon. In parallel, an established suicide vector for M.xanthus, pSWU41, ${ }^{12}$ was hydrolyzed with SacI/BamHI. The linearized vector backbone was ligated with the two homology fragments in one step (triple ligation) yielding the plasmid pMyx-Mch2. Next, a fragment harboring the tetracycline resistance gene $\left(t e t^{R}\right)$, which confers resistance to oxytetracycline in $M$. xanthus, was amplified from pSWU22 (S. S. Wu and D. Kaiser, unpublished results) using the oligonucleotides TetR-for/TetR-rev (Table S3) and Taq DNA polymerase. The resulting $1.4 \mathrm{~kb}$ tetR amplicon was gel-purified, hydrolyzed with $X b a \mathrm{I}$ and subsequently ligated with $\mathrm{XbaI}$ linearized pMyx-Mch2 yielding the construct pMyx-Mch2-tet. After transformation of M. xanthus DK1622 with pMyx-Mch2-tet via electroporation according to established procedures ${ }^{13}$ transformants were selected on CTT medium amended with 
kanamycin $(50 \mu \mathrm{g} / \mathrm{ml})$. Chromosomal integration via either of the two homology regions was verified by Southern Blot analysis (data not shown). A verified mutant was selected and grown in CTT medium amended with oxytetracycline $(12.5 \mu \mathrm{g} / \mathrm{ml})$. After 3-4 days cultivation at 30 ${ }^{\circ} \mathrm{C}$ the well-grown culture was used to inoculate fresh medium. This procedure was repeated three times to increase the possibility of a second crossover event. After repetitive cultivation cycles different dilutions of the cell population were plated out on CTT medium amended with oxytetracycline $(12.5 \mu \mathrm{g} / \mathrm{ml})$ to select for the presence of the $t e t^{R}$ gene and sucrose $(6 \%)$ for counterselection based on the $s a c B$ gene from the pSWU41 vector backbone. ${ }^{12}$ Under these selection conditions only mutants, in which the suicide plasmid was eliminated and the $m c h_{A}$ BGC replaced with the $t e t^{R}$ gene were expected. After 7-10 days the first colonies appeared, which were grown in CTT medium amended with oxytetracycline $(12.5 \mu \mathrm{g} / \mathrm{ml})$ to isolate genomic DNA for genotypic verification via Southern Blot analysis and PCR (data not shown). The resulting mutant was cultivated under standard conditions in parallel to $M$. xanthus DK1622 wild-type and culture extracts were subsequently analyzed by HPLC-MS as described in a previous study on myxochromide production. ${ }^{14}$ Myxochromides A were detected in wildtype extracts, but not in extracts of the mutant M. xanthus DK1622 AmchA-tet confirming the expected phenotype after successful deletion of the $m c h_{A}$ BGC.

The engineered host strain M. xanthus DK1622 AmchA-tet was transformed with the generated expression constructs by electroporation according to previously established procedures. ${ }^{13}$ Transformants were selected on CTT agar containing kanamycin $(50 \mu \mathrm{g} / \mathrm{ml})$. Colonies usually appeared after 5-10 days. For each construct, several colonies were picked and transferred onto new plates. Correct chromosomal integration of the expression constructs via homologous recombination into the $t e t^{R}$ locus was verified by 'colony-PCR'. For this, cells were dissolved in $50 \mu \mathrm{H}_{2} \mathrm{O}$ and lysed by incubation at $95{ }^{\circ} \mathrm{C}$ for 30 min prior of $2 \mu$ suspension being added to the PCR reaction. PCR was performed according to general procedures (see Materials and methods section 4.3). As illustrated in Fig S10, correct chromosomal integration of the expression constructs was confirmed using two primer combinations revealing PCR products of the expected sizes: P1/P2 (1458 bp) and P3/P4 (1461 bp). Genomic DNA of M. xanthus DK1622 $\Delta m c h A$-tet was used as negative control. A complementary experiment using primers P1/P4 revealed a 1461 bp PCR product for M. xanthus DK1622 AmchA-tet, but not for the expression strains. In addition, primer sets to detect fragments of arg genes were designed to further verify the integrity of the arg BGC variants by additional PCRs (respective primer pair and expected PCR product size in brackets): arg2-V1 (arg2V1F/arg2V1R, 428 bp), arg3-V1 $(\arg 3 \mathrm{~V} 1 \mathrm{~F} / \arg 3 \mathrm{~V} 1 \mathrm{R}, \quad 363$ bp), $\quad \arg 4-\mathrm{V} 1 \quad(\arg 4 \mathrm{~V} 1 \mathrm{~F} / \arg 4 \mathrm{~V} 1 \mathrm{R}, \quad 582 \quad$ bp), $\operatorname{arg5-V1}$ 
$(\arg 5 \mathrm{~V} 1 \mathrm{~F} / \arg 5 \mathrm{~V} 1 \mathrm{R}, \quad 516 \quad$ bp), $\quad \arg 2-\mathrm{V} 2 \quad(\arg 2 \mathrm{~V} 2 \mathrm{~F} / \arg 2 \mathrm{~V} 2 \mathrm{R}, \quad 512 \quad$ bp), $\quad \arg 3-\mathrm{V} 2$ (arg3V2F/arg3V2R, 446 bp), arg4-V2 (arg4V2F/arg4V2R, 476 bp) and arg5-V2 ( $\arg 5 \mathrm{~V} 2 \mathrm{~F} / \arg 5 \mathrm{~V} 2 \mathrm{R}, 463 \mathrm{bp})$. Primer sequences are listed in Table S3. Expression strains generated in this study are listed in Table 1.

\section{Analysis of argyrin production in M. xanthus and valine feeding experiment}

Single colonies of the expression strains with verified genotype were grown in $50 \mathrm{ml}$ CTT medium amended with $2 \%$ XAD-16 adsorber resin and $50 \mu \mathrm{g} / \mathrm{ml}$ kanamycin for 5-6 days. After centrifugation, the cells and XAD were extracted with methanol and concentrated crude extracts were analyzed by HPLC-MS. For qualitative analysis of argyrin production profiles, the following HPLC-MS method was applied. Separation was performed on a Dionex UltiMate 3000 RSLC system equipped with a Waters reversed phase UPLC column (Acquity UPLC BEH C18 1,7 $\mu \mathrm{m} ; 2.1 * 100 \mathrm{~mm}$ ) using a linear gradient with solvent A (water $+0.1 \%$ formic acid) and $\mathrm{B}$ (acetonitrile $+0.1 \%$ formic acid) at a flow rate of $600 \mu \mathrm{l} / \mathrm{min}$ and $45{ }^{\circ} \mathrm{C}$. The gradient was initiated by a $0.5 \mathrm{~min}$ isocratic step with $5 \% \mathrm{~B}$ followed by an increase to $15 \% \mathrm{~B}$ within $1 \mathrm{~min}, 50 \% \mathrm{~B}$ within $11.5 \mathrm{~min}$ and $95 \% \mathrm{~B}$ within $1 \mathrm{~min}$, which was kept for $1 \mathrm{~min}$, before decreasing back to initial conditions of $5 \% \mathrm{~B}$ within $0.3 \mathrm{~min}$ and was kept for $1.7 \mathrm{~min}$. HPLC was coupled to a Bruker Daltonics QqToF mass spec maxis4G system in a mass range from $150-2500 \mathrm{~m} / \mathrm{z}$ in positive ionization mode. Structures of the new derivatives were characterized by comparing the $\mathrm{MS}^{2}$ spectra with those of the known argyrins (Table S9). Argyrin production profiles of different $M$. xanthus expression strains in comparison to the native argyrin producer are illustrated in Fig. 3.

To quantify argyrin production levels in expression strains harboring the arg2345 gene set (producing argyrins $\mathrm{A}$ and $\mathrm{B}$ as major derivatives), the following HPLC-MS method was applied. Separation was performed on a Dionex UltiMate 3000 RSLC system equipped with a Waters reversed phase UPLC column (Acquity UPLC BEH C18 1,7 $\mu \mathrm{m} ; 2.1 * 100 \mathrm{~mm}$ ) using a linear gradient with solvent A (water $+0.1 \%$ formic acid) and B (acetonitrile $+0.1 \%$ formic acid) at a flow rate of $600 \mu \mathrm{l} / \mathrm{min}$ and $45^{\circ} \mathrm{C}$. The gradient was initiated by a $0.5 \mathrm{~min}$ isocratic step with $5 \%$ B followed by an increase to $15 \%$ B within $1 \mathrm{~min}, 50 \% \mathrm{~B}$ within $11.5 \mathrm{~min}$ and $95 \%$ B within $1 \mathrm{~min}$, which was kept for $1 \mathrm{~min}$, before decreasing back to initial conditions of $5 \% \mathrm{~B}$ within $0.3 \mathrm{~min}$ and was kept for $1.7 \mathrm{~min}$. HPLC was coupled to a Bruker Daltonics ion trap mass spec 'Amazon speed' system. Mass spectra were acquired in positive ionization mode with a range of $200-2500 \mathrm{~m} / \mathrm{z}$ at a resolution of $\mathrm{R}=30000$. Identities of the argyrins were 
confirmed by comparing with both retention time and $\mathrm{MS}^{2}$ fragmentation pattern of the authentic compounds.

To further verify the incorporation of valine into argyrins $\mathrm{K}$ and $\mathrm{L}\left(\mathrm{R}_{1}=\mathrm{CH}_{2}\left(\mathrm{CH}_{3}\right)_{2}\right)$, a feeding experiment with M.xanthus DK1622 AmchA-tet::pArg2345-5-V1 growing in $50 \mathrm{ml}$ CTT medium (50 $\mu \mathrm{g} / \mathrm{ml}$ kanamycin) was performed. Around $29 \mathrm{mg} L$-valine-D8 (Deutero GmbH) was dissolved in $8 \mathrm{ml} \mathrm{H}_{2} \mathrm{O}$, sterile filtered and equal aliquots were added to the culture after 48 h, 60 h, 72 h, 84 h, 96 h, 108 h, 120 h, and 132 h of growth. Amberlite XAD-16 adsorber resin $(2 \%)$ was added after $144 \mathrm{~h}$. After $168 \mathrm{~h}$ of cultivation, cells and XAD were harvested, extracted with methanol and analyzed by HPLC-MS as described in chapter 2. Argyrins K and $\mathrm{L}$ exhibit in MS analysis the monoisotopic signal $[\mathrm{M}+\mathrm{H}]^{+}$of $853.3469 \mathrm{~m} / \mathrm{z}$ (argyrin $\mathrm{K}$ ) and $869.3412 \mathrm{~m} / \mathrm{z}$ (argyrin L). As shown in Fig. S11, additional isotope signals appeared with a maximum intensity of a peak of $+7.0439 \mathrm{~m} / \mathrm{z}$ indicating the incorporation of $L$-valine-D8 during biosynthesis of both derivatives (Deuterium label in $\alpha$-position of $L$-valine-D8 lost because of frequent H-D exchange).

\section{Engineering of the A1 domain of the argyrin NRPS megasynthetase}

To rationally engineer argyrin the A1 specificity conferring code, ${ }^{15} \mathrm{~A}$ domains from myxobacterial BGCs with known substrate specificity were used as template. Eight A domains, from published myxobacterial NRPS megasynthetases, with specificity for alanine, $\alpha$ aminobutyric acid or valine were selected and their nonribosomal codes were extracted (Table S11). A panel of modified A1 versions was designed, in which residues of the substrate-binding pocket were mutated according to the extracted nonribosomal codes.

In most cases the original code from "template" A domain was implemented, to adapt the original argyrin A1, but in some cases a hybrid code between original argyrin A1 and the "template" A domain was generated instead (Table S11). To avoid any bottlenecks, a codon usage bias of the selected surrogate host was taken into account, meaning that for each amino acid residue that was mutated, a codon with high prevalence in the M. xanthus DK1622 $\Delta m c h A$-tet host genome was employed. Synthetic sequences for 14 modified argyrin A1 domains fragments were designed based on the described procedure (Table S4).

Argyrin expression constructs with engineered A1 domains were constructed as shown in Fig. S12. Synthetic fragments of 14 modified argyrin A1 domain regions, flanked by AarI endonuclease restriction sites were obtained from a gene synthesis company (Table S4). AarI is a type IIS restriction endonuclease that cuts DNA outside of its recognition sequence, which 
allows construction of desired overhangs that are complementary to any selected target sequence. Construct pGH-arg2-M1-VI harboring first module of the Arg2 argyrin subunit was also obtained from a gene synthesis company for construction of the synthetic argyrin BGC (see chapter 4.5). The backbone of the construct was replaced with the pUC18 vector backbone by traditional restriction-ligation using $N d e \mathrm{I}$ and $S d a \mathrm{I}$ restriction endonucleases. Resulting construct pUC18-arg2-M1-V1, now harboring first module of the Arg2 argyrin subunit, was further modified using Red/ET in vivo recombination technique, to replace A1 subdomain region between residues 235 and 330 (based on the GrsA numbering ${ }^{15}$ ) with kanamycin resistance cassette, flanked by AarI endonuclease restriction sites. The cassette was generated by PCR amplification from pTpSmchS ${ }^{16}$ template using Arg42 and Arg43 primer pair (Table S3). The resulting construct pUC18-arg2-M1-V1-Del-Pos235-330 as well as 14 synthetic A domain fragments, subcloned into standard gene synthesis vectors (pGH-A1-mod[1-14], see Table S4), were digested using AarI enzyme and subsequently ligated, to generate 14 modified constructs harboring modified first module (M1) of argyrin BGC. The resulting 14 modified M1 modules were sub-cloned in pArg2345-V1 argyrin expression construct by traditional restriction-ligation using $N d e \mathrm{I}$ and SbfI restriction endonucleases (Fig. S12). Finally 14 modified argyrin heterologous expression constructs (pArg2345-V1-mod[1-14], see Table S5) were generated and the modified region was verified by Sanger sequencing using the primer Arg51 (Table S3).

Generated argyrin BGC expression constructs with modified A1 were transferred into M. xanthus DK1622 AmchA-tet by electroporation. Clones growing on selection plates amended with kanamycin were analyzed for correct chromosomal integration of the expression plasmid by PCR (Fig. S10). To evaluate the production profile of argyrin, the heterologous producers (A1 domain modifications: M. xanthus DK1622 AmchA-tet::pArg2345-V1$\bmod [1-14]$; see Table S5) and control strain M. xanthus DK1622 AmchA-tet::pArg2345-V1 were cultivated in parallel. Strains were inoculated from cryo stocks and grown on agar plates for several days until plates were mostly overgrown with cells. All of the cells were scraped from the plates to inoculate seed medium (50 ml medium in $300 \mathrm{ml}$ Erlenmeyer flask), which was incubated at $30{ }^{\circ} \mathrm{C}, 180 \mathrm{rpm}$ for $48 \mathrm{~h}$. Five $\mathrm{ml}$ of well grown seed culture were used to inoculate $50 \mathrm{ml}$ production medium in which the strain was grown at the same conditions for 6 days. M. xanthus DK1622 derivatives were grown in CTT medium (see 4.2) supplemented with $50 \mu \mathrm{g} / \mathrm{ml}$ kanamycin and 2\% Amberlite XAD-16 adsorber resin. All cultivations were performed in triplicates at $30^{\circ} \mathrm{C}$ and $180 \mathrm{rpm}$ for 6 days. Cultures were harvested by centrifugation at $8000 \mathrm{rpm}$ and $4{ }^{\circ} \mathrm{C}$ for $15 \mathrm{~min}$. Supernatant was removed and pelleted cells 
with XAD were extracted with 1:1 mixture of methanol and acetone (25 $\mathrm{ml}$ of methanol and $25 \mathrm{ml}$ acetone). After filtration, the crude extracts were evaporated to dryness and subsequently re-dissolved in $1 \mathrm{ml}$ of methanol for HPLC-MS analysis (see chapter 2). Argyrin peaks were identified by EIC $[\mathrm{M}+\mathrm{H}]^{+}=825.313(\arg \mathrm{A})$ and $[\mathrm{M}+\mathrm{H}]^{+}=839.329(\arg \mathrm{B})$ and their yields were evaluated by integration and relative comparison of the peak surface area.

\section{Medium optimization for yield improvement}

To further improve argyrin production levels, M7/s4 (0.5\% soy flour, $0.5 \%$ corn starch, $0.2 \%$ glucose, $0.1 \%$ yeast extract, $0.1 \% \mathrm{MgSO}_{4} \times 7 \mathrm{H}_{2} \mathrm{O}, 0.1 \% \mathrm{CaCl}_{2} \times 2 \mathrm{H}_{2} \mathrm{O}, 1 \%$ HEPES, with final $\mathrm{pH} 7.4$ and supplemented with $0.1 \mathrm{mg} / \mathrm{l}$ of vitamin $\mathrm{B} 12$ and $5 \mathrm{mg} / \mathrm{l}$ of $\mathrm{FeCl}_{3}$ after autoclaving) and $\mathrm{M} 7 / \mathrm{s} 6$ (0.5\% soy flour, $0.5 \%$ corn starch, $0.2 \%$ glucose, $0.1 \%$ yeast extract, $1 \%$ potassium acetate, $0.1 \% \mathrm{MgSO}_{4} \times 7 \mathrm{H}_{2} \mathrm{O}, 0.1 \% \mathrm{CaCl}_{2} \times 2 \mathrm{H}_{2} \mathrm{O}, 1 \%$ HEPES, with final $\mathrm{pH} 7.4$ and supplemented with $0.1 \mathrm{mg} / \mathrm{l}$ of vitamin $\mathrm{B} 12$ and $5 \mathrm{mg} / \mathrm{l}$ of $\mathrm{FeCl}_{3}$ after autoclaving) media were investigated as alternative options. The M7/s 4 medium was identified to be the best candidate for further optimization. Experimental details and results are described below.

From a well-grown agar plate of $M$. xanthus DK1622 AmchA-tet::pArg2345-V1-BsaI culture, flasks with $50 \mathrm{ml} \mathrm{M} 7 / \mathrm{s} 4$ medium were inoculated and incubated on a rotary shaker (180 rpm) at $30{ }^{\circ} \mathrm{C}$ for 6 days. Solution of amino acid mixture calculated for the final concentration of $5 \mathrm{mM}$ serine, $5 \mathrm{mM}$ cysteine, $5 \mathrm{mM}$ alanine, $10 \mathrm{mM}$ tryptophan, $10 \mathrm{mM}$ glycine and $10 \mathrm{mM} \alpha$ aminobutyric acid was fed to the production cultures twice daily over the course of 6 days. The control experiment without supplementing the medium with the amino acid solution was performed in parallel. Amberlite XAD-16 adsorber resin (2\%) was added after $24 \mathrm{~h}$ to all cultures. After 6 days of incubation the cultures were harvested by centrifugation and cells/XAD were extracted with $50 \mathrm{ml}$ of ethyl acetate. Concentrated methanol extracts from the feeding experiments and the respective controls without feeding were analyzed by HPLC-MS and argyrin production was quantified as described in chapter 6 . 


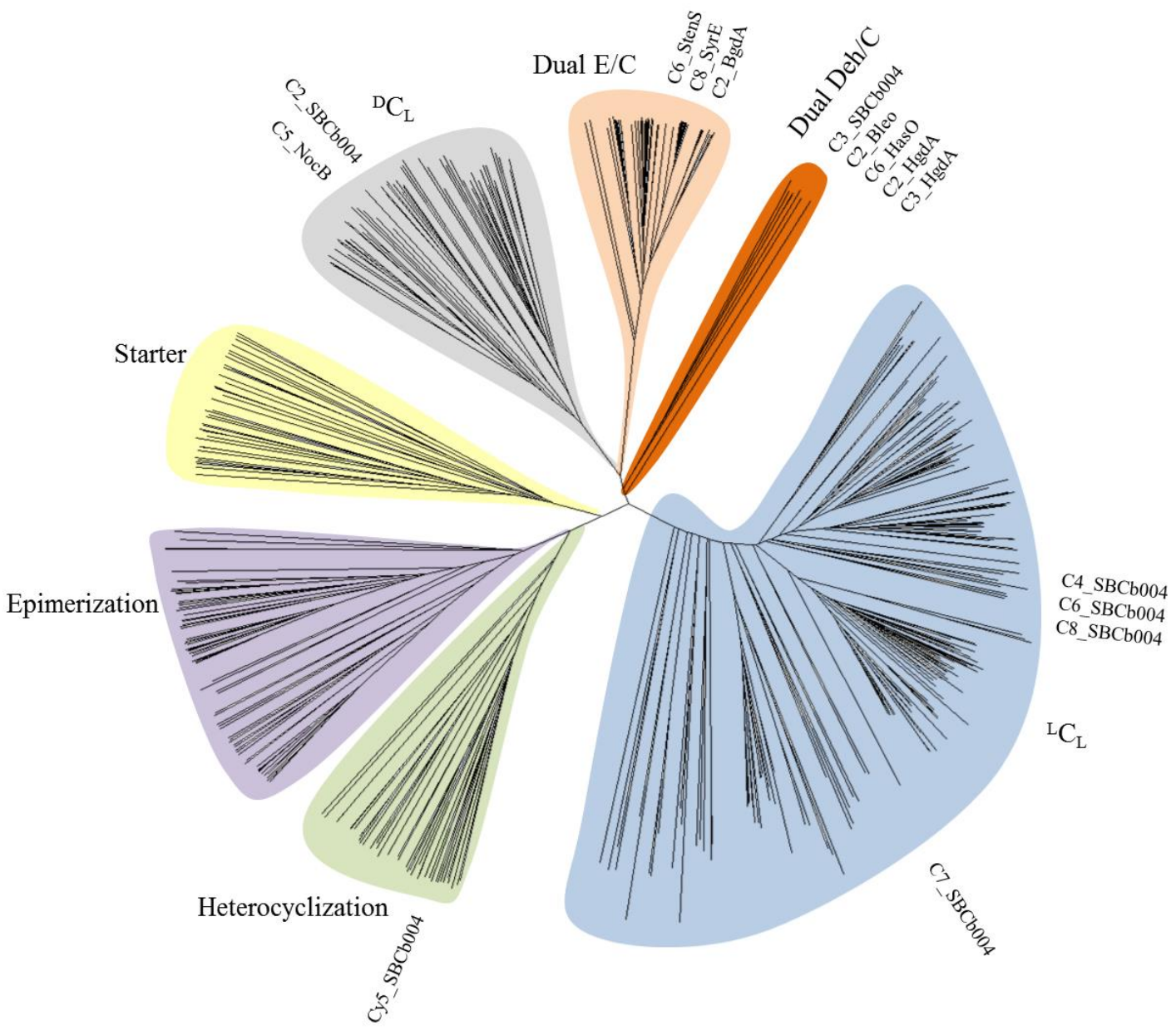

Figure S1. Phylogenetic tree of different $\mathrm{C}$ domain subtypes. Phylogenetic tree of all known $\mathrm{C}$ domain subtypes $\left({ }^{\mathrm{L}} \mathrm{C}_{\mathrm{L}},{ }^{\mathrm{D}} \mathrm{C}_{\mathrm{L}}\right.$, Starter, Dual E/C, Epimerization and Heterocyclization domains), with the new proposed Dual Deh/C subtype highlighted in orange. The phylogeny was reconstructed using phyml, employing the JTT model of amino acid substitution and a gamma-distributed rate variation with four categories. The support values are based on 100fold bootstrapping. The $\mathrm{C}$ domain list includes 525 domains from phylogenetic study by Rausch et. al., ${ }^{17}$ seven $\mathrm{C}$ domains from the argyrin NRPS (C2_SBCb004, C3_SBCb004, C4_SBCb004, Cy5_SBCb004, C6_SBCb004, C7_SBCb004 and C8_SBCb004) as well as selected C domain examples from $\alpha, \beta$-dehydro amino acid forming pathways: bleomycin (blmVI; Q9FB23), burriogladin (BgdA; MH170348), haerogladin (HgdA, MH170356), nocardicin (NocB; Q5J1Q6 ), hassallidin (HasO; K7VZQ9), syringomycin (SyrE; O85168), stenothricin (StenS; EFE73312.1), 
A
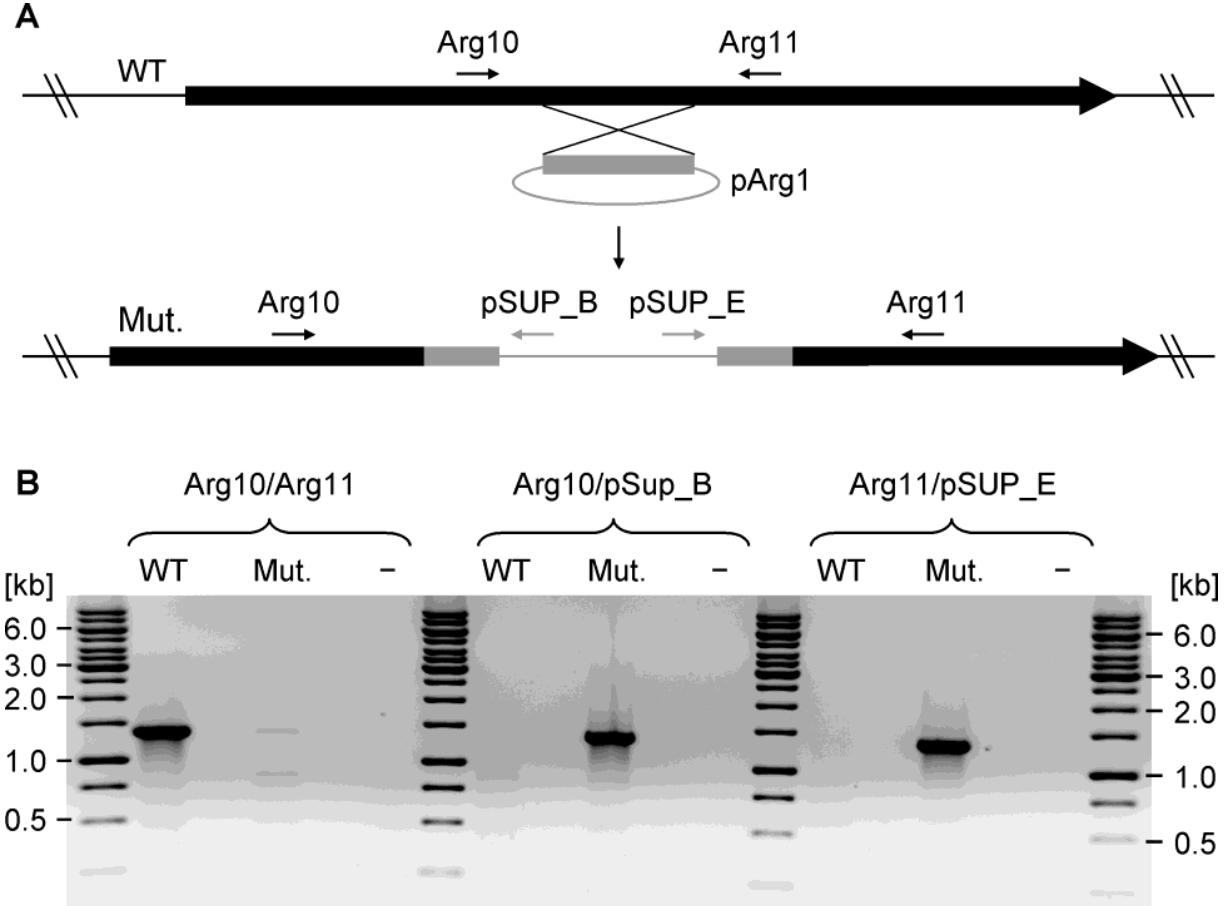

Figure S2. Inactivation of arg3 in Cystobacter sp. SBCb004 by insertional mutagenesis. Integration of the suicide plasmid pArg1 via homologous recombination (A), and verification of the mutant strains via PCR analysis $(\mathbf{B})$.

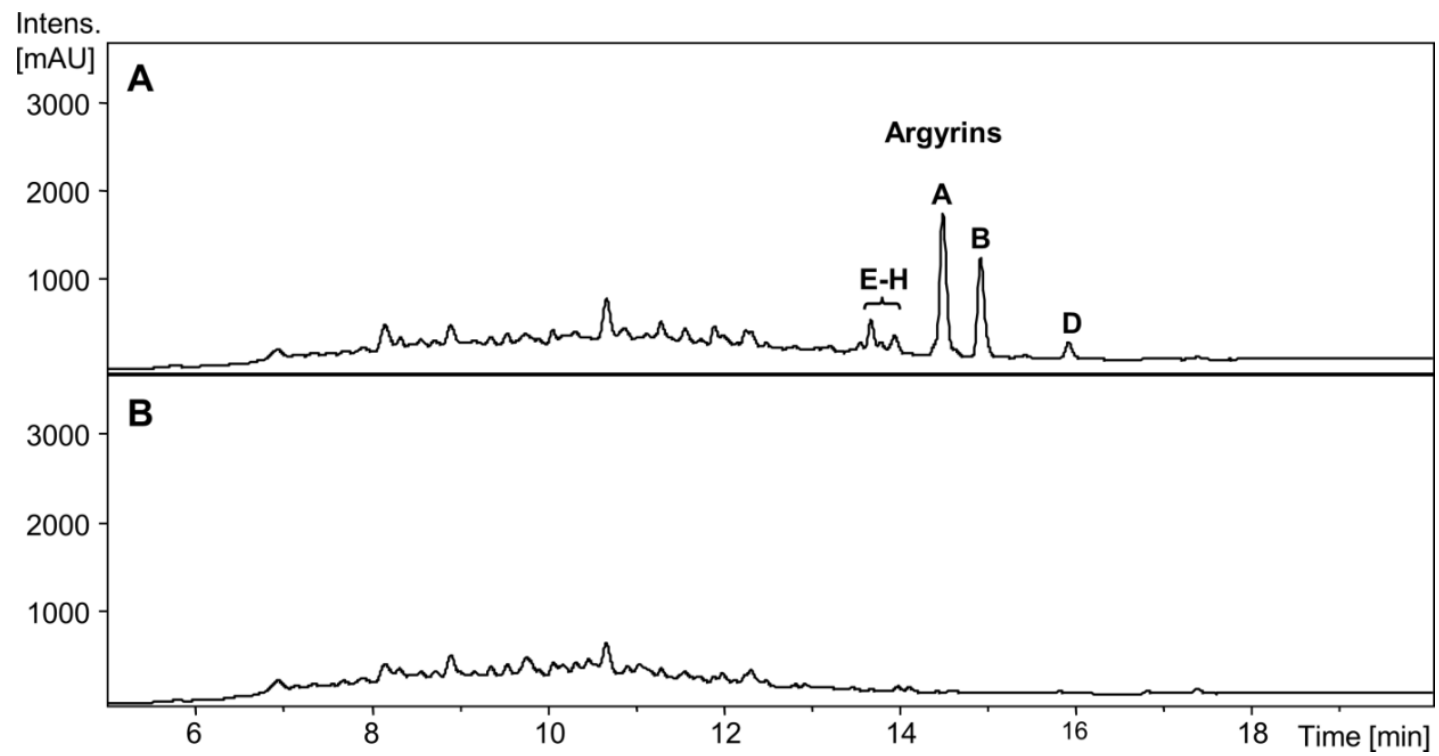

Figure S3. Argyrin production analysis after arg3 inactivation in Cystobacter sp. SBCb004. Culture extracts of Cystobacter sp. SBCb004 wild-type (A) and the arg3 inactivation mutant strain Cystobacter sp. SBCb004::pArg1 (B) were analyzed by HPLC-MS-DAD (DAD chromatograms at 200-600 nm shown). Argyrins A-E were detected in the wild-type, but not in the mutant extract. 
A

B

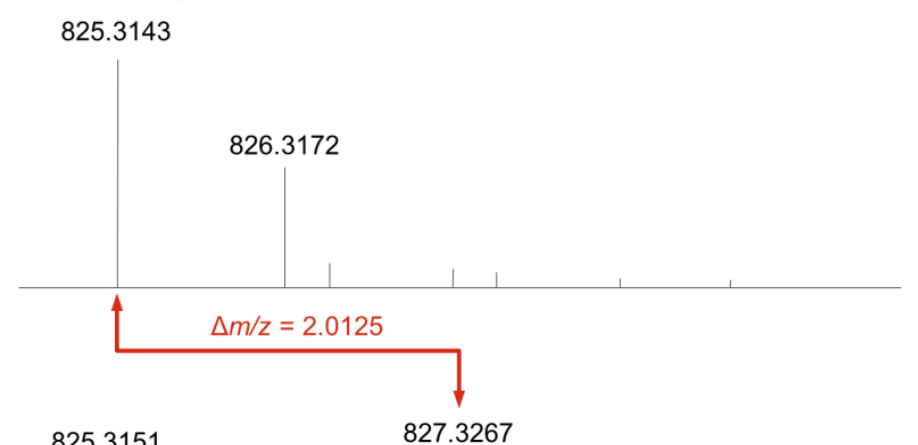

C<smiles></smiles>

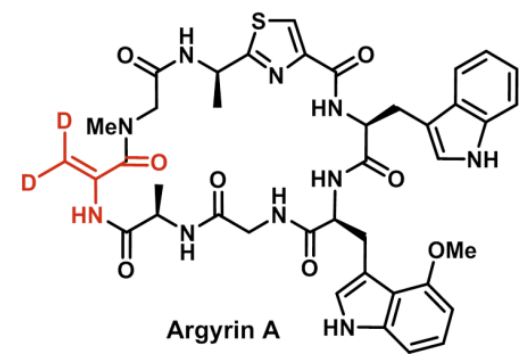

Figure S4. Analysis of the incorporation $L$-serine-2,3,3-D3 during argyrin biosynthesis. MS-spectra of argyrin A after HPLC-MS analysis of culture extracts of Cystobacter sp. SBCb004. The monoisotopic signal of the argyrin $\mathrm{A}[\mathrm{M}+\mathrm{H}]+$ ion is at $825.3143 \mathrm{~m} / \mathrm{z}$ (calc. $825.3137 \mathrm{~m} / \mathrm{z}, \mathrm{C}_{40} \mathrm{H}_{45} \mathrm{~N}_{10} \mathrm{O}_{8} \mathrm{~S}$ ). (A) Control sample to which no labelled precursor was fed, (B) sample from feeding experiment with $L$-serine-2,3,3-D3, (C) expected labelling pattern of argyrin A after incorporation of $L$-serine-2,3,3-D3 and Dha unit generation.

A

839.3300

B
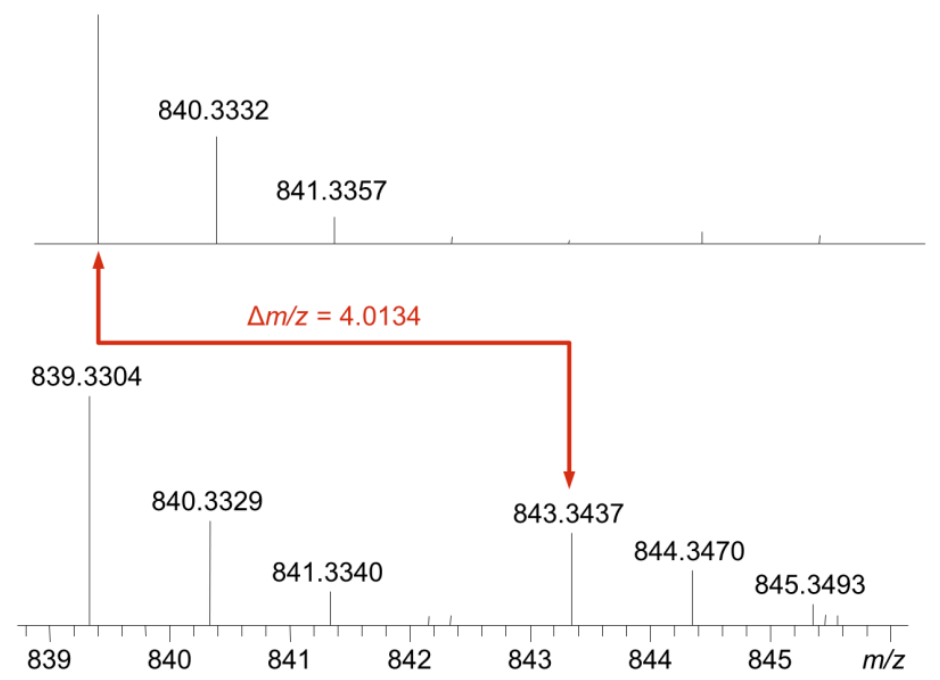

C<smiles>CCCC(=O)OC(=O)C(C)CC</smiles>

L-ThreonineAbu ${ }^{13} \mathrm{C}_{4}-{ }^{15} \mathrm{~N}$<smiles>C1CCCCC1</smiles>

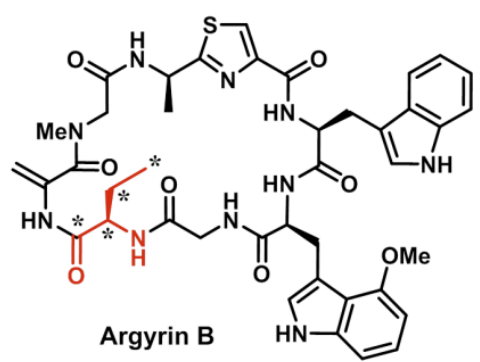

Figure S5. Analysis of the incorporation $L$-threonine- ${ }^{13} \mathrm{C}_{4},{ }^{15} \mathrm{~N}$ during argyrin biosynthesis. MS-spectra of argyrin B after HPLC-MS analysis of culture extracts of Cystobacter sp. SBCb004. The monoisotopic signal of the argyrin B $[\mathrm{M}+\mathrm{H}]^{+}$ion is at $839.3300 \mathrm{~m} / z$ (calc. $839.3294 \mathrm{~m} / z, \mathrm{C}_{41} \mathrm{H}_{47} \mathrm{~N}_{10} \mathrm{O}_{8} \mathrm{~S}$ ). (A) Control sample to which no labelled precursor was fed, (B) sample from feeding experiment with $L$-threonine- $-{ }^{13} \mathrm{C}_{4},{ }^{15} \mathrm{~N},(\mathbf{C})$ expected labelling pattern of argyrin B after incorporation of Abu generated from $L$-threonine $-{ }^{13} \mathrm{C}_{4},{ }^{15} \mathrm{~N}$ metabolism by threonine deaminase and aminotransferase enzymes. ${ }^{3}$ 

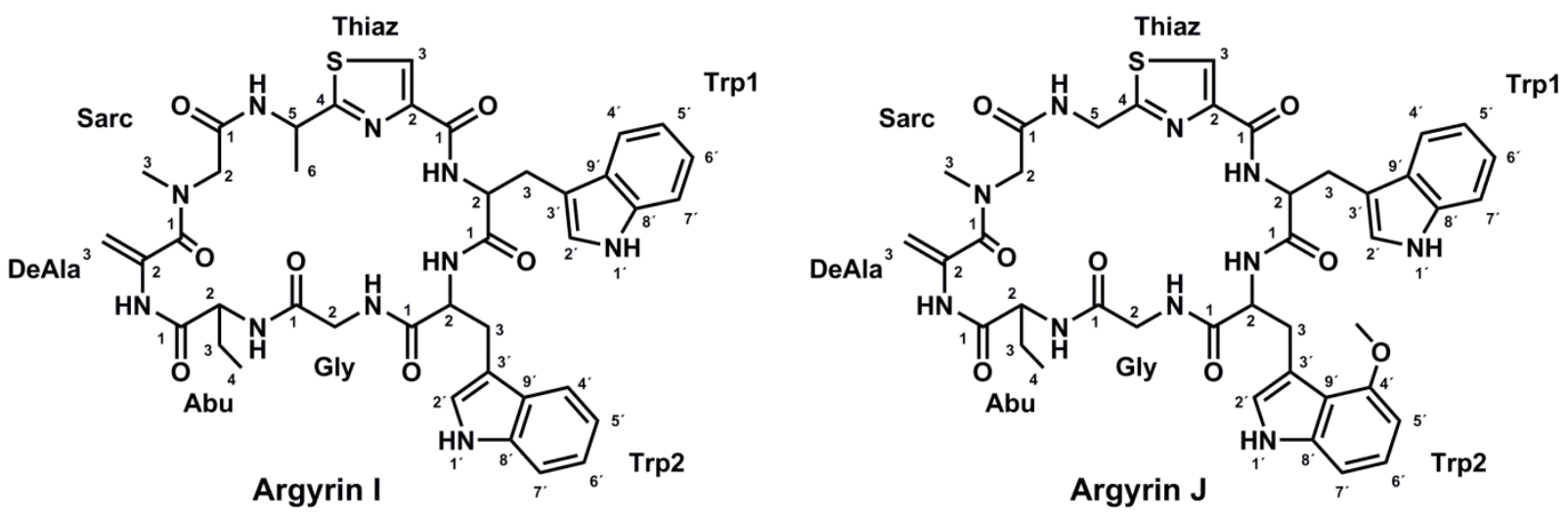

Figure S6. Structures of argyrin I and argyrin J. For NMR data see Tables S6/S7. 


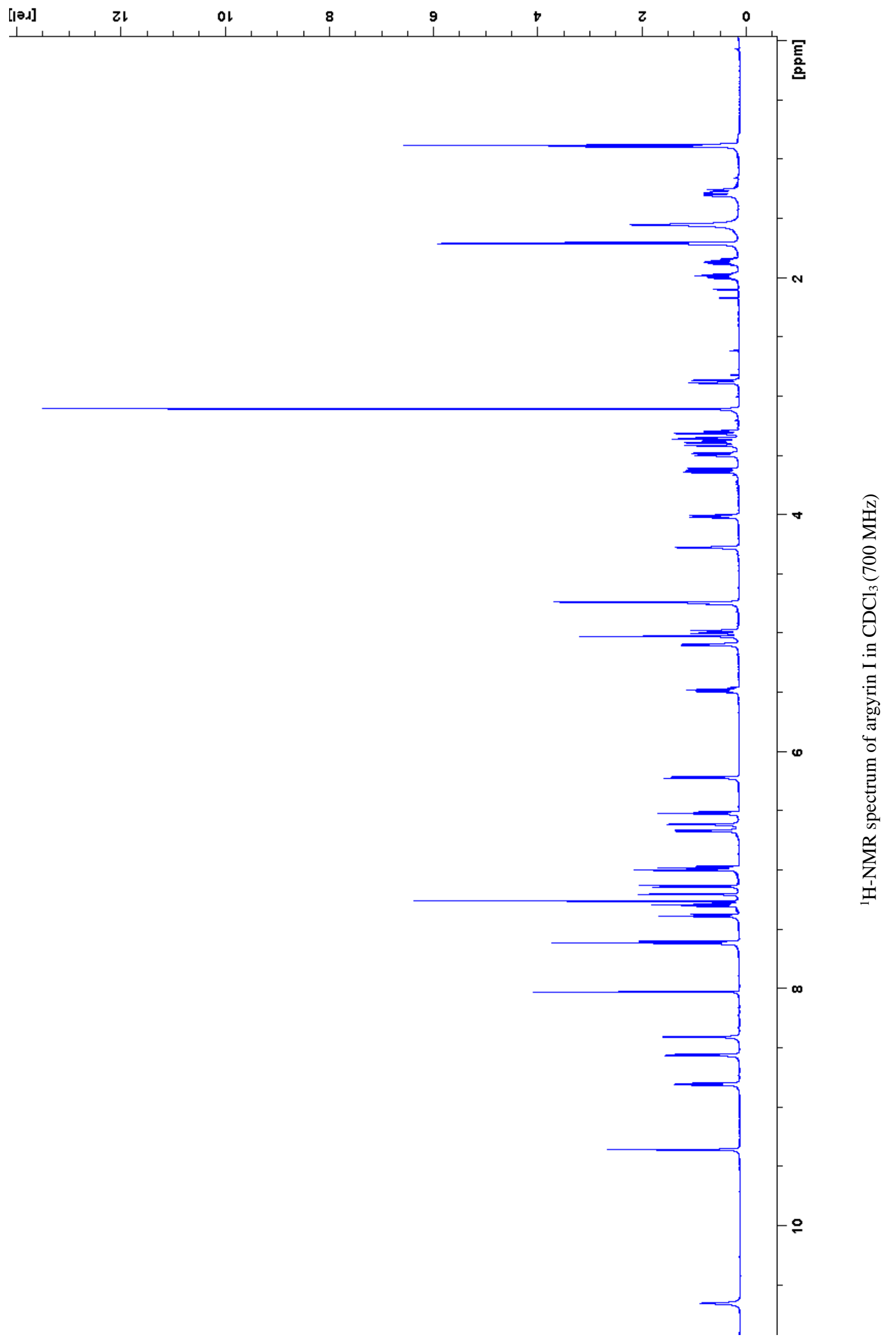




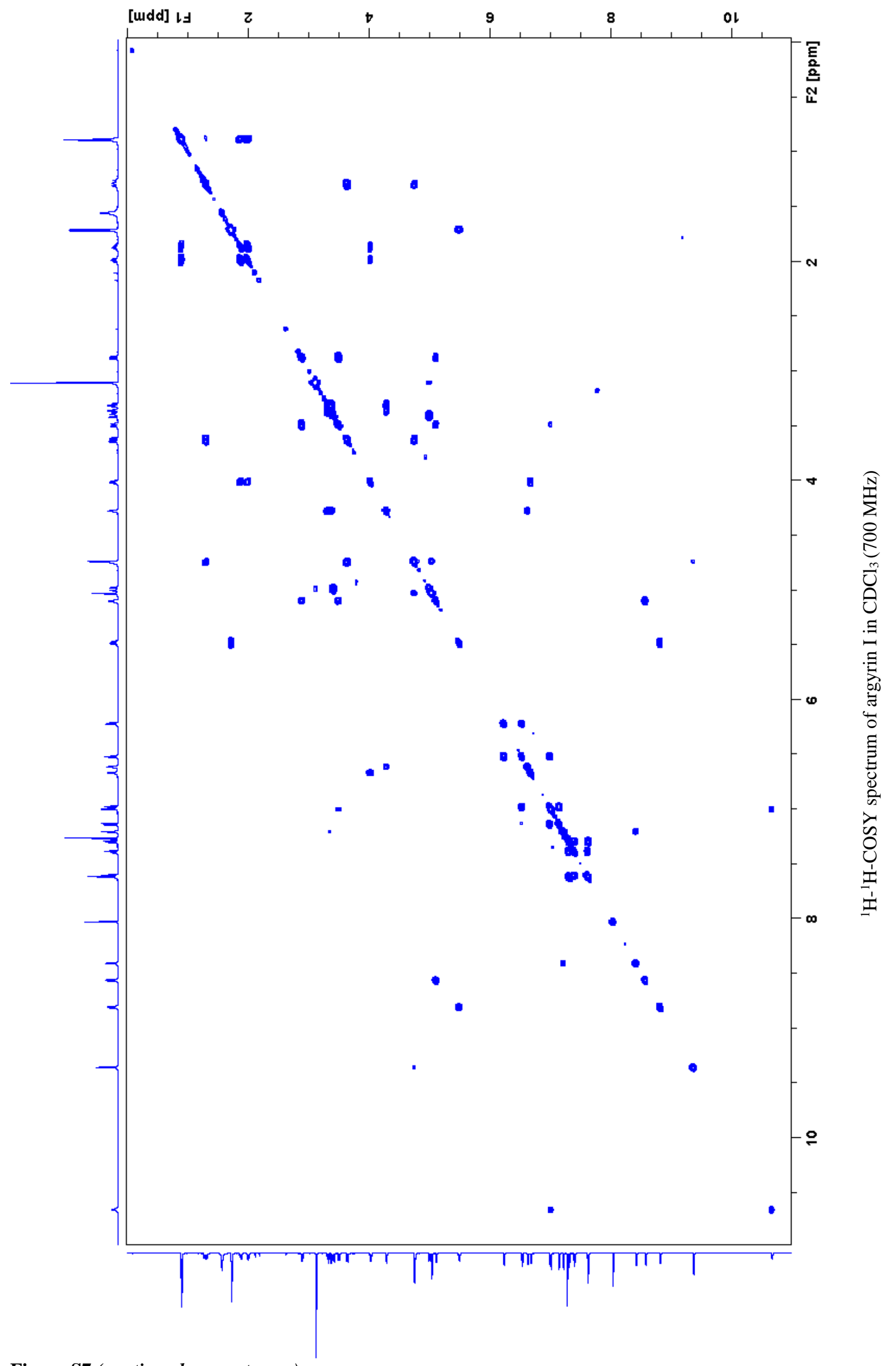

Figure S7 (continued on next page) 


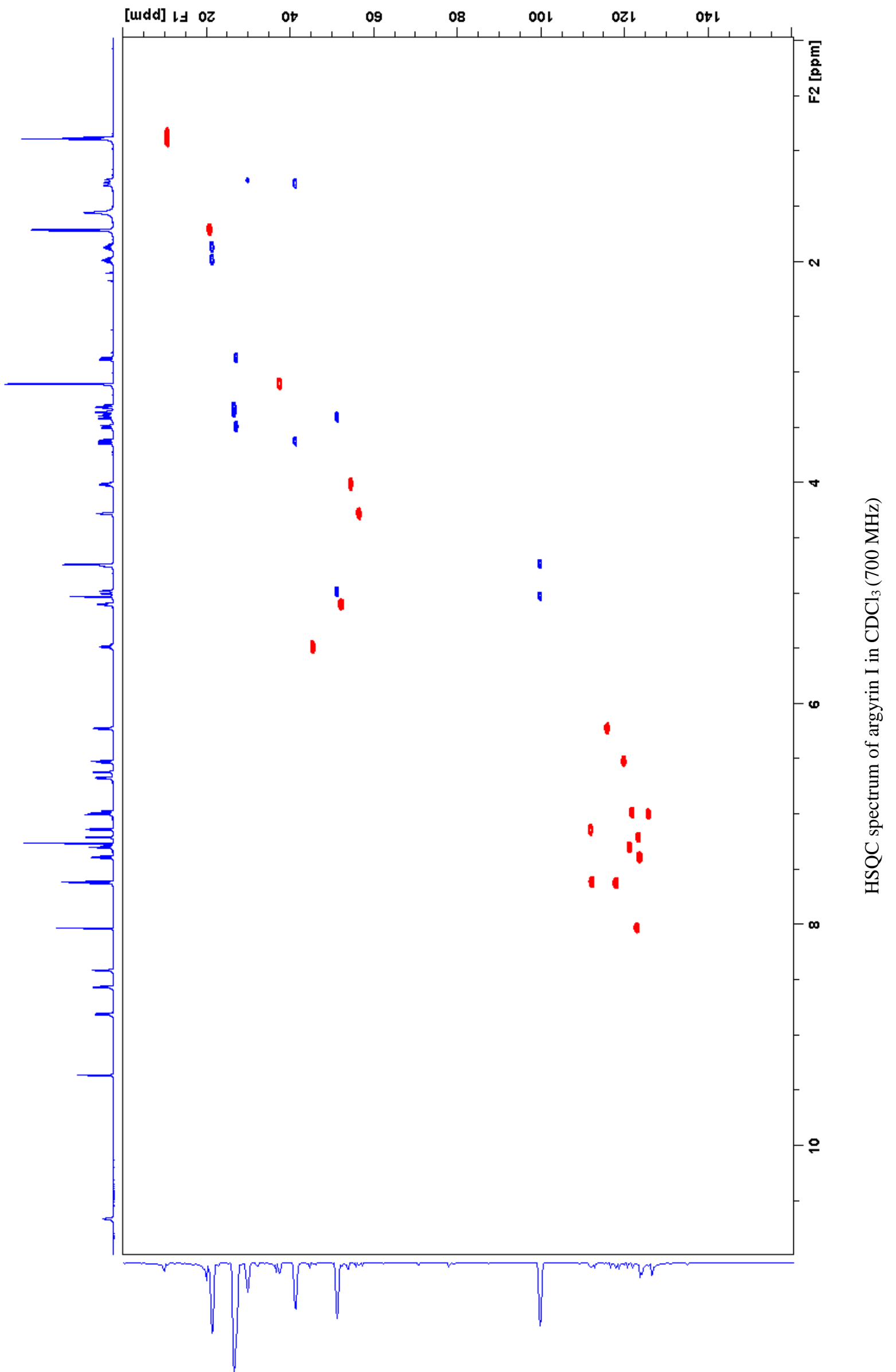

Figure S7 (continued on next page) 


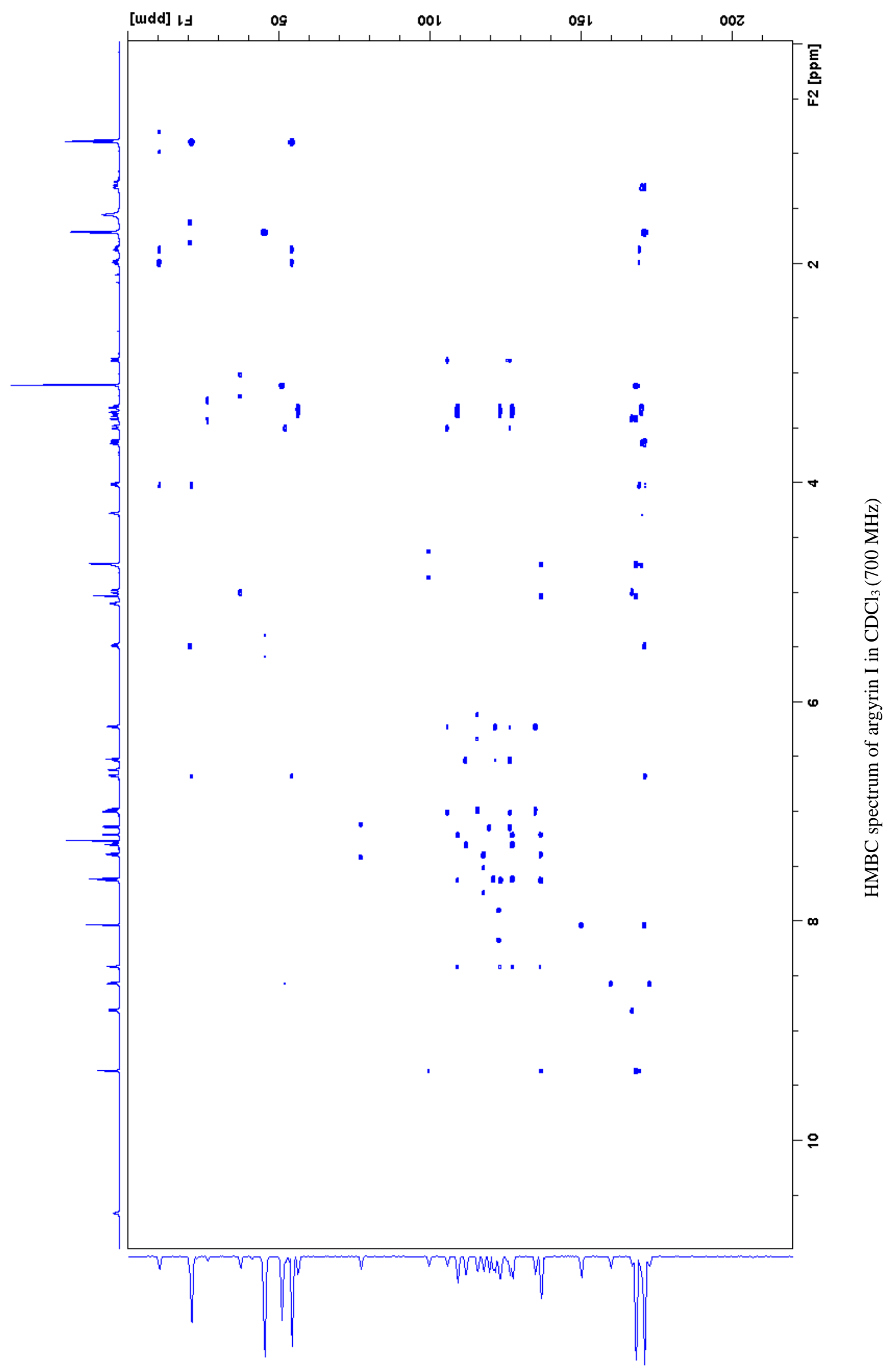

Figure S7. NMR spectra of argyrin I. 


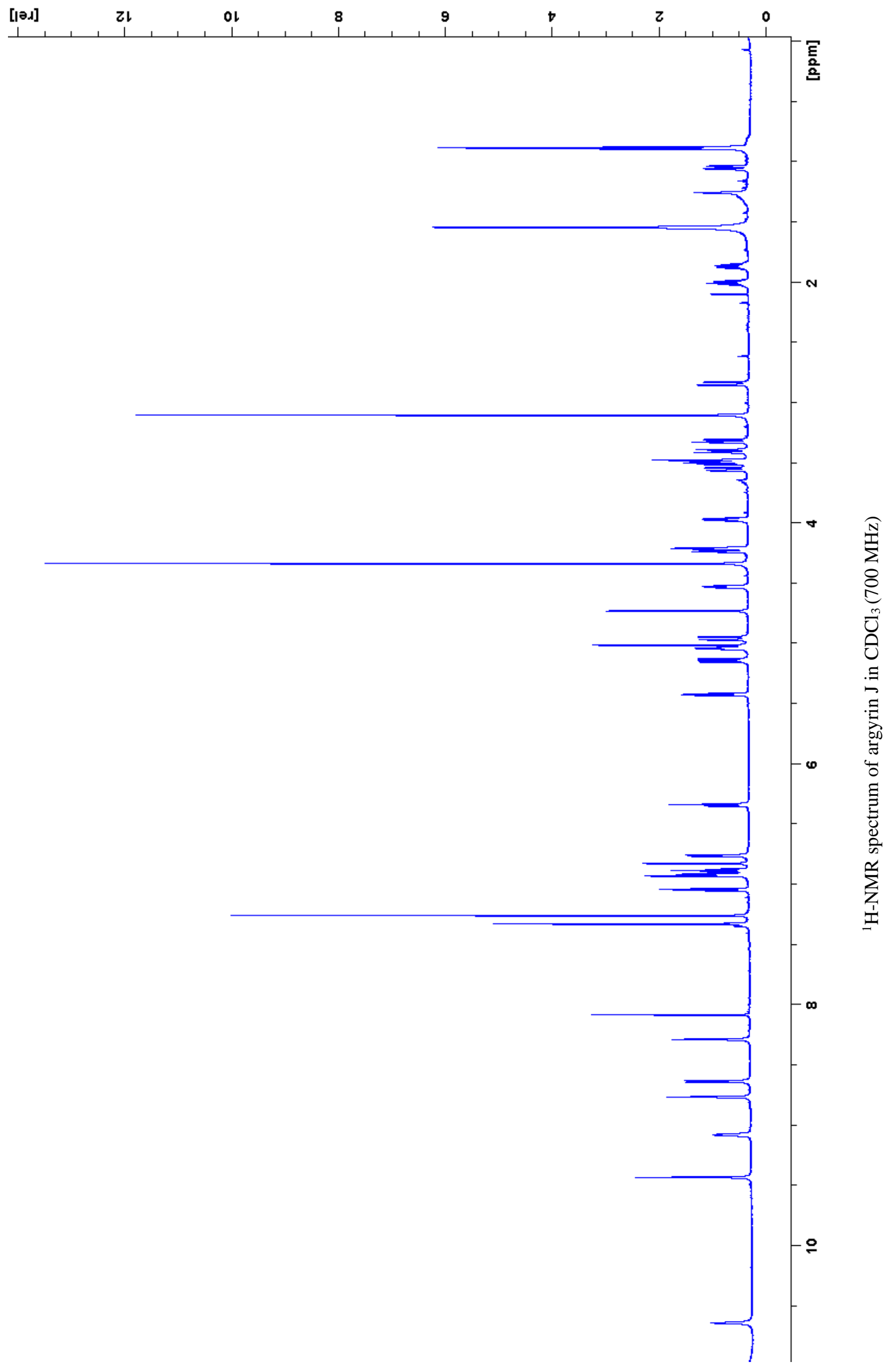




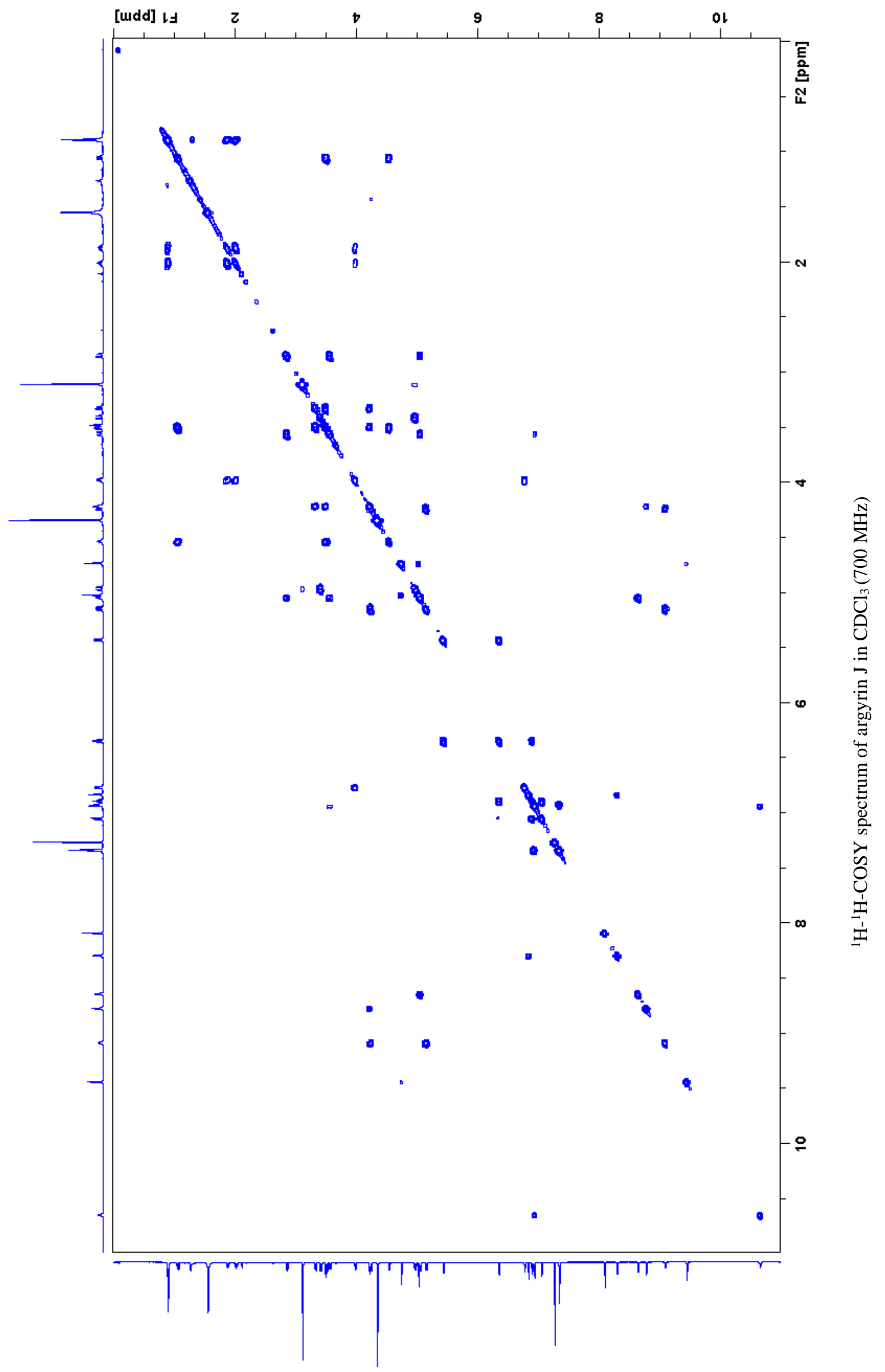

Figure S8 (continued on next page) 


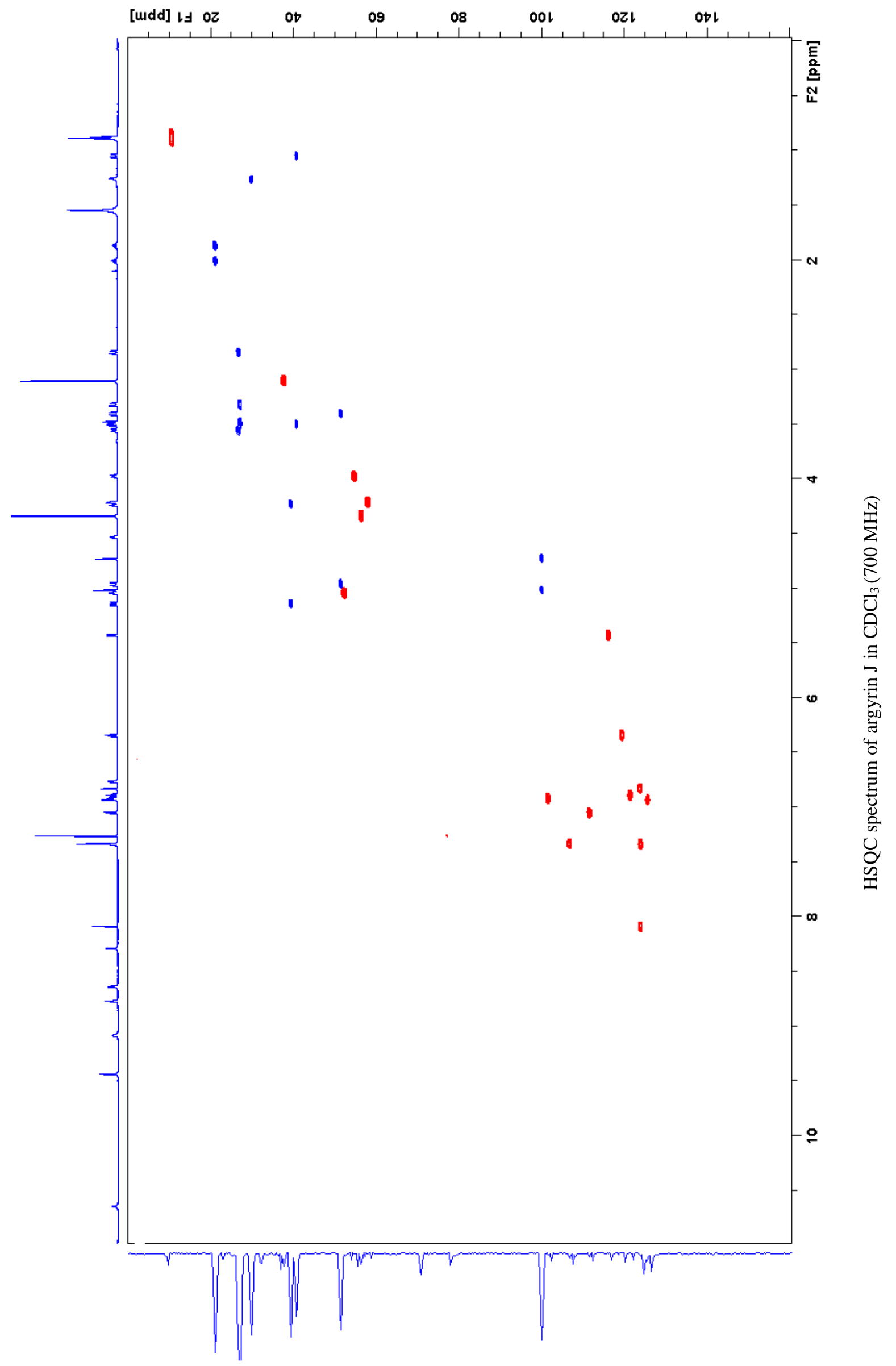

Figure S8 (continued on next page) 


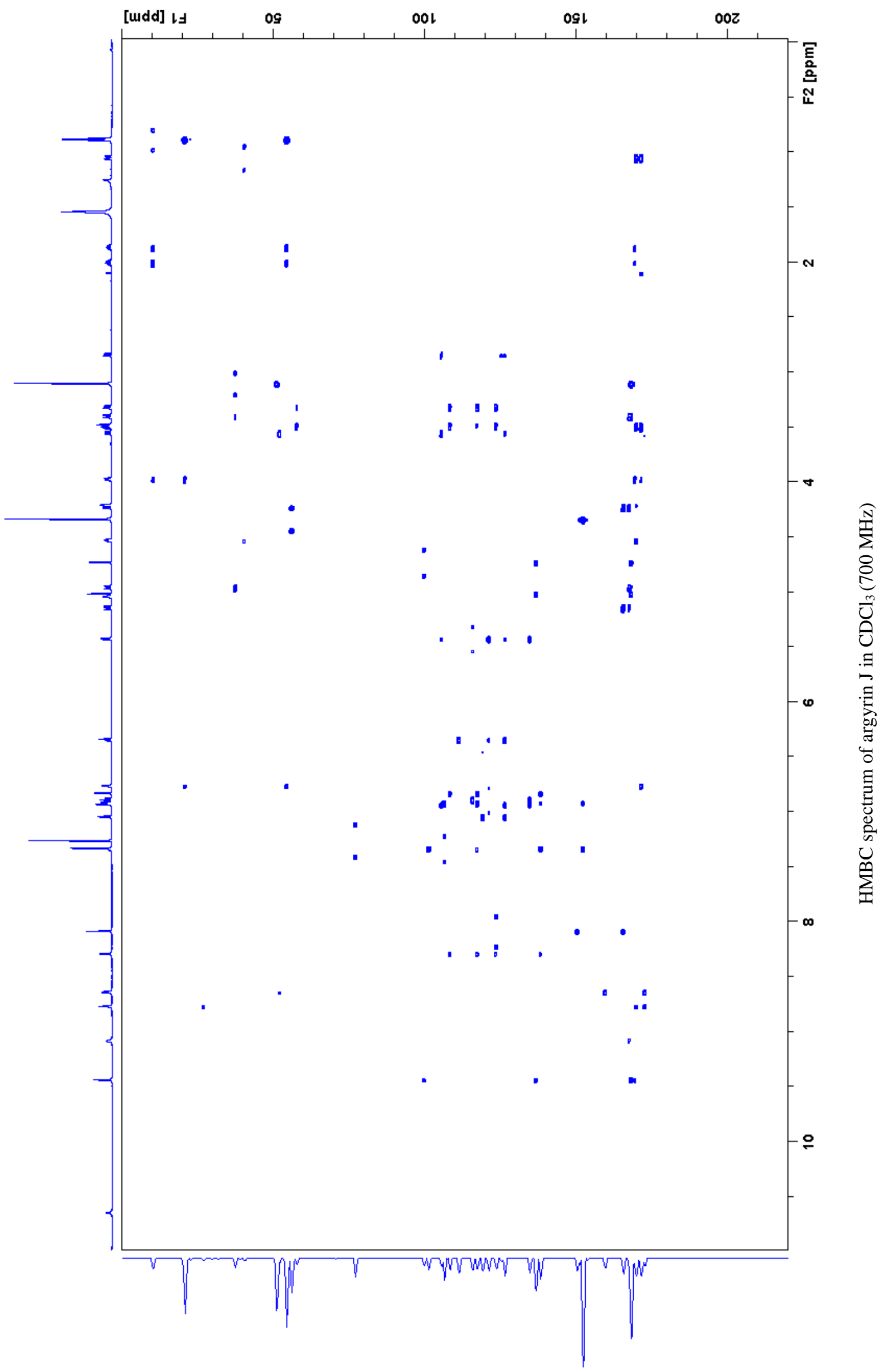

Figure S8. NMR spectra from argyrin J. 
A

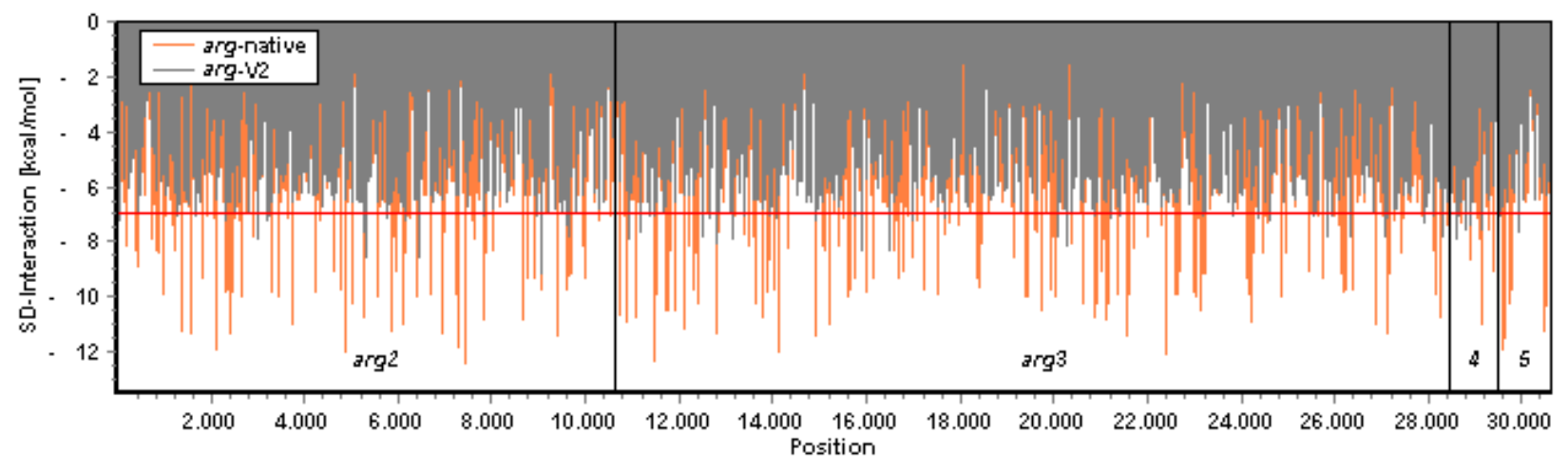

B

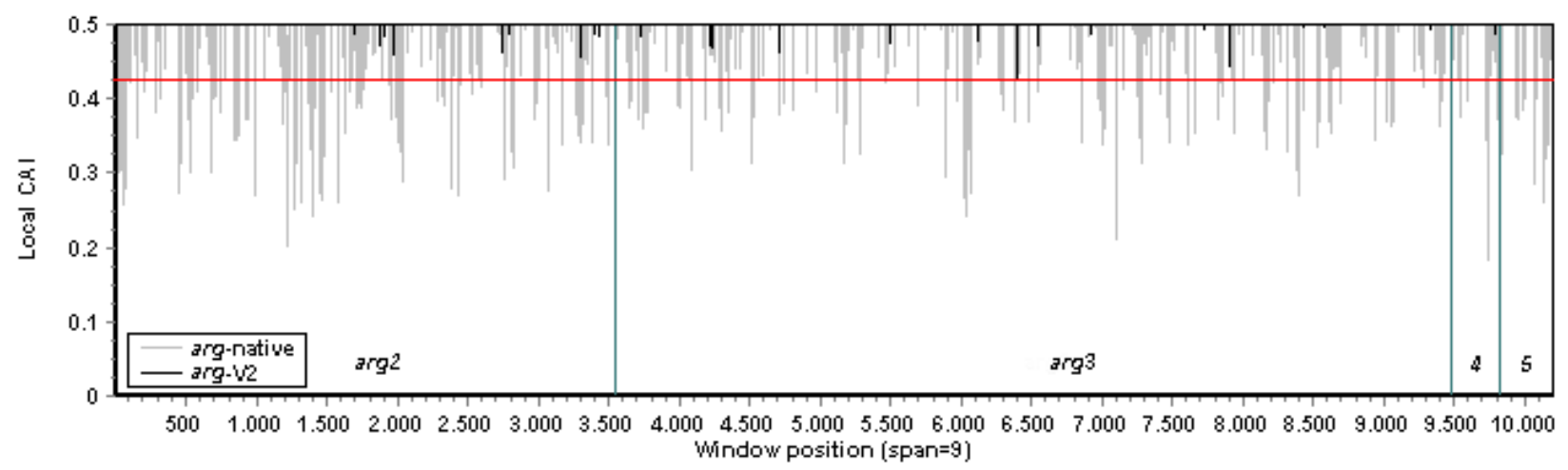

C

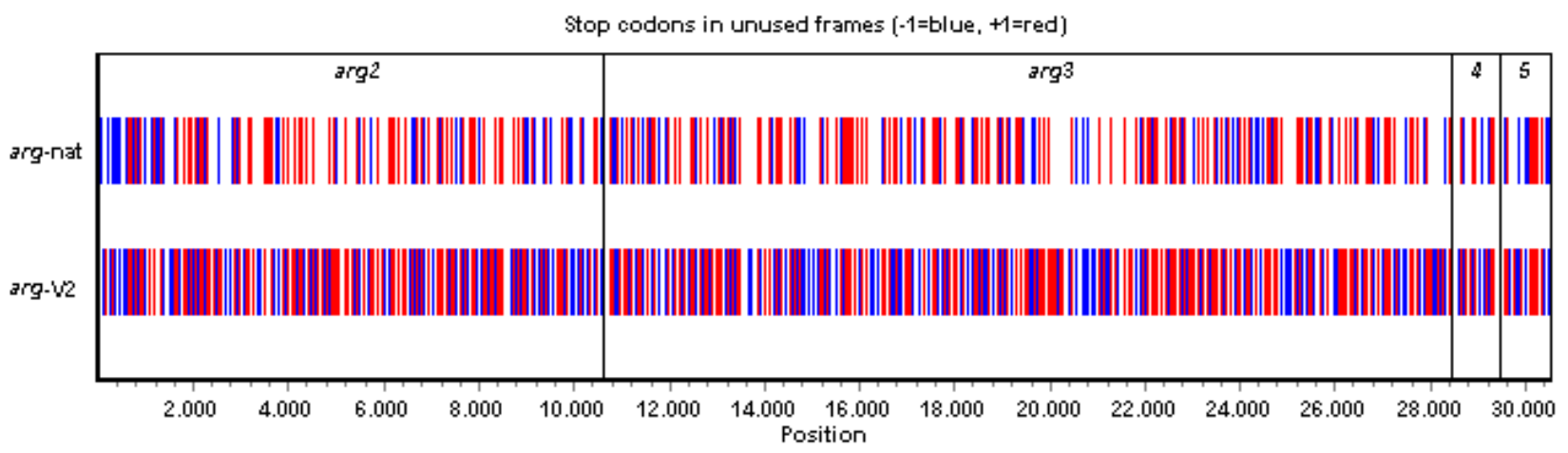

Figure S9. Effect of the $\arg$-V2 sequence modulation on selected features in comparison to arg-native. Untranslated regions between the protein coding sequences of arg2-arg4 were excluded from the graphs. (A) Interaction of the 16s rRNA 3'-end (anti-Shine-Dalgarno (ASD) sequence) and internal Shine-Dalgarno (SD) within the arg CDSs. (B) Occurrence of rare codon clusters within the arg CDSs derived from 9 codon windows (including Trp and Met for CAI calculation). The modified BGC arg-V2 shows no downward peaks below $\mathrm{CAI}=0.425$, whereas the native $\mathrm{BGC}$ has values lower than $\mathrm{CAI}=0.2$. (C) Occurrence patterns of hidden stop codons in neighbouring frames of arg CDSs. 


\section{A}

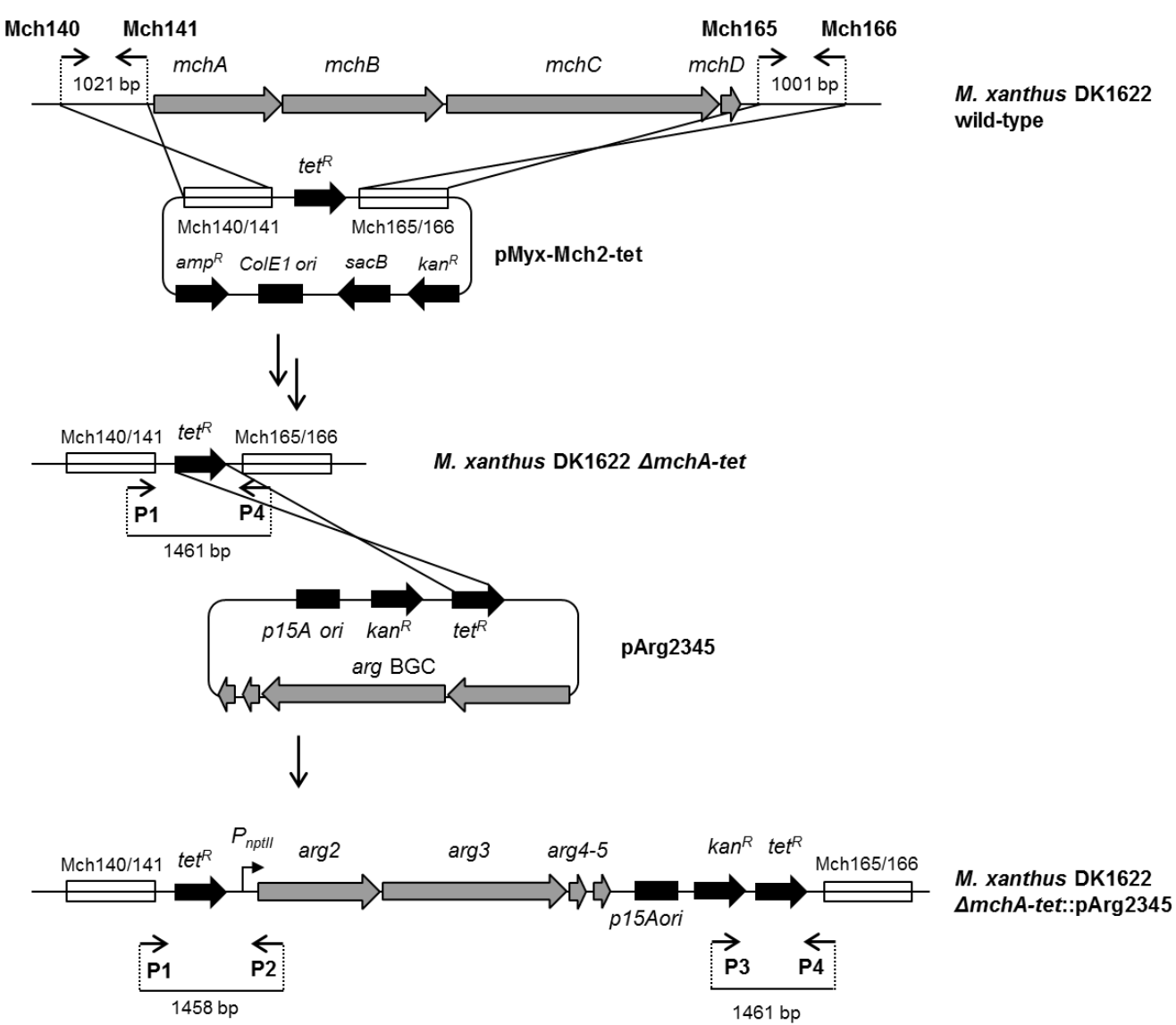

B

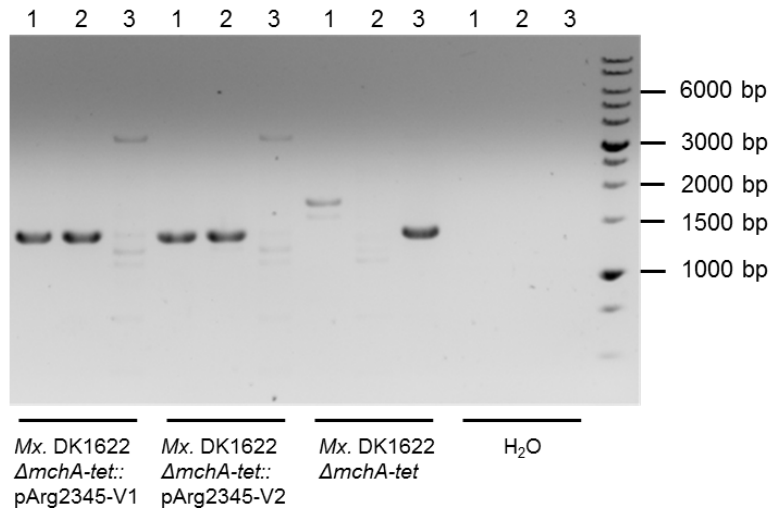

\section{Analyzed PCRs:}

Lanes 1: Primer pair P1/P2

Lanes 2: Primer pair P3/P4

Lanes 3: Primer pair P1/P4

(origin of chromosomal template

DNA indicated below the gel)

Figure S10. Construction and verification of expression strains. (A) After replacement of the $m c h_{A}$ BGC region in M. xanthus DK1622 with the tetracycline resistance gene $\left(t e t^{R}\right)$, arg BGC expression constructs were integrated by homologous recombination via $t e t^{R}$. Genetic elements are not illustrated in uniform scale (B) Correct chromosomal integration was verified by PCR using the oligonucleotides P1-P4 (Table S1) as shown for M. xanthus DK1622 AmchA-tet::pArg2345-V1/V2 in comparison to M. xanthus DK1622 $\Delta m c h A$-tet and water as negative control. 
A

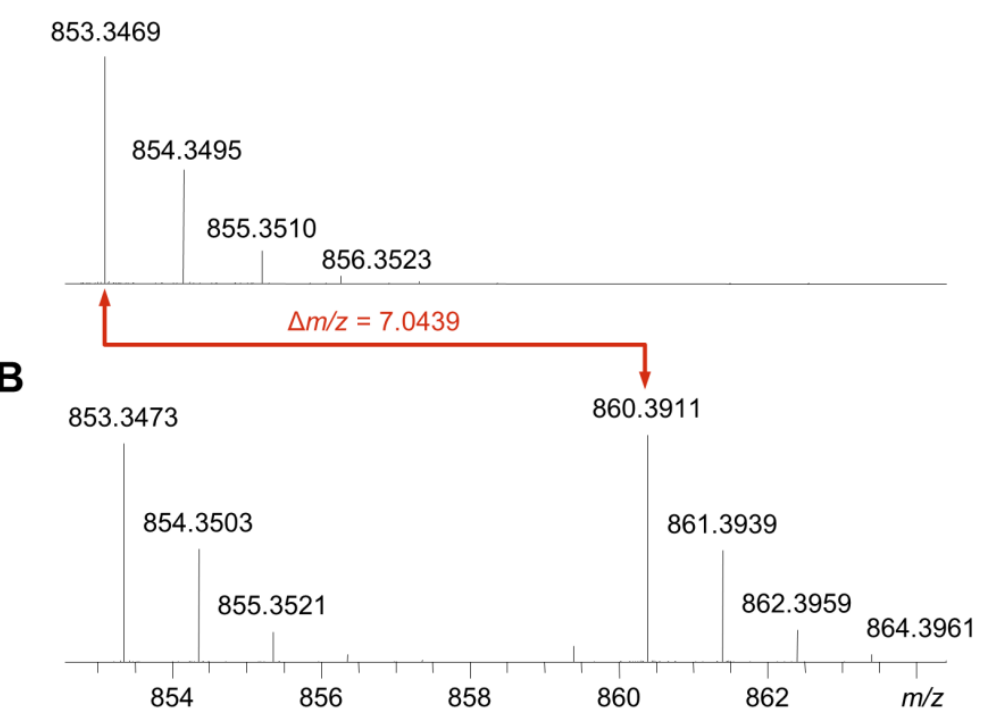

E

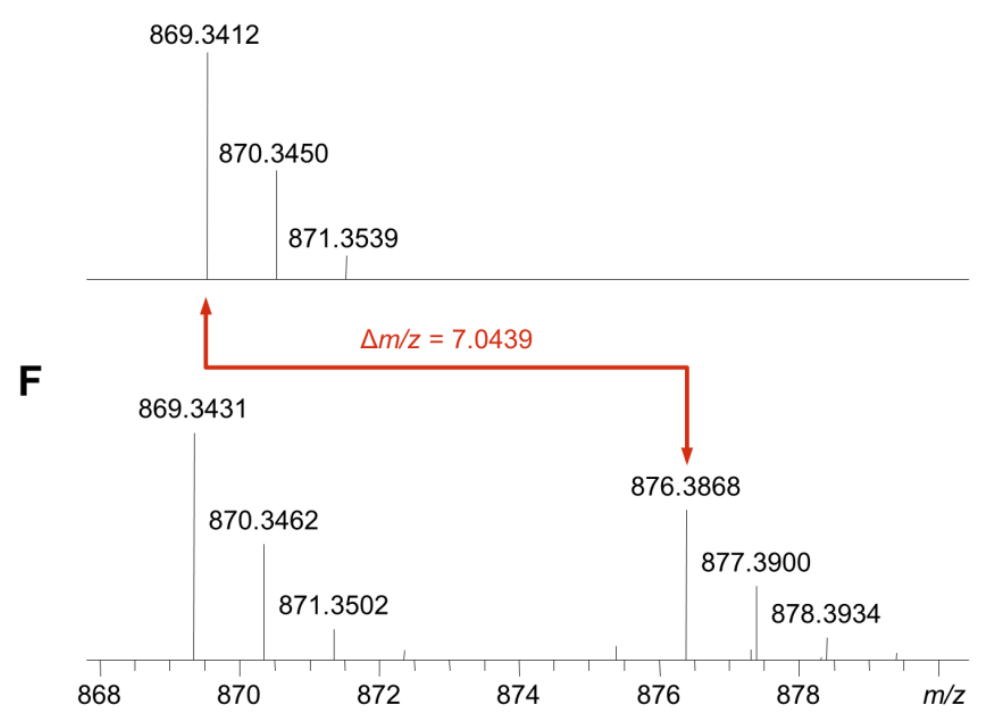

C

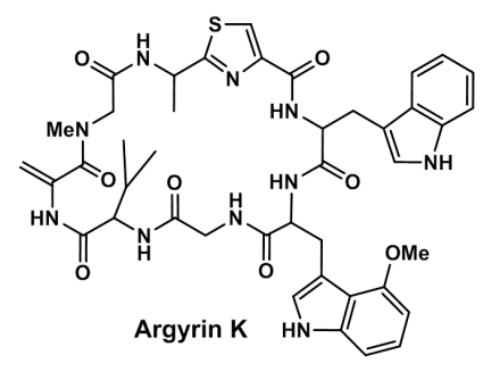

D

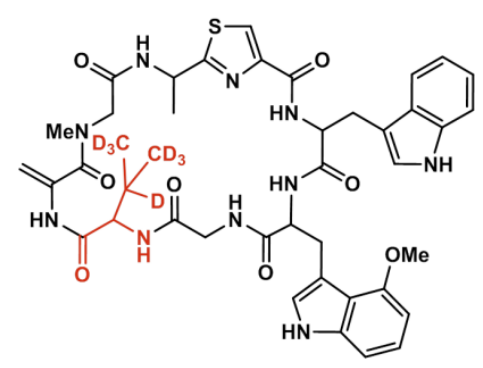

G

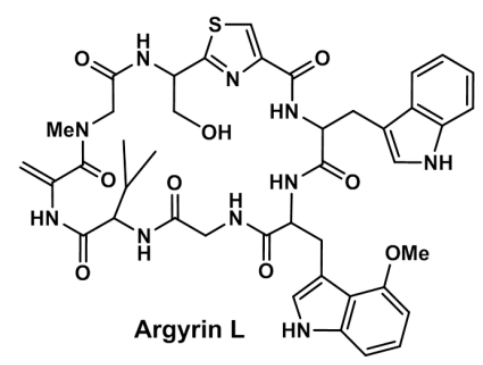

H

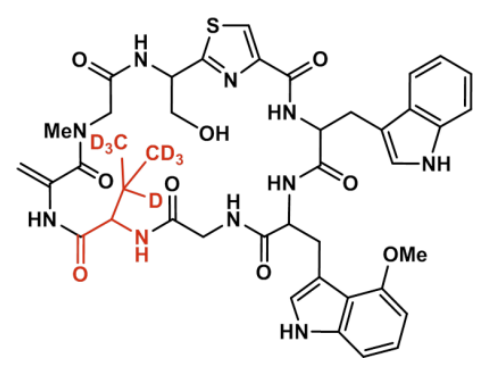

Figure S11. Analysis of the incorporation $L$-valine-D8 during argyrin biosynthesis. MS-spectra of argyrin K (C) and argyrin L (G) after HPLC-MS analysis of culture extracts of Cystobacter sp. SBCb004. The monoisotopic signal of the argyrin $\mathrm{K}[\mathrm{M}+\mathrm{H}]^{+}$ion is at $853.3469 \mathrm{~m} / z$ (calc. $853.3450 \mathrm{~m} / z, \mathrm{C}_{42} \mathrm{H}_{49} \mathrm{~N}_{10} \mathrm{O}_{8} \mathrm{~S}$ ) and of the argyrin $\mathrm{L}$ $[\mathrm{M}+\mathrm{H}]^{+}$ion at $869.3412 \mathrm{~m} / \mathrm{z}$ (calc. $869.3399 \mathrm{~m} / z, \mathrm{C}_{42} \mathrm{H}_{49} \mathrm{~N}_{10} \mathrm{O}_{9} \mathrm{~S}$ ). (A)/(E) Control sample to which no labelled precursor was fed, $(\mathbf{B}) /(\mathbf{F})$ sample from feeding experiment with $L$-valine-D8, $(\mathbf{D}) /(\mathbf{H})$ expected labelling pattern of argyrin $\mathrm{K}$ and $\mathrm{L}$ after incorporation of $L$-valine-D8 ( $\mathrm{D}$ in $\alpha$-position lost because of frequent $\mathrm{H}$-D exchange). 


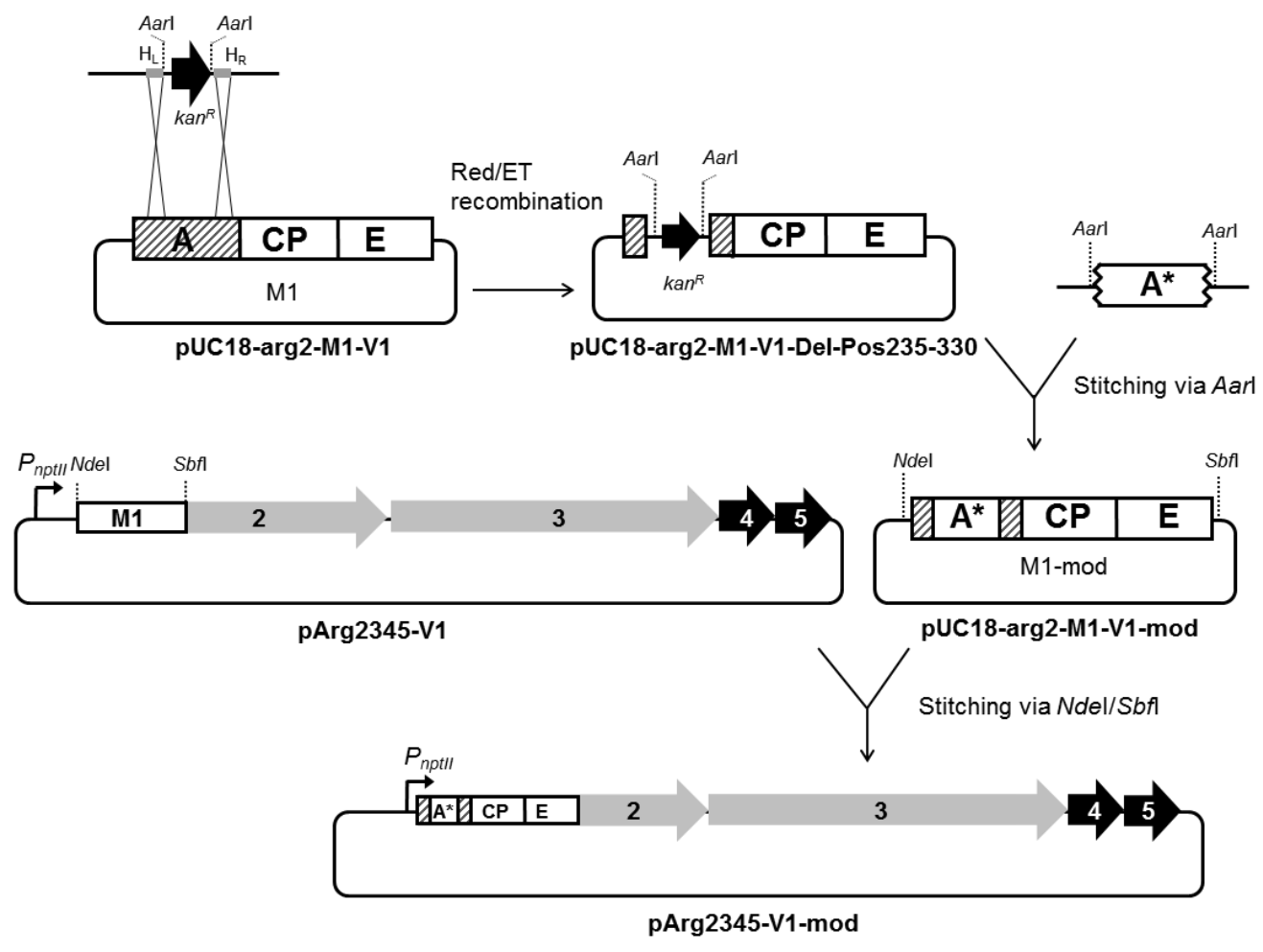

Figure S12. Strategy to exchange the subdomain part of A1. Using this approach 14 expression constructs with engineered A1 domains (pArg2345-V1-mod[1-14]) were generated.

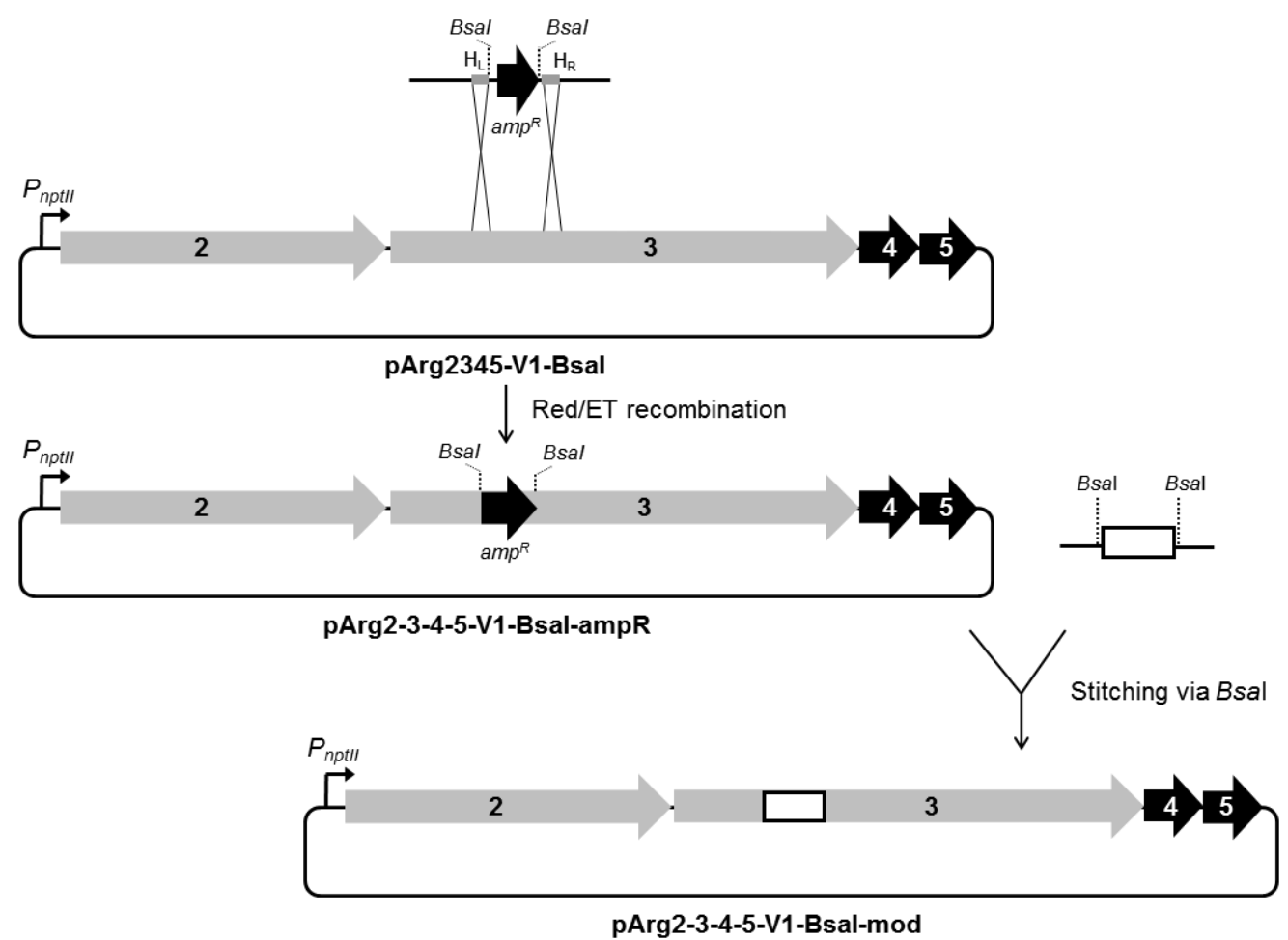

Figure S13. Modification strategy of the pArg2345-V1-BsaI expression construct. General modification strategy of the pArg2345-V1-BsaI expression construct (e.g. Arg3 subunit), employing BsaI type IIS restriction sites. 
Table S1. Genes, proteins, proposed function in the arg BGC from Cystobacter sp. SBCb004.

\begin{tabular}{|l|c|c|c|l|}
\hline Gene name & Gene length & Protein name & Protein length & Putative function \\
\hline $\arg 1$ & $2013 \mathrm{nt}$ & $\operatorname{Arg} 1$ & $670 \mathrm{aa}$ & $\begin{array}{l}\text { radical SAM-dependent } \\
\text { methyltransferase }\end{array}$ \\
\hline $\arg 2$ & $10617 \mathrm{nt}$ & $\operatorname{Arg} 2$ & 3538 aa & $\begin{array}{l}\text { nonribosomal peptide synthetase } \\
\text { (NRPS), subunit 1 }\end{array}$ \\
\hline $\arg 3$ & $17841 \mathrm{nt}$ & $\operatorname{Arg} 3$ & 5946 aa & $\begin{array}{l}\text { nonribosomal peptide synthetase } \\
\text { (NRPS), subunit 2 }\end{array}$ \\
\hline arg4 & $1011 \mathrm{nt}$ & Arg4 & 336 aa & O-methyltransferase \\
\hline arg5 & $1152 \mathrm{nt}$ & Arg5 & 383 aa & tryptophan 2,3-dioxygenase \\
\hline
\end{tabular}

$\mathrm{nt}=$ nucleotides, $\mathrm{aa}=$ amino acids

Table S2. Substrate specificity analysis of A domains from the argyrin NRPS from Cystobacter sp. SBCb004.

\begin{tabular}{|c|c|c|c|c|c|c|c|c|c|c|c|c|c|c|}
\hline & \multicolumn{10}{|c|}{ Residue according to GrsA Phe numbering ${ }^{1}$} & \multirow{2}{*}{\multicolumn{4}{|c|}{ Specificity predictions ${ }^{2}$}} \\
\hline & 235 & 236 & 239 & 278 & 299 & 301 & 322 & 330 & 331 & 517 & & & & \\
\hline A1 & $\mathrm{D}$ & $\mathrm{V}$ & $\mathrm{L}$ & $\mathrm{F}$ & $\mathrm{L}$ & $\mathrm{G}$ & $\mathrm{V}$ & $\mathrm{V}$ & A & $\mathrm{K}$ & (a) & Ile & Ala & - \\
\hline A2 & $\mathrm{D}$ & $\mathrm{V}$ & $\mathrm{W}$ & $\mathrm{H}$ & $\mathrm{F}$ & $\mathrm{S}$ & $\mathrm{L}$ & I & $\mathrm{D}$ & $\mathrm{K}$ & Ser & Ser & Ser & Ser \\
\hline $\mathbf{A 3}$ & $\mathrm{D}$ & I & $\mathrm{L}$ & $\mathrm{Q}$ & $\mathrm{L}$ & $\mathrm{G}$ & $\mathrm{M}$ & $\mathrm{V}$ & $\mathrm{W}$ & $\mathrm{K}$ & Gly & Gly & Gly & Gly \\
\hline $\mathbf{A 4}$ & $\mathrm{D}$ & $\mathrm{L}$ & $\mathrm{W}$ & $\mathrm{N}$ & $\mathrm{M}$ & $\mathrm{G}$ & $\mathrm{E}$ & $\mathrm{V}$ & $\mathrm{W}$ & $\mathrm{K}$ & (b) & Asn & Ala & - \\
\hline A5 & D & $\mathrm{L}$ & $\mathrm{Y}$ & $\mathrm{N}$ & $\mathrm{M}$ & $S$ & $\mathrm{~L}$ & I & $\mathrm{W}$ & $\mathrm{K}$ & Cys & Cys & Cys & Cys \\
\hline A6 & $\mathrm{D}$ & $\mathrm{G}$ & $\mathrm{W}$ & $\mathrm{A}$ & $\mathrm{L}$ & $\mathrm{A}$ & $\mathrm{A}$ & $\mathrm{V}$ & $\mathrm{T}$ & $\mathrm{K}$ & (c) & Trp & Tyr & - \\
\hline A7 & $\mathrm{D}$ & $\mathrm{G}$ & $\mathrm{W}$ & $\mathrm{A}$ & $\mathrm{T}$ & $\mathrm{A}$ & $\mathrm{V}$ & $\mathrm{V}$ & $\mathrm{T}$ & $\mathrm{K}$ & Trp & Trp & Ala & Trp \\
\hline A8 & D & I & $\mathrm{L}$ & $\mathrm{Q}$ & $\mathrm{L}$ & $\mathrm{G}$ & $\mathrm{V}$ & I & W & $\mathrm{K}$ & Gly & Gly & Gly & Gly \\
\hline
\end{tabular}

${ }^{1}$ Ten specificity-conferring residues defined by Stachelhaus et al. ${ }^{15}$

2 Predicted substrate specificities were retrieved from reports of the applied antiSMASH 3.0 gene cluster analysis. ${ }^{18}$ They include substrate predictions based on the NRPSpredictor 2 method ${ }^{19}$ (1st column) / Stachelhaus $\operatorname{code}^{15}$ (2nd column) / method of Minowa et al. ${ }^{20}$ (3rd column) / consensus of the three approaches (4th column; “" indicates no consensus). In some cases, no single substrates but (only) classes/clusters of several amino acids were predicted by NRPSpredictor2 as indicated by (a-c): (a) Hydrophobic aliphatic (Ala, Gly, Val, Leu, Ile, Abu, Iva Ser, Thr, Hpg, Dhpg, Cys, Pro, Pip), (b) Apolar, aliphatic (Gly, Ala, Val, Leu, Ile, Abu, Iva), (c) Apolar aromatic ring (Phe, Trp). 
Table S3. Oligonucleotides used in this study.

\begin{tabular}{|c|c|c|}
\hline Name & $\begin{array}{l}\text { Sequence }\left(\mathbf{5}^{6} \rightarrow \mathbf{3}^{6}\right) \\
\text { (restriction sites in bold, homology arms underlined) }\end{array}$ & $\begin{array}{l}\text { R-sites } \\
\text { (bold) }\end{array}$ \\
\hline Arg1 & CTCGATATCCCAGCGCAAGAGCTATCG & EcoRV \\
\hline $\operatorname{Arg} 2$ & CTCGGATCCGGTCGGGAACCATGTACC & BamHI \\
\hline Arg10 & GAGCGTGCGGAAGAGCTC & \\
\hline Arg11 & CCTCGGTGCTGTTCCAGG & \\
\hline Arg42 & $\begin{array}{l}\text { AACCCGAGGACCGCTTTCTCGCCCTGAGCTCGGTCTCCTTCG } \\
\text { ACGGCAGGTGTGGACAGCAAGCGAACCG }\end{array}$ & \\
\hline Arg43 & $\begin{array}{l}\text { TGCACACTGTCACCCGCGAAGAGCTCTGGCGAAGTGACCGCG } \\
\text { ACGGCAGGTGTCAGAAGAACTCGTCAAG }\end{array}$ & \\
\hline Arg44 & TGACATCATATGCCTAGGGACGAAAGGGCCTCGTGATAC & \\
\hline Arg45 & ATGTCAGCATGCCCTAGGTTACCAATGCTTAATCAGTGAG & \\
\hline Arg47 & CACCAAGCTTTGAATGCGCAAACCAACC & \\
\hline Arg48 & CTAGGTCAGGGCATATGATC & \\
\hline Arg51 & CCCGCCTACTTCATGTACAC & \\
\hline $\operatorname{Arg} 2 \mathrm{~V} 1 \mathrm{~F}$ & GGCTCTTCAATCTGGACGAG & \\
\hline $\operatorname{Arg} 2 \mathrm{~V} 1 \mathrm{R}$ & GATCTTCAGGTCTGGTTTGC & \\
\hline Arg3V1F (= MutArg3V1F) & CTCATGGCTTCTGGCGTCTG & \\
\hline Arg3V1R (= MutArg3V1R) & GGGACACCTTGTGCTTGTCC & \\
\hline $\arg 4 \mathrm{~V} 1 \mathrm{~F}$ & GTTGATGCTCGTCCTGGGTG & \\
\hline $\arg 4 \mathrm{~V} 1 \mathrm{R}$ & CAGGTCGCATCGTCCCAATC & \\
\hline $\arg 5 \mathrm{~V} 1 \mathrm{~F}$ & CCGGCCTATATTCATGAGCG & \\
\hline $\arg 5 \mathrm{~V} 1 \mathrm{R}$ & CTTCAGATGCTCGAAGCCATC & \\
\hline Arg2V2F (= arg2F) & GGTCCGATGTATCGCACC & \\
\hline $\operatorname{Arg} 2 \mathrm{~V} 2 \mathrm{R}(=\arg 2 \mathrm{R})$ & GTGTAGCGCTCACAGTGC & \\
\hline Arg3V2F $(=\arg 3 \mathrm{~F})$ & GATGCCCAGCACTTCAACC & \\
\hline $\operatorname{Arg} 3 \mathrm{~V} 2 \mathrm{R}(=\arg 3 \mathrm{R})$ & GCCTGACCCTCACCTTCC & \\
\hline $\operatorname{Arg} 4 \mathrm{~V} 2 \mathrm{~F}(=\arg 4 \mathrm{~F})$ & CACCTCATCAATAGCACG & \\
\hline Arg4V2R (= arg4R) & GCCTTACGCAGGAGTTCC & \\
\hline $\operatorname{Arg} 5 \mathrm{~V} 2 \mathrm{~F}(=\arg 5 \mathrm{~F})$ & TCTTCGTGGCTGACGTGC & \\
\hline $\operatorname{Arg} 5 \mathrm{~V} 2 \mathrm{R}(=\arg 5 \mathrm{R})$ & GCATGTTCGCGGAACAGC & \\
\hline $\mathrm{P} 1$ (= InMchP1) & CGAGCAATCCGCTATTGGC & \\
\hline $\mathrm{P} 2$ (= InMchP2) & CAGCTGGCAATTCCGGTTCG & \\
\hline P3 (= InMchP3) & ACGGGACGGGATATCTGACC & \\
\hline $\mathrm{P} 4$ (= InMchP4) & CTGTGTCCTTCTGCGACGC & \\
\hline pSUP_B & CGCTCATCGTCATCCTCG & \\
\hline pSUP_E & GCTCATGAGCCCGAAGTG & \\
\hline dpo-A4-ampR-F & $\begin{array}{l}\text { GGCCAGTCCGCGGGGAACCTGGACCTGGATTACGCCTCCGGG } \\
\text { GATGAGACCGACGAAAGGGCCTCGTGATAC }\end{array}$ & $B s a \mathrm{I}$ \\
\hline dpo-A4-ampR-R & $\begin{array}{l}\text { AAGGGAGACGTGGACGAACTTCTCCTTGTTCAGCTCTGGCCG } \\
\text { CTTCGAGACCTTACCAATGCTTAATCAGTGAG }\end{array}$ & $B s a \mathrm{I}$ \\
\hline dpo-BsaI-A4-R & GTCTTGTAGAGGCGGACGTTG & \\
\hline Ampint3 & GGACCACTTCTGCGCTCG & \\
\hline Ampint5 & GTCTCATGAGCGGATAC & \\
\hline Mch140 & CATGAGCTCGGAAACGGACGCGCCAATCC & SacI \\
\hline Mch141 & CATTCTAGACTACGCCAATAGCGGATTGC & $X b a \mathrm{I}$ \\
\hline Mch165 & CATTCTAGACGATGTCGCGCAGGTACG & $X b a \mathrm{I}$ \\
\hline Mch166 & CATGGATCCCATCCAGCAGAAGGCCATC & BamI \\
\hline TetR-for & CACGGTTCTAGACGTAATTCTCATGTTTGACAGC & $X b a \mathrm{I}$ \\
\hline TetR-rev & CACGGTTCTAGACAAGGGTTGGTTTGCGCA & $X b a \mathrm{I}$ \\
\hline
\end{tabular}


Table S4. Gene synthesis constructs obtained from ATG:biosynthetics GmbH.

\begin{tabular}{|c|c|c|}
\hline Construct name & Fragment size & Description \\
\hline pGH-arg2-M1-V1 & $3129 \mathrm{bp}$ & NdeI-AvrII-arg2-M1-V1-Sbfl-BglII \\
\hline pGH-arg2-M2-V1 & $3374 \mathrm{bp}$ & NdeI-SbfI-arg2-M2-V1-MluI-BglII \\
\hline pGH-arg2-M3-V1 & $4317 \mathrm{bp}$ & NdeI-MluI-arg2-M3-V1-SphI-BglII \\
\hline pGH-arg3-M4-V1 & $3238 \mathrm{bp}$ & NdeI-SphI-arg3-M4-V1-KpnI-BglII \\
\hline pGH-arg3-M5-V1 & 4446 bp & NdeI-KpnI-arg3-M5-V1-AscI-BglII \\
\hline pGH-arg3-M6-V1 & $3168 \mathrm{bp}$ & NdeI-AscI-arg3-M6-V1-NotI-BglII \\
\hline pGH-arg3-M7-V1 & $3172 \mathrm{bp}$ & NdeI-NotI-arg3-M7-V1-MfeI-BglII \\
\hline pGH-arg3-M8-V1 & $4037 \mathrm{bp}$ & NdeI-MfeI-arg3-M8-V1-NsiI-NcoI \\
\hline pGH-arg4-V1 & $1061 \mathrm{bp}$ & NdeI-NsiI-arg4-V1-NcoI-BglII \\
\hline pGH-arg5-V1 & $1236 \mathrm{bp}$ & NdeI-NcoI-arg5-V1-BglII \\
\hline pGH-arg2-M1-V2 & $3129 \mathrm{bp}$ & NdeI-AvrII-arg2-M1-V2-SbfI-BglII \\
\hline pGH-arg2-M2-V2 & $3374 \mathrm{bp}$ & NdeI-SbfI-arg2-M2-V2-MluI-BglII \\
\hline pGH-arg2-M3-V2 & $4317 \mathrm{bp}$ & NdeI-MluI-arg2-M3-V2-SphI-BglII \\
\hline pGH-arg3-M4-V2 & $3238 \mathrm{bp}$ & NdeI-SphI-arg3-M4-V2-KpnI-BglII \\
\hline pGH-arg3-M5-V2 & 4446 bp & NdeI-KpnI-arg3-M5-V2-AscI-BglII \\
\hline pGH-arg3-M6-V2 & $3168 \mathrm{bp}$ & NdeI-AscI-arg3-M6-V2-NotI-BglII \\
\hline pGH-arg3-M7-V2 & $3172 \mathrm{bp}$ & NdeI-NotI-arg3-M7-V2-MfeI-BglII \\
\hline pGH-arg3-M8-V2 & $4037 \mathrm{bp}$ & NdeI-MfeI-arg3-M8-V2-NsiI-NcoI \\
\hline pGH-arg4-V2 & $1061 \mathrm{bp}$ & NdeI-NsiI-arg4-V2-NcoI-BglII \\
\hline pGH-arg5-V2 & $1236 \mathrm{bp}$ & NdeI-NcoI-arg5-V2-BglII \\
\hline pGH-15A-kanR & $2088 \mathrm{bp}$ & PmeI-AflII-p15Aori-kanR-EcoRV-PacI \\
\hline pGH-tetR-PnptII-MCS-TD1 & $2002 \mathrm{bp}$ & EcoRV-PacI-tetR-PnptII-MCS-TD1-PmeI-AflII \\
\hline pGH-A1-mod1 & $324 \mathrm{bp}$ & AarI-A1-mod1-AarI \\
\hline pGH-A1-mod2 & $324 \mathrm{bp}$ & AarI-A1-mod2-AarI \\
\hline pGH-A1-mod3 & $324 \mathrm{bp}$ & AarI-A1-mod3-AarI \\
\hline pGH-A1-mod4 & $324 \mathrm{bp}$ & AarI-A1-mod4-AarI \\
\hline pGH-A1-mod5 & $324 \mathrm{bp}$ & AarI-A1-mod5-AarI \\
\hline pGH-A1-mod6 & $324 \mathrm{bp}$ & AarI-A1-mod6-AarI \\
\hline pGH-A1-mod7 & $324 \mathrm{bp}$ & AarI-A1-mod7-AarI \\
\hline pGH-A1-mod8 & $324 \mathrm{bp}$ & AarI-A1-mod8-AarI \\
\hline pGH-A1-mod9 & $324 \mathrm{bp}$ & AarI-A1-mod9-AarI \\
\hline pGH-A1-mod10 & 324 bp & AarI-A1-mod10-AarI \\
\hline pGH-A1-mod11 & $324 \mathrm{bp}$ & AarI-A1-mod11-AarI \\
\hline pGH-A1-mod12 & $324 \mathrm{bp}$ & AarI-A1-mod12-AarI \\
\hline pGH-A1-mod13 & $324 \mathrm{bp}$ & AarI-A1-mod13-AarI \\
\hline pGH-A1-mod14 & $324 \mathrm{bp}$ & AarI-A1-mod14-AarI \\
\hline pGH-arg2-M1-V1-BsaI & $3374 \mathrm{bp}$ & NdeI-AvrII-arg2-M1-V1-BsaI-SbfI-BglII \\
\hline pGH-arg2-M2-V1-BsaI & $4317 \mathrm{bp}$ & NdeI-SbfI-arg2-M2-V1-BsaI-MluI-BglII \\
\hline pGH-arg2-M3-V1-BsaI & $3226 \mathrm{bp}$ & NdeI-MluI-arg2-M3-V1-BsaI-SphI-BglII \\
\hline pGH-arg3-M4-V1-BsaI & $4446 \mathrm{bp}$ & NdeI-SphI-arg3-M4-V1-BsaI-KpnI-BglII \\
\hline pGH-arg3-M5-V1-BsaI & $3168 \mathrm{bp}$ & NdeI-KpnI-arg3-M5-V1-BsaI-AscI-BglII \\
\hline pGH-arg3-M6-V1-BsaI & $3172 \mathrm{bp}$ & NdeI-AscI-arg3-M6-V1-BsaI-NotI-BglII \\
\hline pGH-arg3-M7-V1-BsaI & $4037 \mathrm{bp}$ & NdeI-NotI-arg3-M7-V1-BsaI-MfeI-BglII \\
\hline pGH-arg3-M8-V1-BsaI & $1061 \mathrm{bp}$ & NdeI-MfeI-arg3-M8-V1-BsaI-NsiI-NcoI \\
\hline pGH-arg4-V1-BsaI & $1236 \mathrm{bp}$ & NdeI-NsiI-arg4-V1-BsaI-NcoI-BglII \\
\hline pGH-arg5-V1-BsaI & $3374 \mathrm{bp}$ & NdeI-NcoI-arg5-V1-BsaI-BglII \\
\hline
\end{tabular}


Table S5. Plasmids and expression constructs generated in this study.

\begin{tabular}{|c|c|c|}
\hline Construct name & Construction & Description/Characteristics \\
\hline $\begin{array}{l}\text { pSynBio3 } \\
\text { (p15A-kan-tet- } \\
\text { PnptII-MCS-TD1) }\end{array}$ & $\begin{array}{l}1986 \text { bp PacI-tetR-PnptII-MCS-TD1- } \\
\text { PmeI-AflII fragment from pGH-tetR- } \\
\text { PnptII-MCS-TD1 ligated with } 2070 \text { bp } \\
\text { AflII-p15Aori-kanR-EcoRV-PacI fragment } \\
\text { from pGH-15A-kanR }\end{array}$ & $\begin{array}{l}\text { Expression vector backbone, } \\
\text { p15A ori, } \text { kan }^{R}, \text { tet }^{R}\end{array}$ \\
\hline $\begin{array}{l}\text { pGH-arg2-M1-M2- } \\
\text { V1 }\end{array}$ & $\begin{array}{l}3359 \text { bp SbfI-arg2-M2-V1-BglII fragment } \\
\text { derived from pGH-arg2-M2-V1 ligated } \\
\text { into pGH-arg2-M1-V1 hydrolyzed with } \\
\text { the same enzymes }\end{array}$ & $\begin{array}{l}\text { synthetic arg2-V1 fragment (encoding } \\
\text { modules M1-M2 of NRPS Arg2), } \\
\text { pUC ori, } a m p^{R}\end{array}$ \\
\hline pGH-arg2-V1 & $\begin{array}{l}4303 \text { bp } M l u \mathrm{I}-\arg 2-\mathrm{M} 3-\mathrm{V} 1-B g l \mathrm{II} \text { fragment } \\
\text { derived from pGH-arg2-M3-V1 ligated } \\
\text { into pGH-arg2-M1-M2-V1 hydrolyzed } \\
\text { with the same enzymes }\end{array}$ & $\begin{array}{l}\text { complete synthetic arg2-V1 gene } \\
\text { (encoding modules M1-M3 of NRPS } \\
\text { Arg2), } \\
\text { pUC ori, } a m p^{R}\end{array}$ \\
\hline $\begin{array}{l}\text { pGH-arg3-M4-M5- } \\
\text { V1 }\end{array}$ & $\begin{array}{l}4432 \text { bp KpnI-arg3-M5-V1-BglII } \\
\text { fragment from pGH-arg3-M5-V1 ligated } \\
\text { into pGH-arg3-M4-V1 hydrolyzed with } \\
\text { the same enzymes }\end{array}$ & $\begin{array}{l}\text { synthetic } \arg 3-\mathrm{V} 1 \text { fragment (encoding } \\
\text { modules M4-M5 of NRPS Arg3), } \\
\text { pUC ori, } a m p^{R}\end{array}$ \\
\hline $\begin{array}{l}\text { pGH-arg3-M4-M5- } \\
\text { M6-V1 }\end{array}$ & $\begin{array}{l}3153 \text { bp AscI-arg3-M6-V1-BglII fragment } \\
\text { from pGH-arg3-M6-V1 ligated into pGH- } \\
\text { arg3-M4-M5-V1 hydrolyzed with the same } \\
\text { enzymes }\end{array}$ & $\begin{array}{l}\text { synthetic arg3-V1 fragment (encoding } \\
\text { modules M4-M6 of NRPS Arg3), } \\
\text { pUC ori, } a m p^{R}\end{array}$ \\
\hline $\begin{array}{l}\text { pGH-arg3-M4-M5- } \\
\text { M6-M7-V1 }\end{array}$ & $\begin{array}{l}3157 \text { bp NotI-arg3-M7-V1-BglII fragment } \\
\text { from pGH-arg3-M7-V1 ligated into pGH- } \\
\text { arg3-M4-M5-M6-V1 hydrolyzed with the } \\
\text { same enzymes }\end{array}$ & $\begin{array}{l}\text { synthetic } \arg 3-\mathrm{V} 1 \text { fragment (encoding } \\
\text { modules M4-M7 of NRPS Arg3), } \\
\text { pUC ori, } a m p^{R}\end{array}$ \\
\hline pGH-arg3-V1 & $\begin{array}{l}4023 \text { bp } M f e I-a r g 3-M 8-V 1-B g l \mathrm{II} \text { fragment } \\
\text { from pGH-arg3-M8-V1 ligated into pGH- } \\
\text { arg3-M4-M5-M6-M7-V1 hydrolyzed with } \\
\text { the same enzymes }\end{array}$ & $\begin{array}{l}\text { complete synthetic arg3-V1 gene } \\
\text { (encoding modules M4-M8 of NRPS } \\
\text { Arg3), } \\
\text { pUC ori, } a m p^{R}\end{array}$ \\
\hline pArg2-V1 & $\begin{array}{l}10755 \text { bp NdeI-arg2-V1-BglII fragment } \\
\text { from pGH-arg2-V1 ligated into pSynBio3 } \\
\text { hydrolyzed with the same enzymes }\end{array}$ & $\begin{array}{l}\text { expression vector with } P_{n p t I-} \text {-arg2-V1- } t_{D I} \\
\text { transcription unit, } \\
\text { p15A ori, } \text { kan }^{R}, \text { tet }^{R}\end{array}$ \\
\hline pArg23-V1 & $\begin{array}{l}17923 \text { bp SphI-arg3-V1-BglII fragment } \\
\text { from pGH-arg3-V1 ligated into pArg2-V1 } \\
\text { hydrolyzed with the same enzymes }\end{array}$ & $\begin{array}{l}\text { expression vector with } P_{n p t I I}-\arg 2-\arg 3- \\
\text { V1- } t_{D I} \text { transcription unit, } \\
\text { p15A ori, } \text { kan }^{R}, \text { tet }^{R}\end{array}$ \\
\hline pArg235-V1 & $\begin{array}{l}1222 \text { bp NcoI-arg5-V1-BglII fragment } \\
\text { from pGH-arg5-V1 ligated into pArg23- } \\
\text { V1 hydrolyzed with the same enzymes }\end{array}$ & $\begin{array}{l}\text { expression vector with } P_{n p t I I} \text {-arg2-arg3- } \\
\arg 5-\mathrm{V} 1-t_{D I} \text { transcription unit, } \\
\text { p15A ori, } \mathrm{kan}^{R}, \text { tet }^{R}\end{array}$ \\
\hline pArg2345-V1 & $\begin{array}{l}1035 \text { bp NsiI-arg4-V1-NcoI fragment from } \\
\text { pGH-arg4-V1 ligated into pArg235-V1 } \\
\text { hydrolyzed with the same enzymes }\end{array}$ & $\begin{array}{l}\text { expression vector with } P_{n p t I I}-\arg 2-\arg 3- \\
\arg 4-\arg 5-\mathrm{V} 1-t_{D I} \text { transcription unit, } \\
\text { p15A ori, } \mathrm{kan}^{R}, \text { tet }^{R}\end{array}$ \\
\hline $\begin{array}{l}\text { pGH-arg2-LM-M1- } \\
\text { V2 }\end{array}$ & $\begin{array}{l}3359 \text { bp SbfI-arg2-M2-V2-BglII fragment } \\
\text { derived from pGH-arg2-M2-V2 ligated } \\
\text { into pGH-arg2-M1-V2 hydrolyzed with } \\
\text { the same enzymes }\end{array}$ & $\begin{array}{l}\text { synthetic } \arg 2-\mathrm{V} 2 \text { fragment (encoding } \\
\text { modules M1-M2 of NRPS Arg2), } \\
\text { pUC ori, } a m p^{R}\end{array}$ \\
\hline pGH-arg2-V2 & $\begin{array}{l}4303 \text { bp } M l u \mathrm{I}-\arg 2-\mathrm{M} 3-\mathrm{V} 2-B g l \mathrm{II} \text { fragment } \\
\text { derived from pGH-arg2-M3-V2 ligated } \\
\text { into pGH-arg2-M1-M2-V2 hydrolyzed } \\
\text { with the same enzymes }\end{array}$ & $\begin{array}{l}\text { complete synthetic arg2-V2 gene } \\
\text { (encoding modules M1-M3 of NRPS } \\
\text { Arg2), } \\
\text { pUC ori, } a m p^{R}\end{array}$ \\
\hline $\begin{array}{l}\text { pGH-arg3-M4-M5- } \\
\text { V2 }\end{array}$ & $\begin{array}{l}4432 \text { bp KpnI-arg3-M5-V2-BglII } \\
\text { fragment from pGH-arg3-M5-V2 ligated } \\
\text { into pGH-arg3-M4-V2 hydrolyzed with } \\
\text { the same enzymes }\end{array}$ & $\begin{array}{l}\text { synthetic } \arg 3-\mathrm{V} 2 \text { fragment (encoding } \\
\text { modules M4-M5 of NRPS Arg3), } \\
\text { pUC ori, } a m p^{R}\end{array}$ \\
\hline $\begin{array}{l}\text { pGH-arg3-M4-M5- } \\
\text { M6-V2 }\end{array}$ & $\begin{array}{l}3153 \text { bp AscI-arg3-M6-V2-BglII fragment } \\
\text { from pGH-arg3-M6-V2 ligated into pGH- } \\
\text { arg3-M4-M5-V2 hydrolyzed with the same } \\
\text { enzymes }\end{array}$ & $\begin{array}{l}\text { synthetic } \arg 3-\mathrm{V} 2 \text { fragment (encoding } \\
\text { modules M4-M6 of NRPS Arg3), } \\
\text { pUC ori, } a m p^{R}\end{array}$ \\
\hline pGH-arg3-M4-M5- & 3157 bp NotI-arg3-M7-V2-BglII fragment & synthetic $\arg 3-\mathrm{V} 2$ fragment (encoding \\
\hline
\end{tabular}




\begin{tabular}{|c|c|c|}
\hline M6-M7-V2 & $\begin{array}{l}\text { from pGH-arg3-M7-V2 ligated into pGH- } \\
\text { arg3-M4-M5-M6-V2 hydrolyzed with the } \\
\text { same enzymes }\end{array}$ & $\begin{array}{l}\text { modules M4-M7 of NRPS Arg3), } \\
\text { pUC ori, } a m p^{R}\end{array}$ \\
\hline pGH-arg3-V2 & $\begin{array}{l}4023 \text { bp } M f e \mathrm{I}-\arg 3-\mathrm{M} 8-\mathrm{V} 2-\mathrm{Bg} l \mathrm{II} \text { fragment } \\
\text { from pGH-arg3-M8-V2 ligated into pGH- } \\
\text { arg3-M4-M5-M6-M7-V2 hydrolyzed with } \\
\text { the same enzymes }\end{array}$ & $\begin{array}{l}\text { complete synthetic arg3-V2 gene } \\
\text { (encoding modules M4-M8 of NRPS } \\
\text { Arg3), } \\
\text { pUC ori, } a m p^{R}\end{array}$ \\
\hline pArg2-V2 & $\begin{array}{l}10755 \text { bp NdeI-arg2-V2-BglII fragment } \\
\text { from pGH-arg2-V2 ligated into pSynBio3 } \\
\text { hydrolyzed with the same enzymes }\end{array}$ & $\begin{array}{l}\text { expression vector with } P_{n p t I-} \text { arg2-V2- } t_{D 1} \\
\text { transcription unit, } \\
\text { p15A ori, } \mathrm{kan}^{R}, \text { tet }^{R}\end{array}$ \\
\hline pArg23-V2 & $\begin{array}{l}17923 \text { bp SphI-arg3-V2-BglII fragment } \\
\text { from pGH-arg3-V2 ligated into pArg2-V2 } \\
\text { hydrolyzed with the same enzymes }\end{array}$ & $\begin{array}{l}\text { expression vector with } P_{n p t I I}-\arg 2-\arg 3- \\
\text { V2- } t_{D I} \text { transcription unit, } \\
\text { p15A ori, } \mathrm{kan}^{R}, \mathrm{tet}^{R}\end{array}$ \\
\hline pArg235-V2 & $\begin{array}{l}1222 \text { bp NcoI-arg5-V2-BglII fragment } \\
\text { from pGH-arg5-V2 ligated into pArg23- } \\
\text { V2 hydrolyzed with the same enzymes }\end{array}$ & $\begin{array}{l}\text { expression vector with } P_{n p t I I}-\arg 2-\arg 3- \\
\arg 5-\mathrm{V} 2-t_{D 1} \text { transcription unit, } \\
\text { p15A ori, } \text { kan }^{R}, \text { tet }^{R}\end{array}$ \\
\hline pArg2345-V2 & $\begin{array}{l}1035 \text { bp NsiI-arg4-V2-NcoI fragment from } \\
\text { pGH-arg4-V2 ligated into pArg235-V2 } \\
\text { hydrolyzed with the same enzymes }\end{array}$ & $\begin{array}{l}\text { expression vector with } P_{n p t I I}-\arg 2-\arg 3- \\
\arg 4-\arg 5-\mathrm{V} 2-t_{D I} \text { transcription unit, } \\
\text { p15A ori, } \mathrm{kan}^{R}, \text { tet }^{R}\end{array}$ \\
\hline pUC18-arg2-M1-V1 & $\begin{array}{l}3113 \text { bp NdeI-arg2-M1-VI-SdaI fragment } \\
\text { ligated into pUC18 hydrolyzed with the } \\
\text { same enzymes }\end{array}$ & $\begin{array}{l}\text { cloning vector with arg2-M1-V1 } \\
\text { synthetic fragment, pUC18 ori, } a m p^{R}\end{array}$ \\
\hline $\begin{array}{l}\text { pUC18-arg2-M1-V1- } \\
\text { Del-Pos235-330 }\end{array}$ & $\begin{array}{l}\text { A1 subdomain region of pUC18-arg2-M1- } \\
\text { V1 replaced with } 1052 \mathrm{bp} \mathrm{kan}^{R} \text { fragment } \\
\text { by in vivo recombination }\end{array}$ & $\begin{array}{l}\text { cloning vector with arg2-M1-V1-Del- } \\
\text { Pos235-330 synthetic fragment, pUC18 } \\
\text { ori, } a m p^{R}\end{array}$ \\
\hline $\begin{array}{l}\text { pUC18-arg2-M1-V1- } \\
\text { mod1 }\end{array}$ & $\begin{array}{l}302 \text { bp AarI-A1-mod1-AarI fragment } \\
\text { ligated into pUC18-arg2-M1-V1-Del- } \\
\text { Pos235-330 hydrolyzed with the same } \\
\text { enzyme }\end{array}$ & $\begin{array}{l}\text { cloning vector with arg2-M1-V1-mod1 } \\
\text { synthetic fragment, pUC18 ori, } a m p^{R}\end{array}$ \\
\hline $\begin{array}{l}\text { pUC18-arg2-M1-V1- } \\
\text { mod2 }\end{array}$ & $\begin{array}{l}302 \text { bp AarI-A1-mod2-AarI fragment } \\
\text { ligated into pUC18-arg2-M1-V1-Del- } \\
\text { Pos } 235-330 \text { hydrolyzed with the same } \\
\text { enzyme }\end{array}$ & $\begin{array}{l}\text { cloning vector with arg2-M1-V1-mod2 } \\
\text { synthetic fragment, pUC18 ori, } a m p^{R}\end{array}$ \\
\hline $\begin{array}{l}\text { pUC18-arg2-M1-V1- } \\
\text { mod3 }\end{array}$ & $\begin{array}{l}302 \text { bp AarI-A1-mod3-AarI fragment } \\
\text { ligated into pUC18-arg2-M1-V1-Del- } \\
\text { Pos } 235-330 \text { hydrolyzed with the same } \\
\text { enzyme }\end{array}$ & $\begin{array}{l}\text { cloning vector with arg2-M1-V1-mod3 } \\
\text { synthetic fragment, pUC18 ori, } a m p^{R}\end{array}$ \\
\hline $\begin{array}{l}\text { pUC18-arg2-M1-V1- } \\
\text { mod4 }\end{array}$ & $\begin{array}{l}302 \text { bp AarI-A1-mod4-AarI fragment } \\
\text { ligated into pUC18-arg2-M1-V1-Del- } \\
\text { Pos235-330 hydrolyzed with the same } \\
\text { enzyme }\end{array}$ & $\begin{array}{l}\text { cloning vector with arg2-M1-V1-mod4 } \\
\text { synthetic fragment, pUC18 ori, } a m p^{R}\end{array}$ \\
\hline $\begin{array}{l}\text { pUC18-arg2-M1-V1- } \\
\text { mod5 }\end{array}$ & $\begin{array}{l}302 \text { bp AarI-A1-mod5-AarI fragment } \\
\text { ligated into pUC18-arg2-M1-V1-Del- } \\
\text { Pos235-330 hydrolyzed with the same } \\
\text { enzyme }\end{array}$ & $\begin{array}{l}\text { cloning vector with arg2-M1-V1-mod5 } \\
\text { synthetic fragment, pUC18 ori, } a m p^{R}\end{array}$ \\
\hline $\begin{array}{l}\text { pUC18-arg2-M1-V1- } \\
\text { mod6 }\end{array}$ & $\begin{array}{l}302 \text { bp AarI-A1-mod6-AarI fragment } \\
\text { ligated into pUC18-arg2-M1-V1-Del- } \\
\text { Pos } 235-330 \text { hydrolyzed with the same } \\
\text { enzyme }\end{array}$ & $\begin{array}{l}\text { cloning vector with arg2-M1-V1-mod6 } \\
\text { synthetic fragment, pUC18 ori, } a m p^{R}\end{array}$ \\
\hline $\begin{array}{l}\text { pUC18-arg2-M1-V1- } \\
\bmod 7\end{array}$ & $\begin{array}{l}302 \text { bp AarI-A1-mod7-AarI fragment } \\
\text { ligated into pUC18-arg2-M1-V1-Del- } \\
\text { Pos235-330 hydrolyzed with the same } \\
\text { enzyme }\end{array}$ & $\begin{array}{l}\text { cloning vector with arg2-M1-V1-mod7 } \\
\text { synthetic fragment, pUC18 ori, } a m p^{R}\end{array}$ \\
\hline $\begin{array}{l}\text { pUC18-arg2-M1-V1- } \\
\bmod 8\end{array}$ & $\begin{array}{l}302 \text { bp AarI-A1-mod8-AarI fragment } \\
\text { ligated into pUC18-arg2-M1-V1-Del- } \\
\text { Pos } 235-330 \text { hydrolyzed with the same } \\
\text { enzyme }\end{array}$ & $\begin{array}{l}\text { cloning vector with arg2-M1-V1-mod8 } \\
\text { synthetic fragment, pUC18 ori, } a m p^{R}\end{array}$ \\
\hline $\begin{array}{l}\text { pUC18-arg2-M1-V1- } \\
\text { mod9 }\end{array}$ & $\begin{array}{l}302 \text { bp AarI-A1-mod9-AarI fragment } \\
\text { ligated into pUC18-arg2-M1-V1-Del- } \\
\text { Pos235-330 hydrolyzed with the same } \\
\text { enzyme }\end{array}$ & $\begin{array}{l}\text { cloning vector with arg2-M1-V1-mod9 } \\
\text { synthetic fragment, pUC18 ori, } a m p^{R}\end{array}$ \\
\hline
\end{tabular}




\begin{tabular}{|c|c|c|}
\hline $\begin{array}{l}\text { pUC18-arg2-M1-V1- } \\
\text { mod10 }\end{array}$ & $\begin{array}{l}302 \text { bp AarI-A1-mod10-AarI fragment } \\
\text { ligated into pUC18-arg2-M1-V1-Del- } \\
\text { Pos } 235-330 \text { hydrolyzed with the same } \\
\text { enzyme }\end{array}$ & $\begin{array}{l}\text { cloning vector with arg2-M1-V1-mod10 } \\
\text { synthetic fragment, pUC18 ori, } a m p^{R}\end{array}$ \\
\hline $\begin{array}{l}\text { pUC18-arg2-M1-V1- } \\
\bmod 11\end{array}$ & $\begin{array}{l}302 \text { bp AarI-A1-mod11-AarI fragment } \\
\text { ligated into pUC18-arg2-M1-V1-Del- } \\
\text { Pos } 235-330 \text { hydrolyzed with the same } \\
\text { enzyme }\end{array}$ & $\begin{array}{l}\text { cloning vector with arg2-M1-V1-mod11 } \\
\text { synthetic fragment, pUC18 ori, } a m p^{R}\end{array}$ \\
\hline $\begin{array}{l}\text { pUC18-arg2-M1-V1- } \\
\text { mod12 }\end{array}$ & $\begin{array}{l}302 \text { bp AarI-A1-mod12-AarI fragment } \\
\text { ligated into pUC18-arg2-M1-V1-Del- } \\
\text { Pos } 235-330 \text { hydrolyzed with the same } \\
\text { enzyme }\end{array}$ & $\begin{array}{l}\text { cloning vector with arg2-M1-V1-mod12 } \\
\text { synthetic fragment, pUC18 ori, } a m p^{R}\end{array}$ \\
\hline $\begin{array}{l}\text { pUC18-arg2-M1-V1- } \\
\bmod 13\end{array}$ & $\begin{array}{l}302 \text { bp AarI-A1-mod13-AarI fragment } \\
\text { ligated into pUC18-arg2-M1-V1-Del- } \\
\text { Pos } 235-330 \text { hydrolyzed with the same } \\
\text { enzyme }\end{array}$ & $\begin{array}{l}\text { cloning vector with arg2-M1-V1-mod13 } \\
\text { synthetic fragment, pUC18 ori, } a m p^{R}\end{array}$ \\
\hline $\begin{array}{l}\text { pUC18-arg2-M1-V1- } \\
\bmod 14\end{array}$ & $\begin{array}{l}302 \text { bp AarI-A1-mod14-AarI fragment } \\
\text { ligated into pUC18-arg2-M1-V1-Del- } \\
\text { Pos235-330 hydrolyzed with the same } \\
\text { enzyme }\end{array}$ & $\begin{array}{l}\text { cloning vector with arg2-M1-V1-mod14 } \\
\text { synthetic fragment, pUC18 ori, } a m p^{R}\end{array}$ \\
\hline pArg2345-V1-mod1 & $\begin{array}{l}3133 \text { bp NdeI-arg2-M1-V1-mod1-SbfI } \\
\text { fragment from pUC18-arg2-M1-V1-mod1 } \\
\text { ligated into pArg2345-V1 hydrolyzed with } \\
\text { the same enzymes }\end{array}$ & $\begin{array}{l}\text { expression vector with } P_{n p t I I}-\arg 2 * \text {-arg3- } \\
\text { arg4-arg5-V1- } t_{D I} \text { transcription unit } \\
(* \text { A1 mutation mod1; Table S11), } \\
\text { p15A ori, } \text { kan }^{R}, \text { tet }^{R}\end{array}$ \\
\hline pArg2345-V1-mod2 & $\begin{array}{l}3133 \text { bp NdeI-arg2-M1-V1-mod2-SbfI } \\
\text { fragment from pUC18-arg2-M1-V1-mod2 } \\
\text { ligated into pArg2345-V1 hydrolyzed with } \\
\text { NdeI/SbfI }\end{array}$ & $\begin{array}{l}\text { expression vector with } P_{n p t I I}-\arg 2 *_{-} \arg 3- \\
\arg 4-\arg 5-\mathrm{V} 1-t_{D I} \text { transcription unit } \\
(* \mathrm{~A} 1 \text { mutation } \bmod 2 ; \text { Table S11), } \\
\text { p15A ori, } \mathrm{kan}^{R}, \text { tet }^{R}\end{array}$ \\
\hline pArg2345-V1-mod3 & $\begin{array}{l}3133 \text { bp NdeI-arg2-M1-V1-mod3-SbfI } \\
\text { fragment from pUC18-arg2-M1-V1-mod3 } \\
\text { ligated pArg2345-V1 hydrolyzed with the } \\
\text { same enzymes }\end{array}$ & $\begin{array}{l}\text { expression vector with } P_{n p t I I}-\arg 2 * \text {-arg3- } \\
\text { arg4-arg5-V1- } t_{D I} \text { transcription unit } \\
(* \mathrm{~A} 1 \text { mutation mod3; Table S11), } \\
\text { p15A ori, } \mathrm{kan}^{R}, \mathrm{tet}^{R}\end{array}$ \\
\hline pArg2345-V1-mod4 & $\begin{array}{l}3133 \text { bp NdeI-arg2-M1-V1-mod4-SbfI } \\
\text { fragment from pUC18-arg2-M1-V1-mod4 } \\
\text { ligated into pArg2345-V1 hydrolyzed with } \\
\text { the same enzymes }\end{array}$ & $\begin{array}{l}\text { expression vector with } P_{n p t I I}-\arg 2 *_{-} \text {arg3- } \\
\text { arg4-arg5-V1- } t_{D I} \text { transcription unit } \\
(* \mathrm{~A} 1 \text { mutation mod4; Table S11), } \\
\text { p15A ori, } \mathrm{kan}^{R}, \mathrm{tet}^{R}\end{array}$ \\
\hline pArg2345-V1-mod5 & $\begin{array}{l}3133 \text { bp NdeI-arg2-M1-V1-mod5-SbfI } \\
\text { fragment from pUC18-arg2-M1-V1-mod5 } \\
\text { ligated into pArg2345-V1 hydrolyzed with } \\
\text { the same enzymes }\end{array}$ & $\begin{array}{l}\text { expression vector with } P_{n p t I I}-\arg 2 *_{-} \text {-arg3- } \\
\text { arg4-arg5-V1- } t_{D I} \text { transcription unit } \\
(* \mathrm{~A} 1 \text { mutation mod5; Table S11), } \\
\text { p15A ori, } \mathrm{kan}^{R}, \text { tet }^{R}\end{array}$ \\
\hline pArg2345-V1-mod6 & $\begin{array}{l}3133 \text { bp NdeI-arg2-M1-V1-mod6-SbfI } \\
\text { fragment from pUC18-arg2-M1-V1-mod6 } \\
\text { ligated into pArg2345-V1 hydrolyzed with } \\
\text { the same enzymes }\end{array}$ & $\begin{array}{l}\text { expression vector with } P_{n p t I I}-\arg 2 *_{-} \text {arg3- } \\
\text { arg4-arg5-V1- } t_{D 1} \text { transcription unit } \\
(* \mathrm{~A} 1 \text { mutation mod6; Table S11), } \\
\text { p15A ori, } \mathrm{kan}^{R}, \mathrm{tet}^{R}\end{array}$ \\
\hline pArg2345-V1-mod7 & $\begin{array}{l}3133 \text { bp NdeI-arg2-M1-V1-mod7-SbfI } \\
\text { fragment from pUC18-arg2-M1-V1-mod7 } \\
\text { ligated into pArg2345-V1 hydrolyzed with } \\
\text { the same enzymes }\end{array}$ & $\begin{array}{l}\text { expression vector with } P_{n p t I I}-\arg 2 *_{-} \text {arg3- } \\
\text { arg4-arg5-V1- } t_{D I} \text { transcription unit } \\
(* \mathrm{~A} 1 \text { mutation mod7; Table S11), } \\
\text { p15A ori, } \mathrm{kan}^{R}, \mathrm{tet}^{R}\end{array}$ \\
\hline pArg2345-V1-mod8 & $\begin{array}{l}3133 \text { bp NdeI-arg2-M1-V1-mod8-SbfI } \\
\text { fragment from pUC18-arg2-M1-V1-mod8 } \\
\text { ligated into pArg2345-V1 hydrolyzed with } \\
\text { the same enzymes }\end{array}$ & $\begin{array}{l}\text { expression vector with } P_{n p t I I}-\arg 2 *_{-} \text {arg } 3- \\
\text { arg4-arg5-V1- } t_{D I} \text { transcription unit } \\
(* \mathrm{~A} 1 \text { mutation mod8; Table } \mathrm{S} 11) \\
\text { p15A ori, } \mathrm{kan}^{R}, \mathrm{tet}^{R}\end{array}$ \\
\hline pArg2345-V1-mod9 & $\begin{array}{l}3133 \text { bp NdeI-arg2-M1-V1-mod9-SbfI } \\
\text { fragment from pUC18-arg2-M1-V1-mod9 } \\
\text { ligated into pArg2345-V1 hydrolyzed with } \\
\text { the same enzymes }\end{array}$ & $\begin{array}{l}\text { expression vector with } P_{n p t I I}-\arg 2 * \text {-arg3- } \\
\text { arg4-arg5-V1- } t_{D I} \text { transcription unit } \\
(* \mathrm{~A} 1 \text { mutation mod9; Table S11), } \\
\text { p15A ori, } \mathrm{kan}^{R}, \text { tet }^{R}\end{array}$ \\
\hline $\begin{array}{l}\mathrm{pArg} 2345-\mathrm{V} 1- \\
\bmod 10\end{array}$ & $\begin{array}{l}3133 \text { bp NdeI-arg2-M1-V1-mod10-SbfI } \\
\text { fragment from pUC18-arg2-M1-V1- } \\
\text { mod10 ligated pArg2345-V1 hydrolyzed } \\
\text { with NdeI/SbfI }\end{array}$ & $\begin{array}{l}\text { expression vector with } P_{n p t I I}-\arg 2 * \text {-arg3- } \\
\text { arg4-arg5-V1- } t_{D I} \text { transcription unit } \\
(* \text { A1 mutation mod10; Table S11), } \\
\text { p15A ori, } \mathrm{kan}^{R}, \text { tet }^{R}\end{array}$ \\
\hline pArg2345-V1- & 3133 bp NdeI-arg2-M1-V1-mod11-SbfI & expression vector with $P_{n p t I I}-\arg 2 *$-arg3- \\
\hline
\end{tabular}




\begin{tabular}{|c|c|c|}
\hline $\bmod 11$ & $\begin{array}{l}\text { fragment from pUC18-arg2-M1-V1- } \\
\text { mod11 ligated into pArg2345-V1 } \\
\text { hydrolyzed with the same enzymes }\end{array}$ & 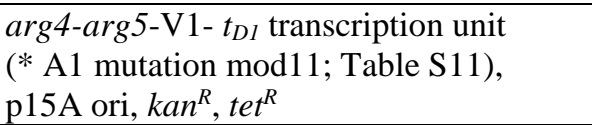 \\
\hline $\begin{array}{l}\text { pArg2345-V1- } \\
\text { mod12 }\end{array}$ & $\begin{array}{l}3133 \text { bp NdeI-arg2-M1-V1-mod12-SbfI } \\
\text { fragment from pUC18-arg2-M1-V1- } \\
\text { mod12 ligated into pArg2345-V1 } \\
\text { hydrolyzed with the same enzymes }\end{array}$ & $\begin{array}{l}\text { expression vector with } P_{n p t I I}-\arg 2 * \text {-arg } 3- \\
\arg 4-\arg 5-\mathrm{V} 1-t_{D I} \text { transcription unit } \\
(* \mathrm{~A} 1 \text { mutation mod12; Table S11), } \\
\text { p15A ori, } \mathrm{kan}^{R}, \text { tet }^{R}\end{array}$ \\
\hline $\begin{array}{l}\text { pArg2345-V1- } \\
\text { mod13 }\end{array}$ & $\begin{array}{l}3133 \text { bp NdeI-arg2-M1-V1-mod13-SbfI } \\
\text { fragment from pUC18-arg2-M1-V1- } \\
\text { mod13 ligated into pArg2345-V1 } \\
\text { hydrolyzed with the same enzymes }\end{array}$ & $\begin{array}{l}\text { expression vector with } P_{n p t I I}-\arg 2 * \text {-arg } 3- \\
\arg 4-\arg 5-\mathrm{V} 1-t_{D I} \text { transcription unit } \\
(* \mathrm{~A} 1 \text { mutation mod13; Table S11), } \\
\text { p15A ori, } \mathrm{kan}^{R}, \text { tet }^{R}\end{array}$ \\
\hline $\begin{array}{l}\text { pArg2345-V1- } \\
\text { mod14 }\end{array}$ & $\begin{array}{l}3133 \text { bp NdeI-arg2-M1-V1-mod14-SbfI } \\
\text { fragment from pUC18-arg2-M1-V1- } \\
\text { mod14 ligated into pArg2345-V1 } \\
\text { hydrolyzed with the same enzymes }\end{array}$ & $\begin{array}{l}\text { expression vector with } P_{n p t I I}-\arg 2 * \text {-arg3- } \\
\text { arg4-arg5-V1- } t_{D I} \text { transcription unit } \\
(* \text { A1 mutation mod14; Table S11), } \\
\text { p15A ori, } \text { kan }^{R}, \text { tet }^{R}\end{array}$ \\
\hline $\begin{array}{l}\text { pGH-arg2-M1-M2- } \\
\text { V1-BsaI }\end{array}$ & $\begin{array}{l}3359 \text { bp SbfI-arg2-M2-V1-BsaI-BglII } \\
\text { fragment derived from pGH-arg2-M2-V1 } \\
\text { ligated into pGH-arg2-M1-V1 hydrolyzed } \\
\text { with the same enzymes }\end{array}$ & $\begin{array}{l}\text { synthetic arg2-V1-BsaI fragment } \\
\text { (encoding modules M1-M2 of NRPS } \\
\text { Arg2), pUC ori, } a m p^{R}\end{array}$ \\
\hline pGH-arg2-V1-BsaI & $\begin{array}{l}4303 \text { bp } M l u \mathrm{I}-\arg 2-\mathrm{M} 3-\mathrm{V} 1-\mathrm{BsaI}-\mathrm{Bg} \mathrm{III} \\
\text { fragment derived from pGH-arg2-M3-V1 } \\
\text { ligated into pGH-arg2-M1-M2-V1 } \\
\text { hydrolyzed with the same enzymes }\end{array}$ & $\begin{array}{l}\text { complete synthetic arg2-V1-BsaI gene } \\
\text { (encoding modules M1-M3 of NRPS } \\
\text { Arg2), pUC ori, } a m p^{R}\end{array}$ \\
\hline $\begin{array}{l}\text { pGH-arg3-M5-M6- } \\
\text { V1-BsaI }\end{array}$ & $\begin{array}{l}3153 \text { bp AscI-arg3-M6-V1-BsaI-BglII } \\
\text { fragment from pGH-arg3-M6-V1-BsaI } \\
\text { ligated into pGH-arg3-M5-V1-BsaI } \\
\text { hydrolyzed with the same enzymes }\end{array}$ & $\begin{array}{l}\text { synthetic arg3-M5-M6-V1-BsaI fragment } \\
\text { (encoding modules M5-M6 of NRPS } \\
\text { Arg3), pUC ori, } a m p^{R}\end{array}$ \\
\hline $\begin{array}{l}\text { pGH-arg3-M5-M6- } \\
\text { M7-V1-BsaI }\end{array}$ & $\begin{array}{l}3157 \text { bp NotI-arg3-M7-V1-BsaI- BglII } \\
\text { fragment from pGH-arg3-M7-V1-BsaI } \\
\text { ligated into pGH-arg3-M5-M6-V1-BsaI } \\
\text { hydrolyzed with the same enzymes }\end{array}$ & $\begin{array}{l}\text { synthetic arg3-M5-M6-M7-V1-BsaI } \\
\text { fragment (encoding modules M5-M7 of } \\
\text { NRPS Arg3), pUC ori, amp }\end{array}$ \\
\hline $\begin{array}{l}\text { pGH-arg3-M5-M6- } \\
\text { M7-M8-V1-BsaI }\end{array}$ & $\begin{array}{l}4023 \text { bp MfeI-arg3-M8-V1-BsaI-BglII } \\
\text { fragment from pGH-arg3-M8-V1-BsaI } \\
\text { ligated into pGH-arg3-M5-M6-M7-V1- } \\
\text { BsaI hydrolyzed with the same enzymes }\end{array}$ & $\begin{array}{l}\text { synthetic arg3-M5-M6-M7-M8-V1-BsaI } \\
\text { fragment (encoding modules M5-M8 of } \\
\text { NRPS Arg3), pUC ori, } a m p^{R}\end{array}$ \\
\hline pGH-arg3-V1-BsaI & $\begin{array}{l}3223 \text { bp NdeI-arg3-M4-V1-BsaI-KpnI } \\
\text { fragment from pGH-arg3-M4-V1-BsaI } \\
\text { ligated into pGH-arg3-M5-M6-M7-M8- } \\
\text { V1-BsaI hydrolyzed with the same } \\
\text { enzymes }\end{array}$ & $\begin{array}{l}\text { complete synthetic arg3-V1-BsaI } \\
\text { fragment (encoding modules M4-M8 of } \\
\text { NRPS Arg3), pUC ori, } a m p^{R}\end{array}$ \\
\hline pArg2-V1-BsaI & $\begin{array}{l}10755 \text { bp NdeI-arg2-V1-BsaI- } B g l \mathrm{II} \\
\text { fragment from pGH-arg2-V1 ligated into } \\
\text { pSynBio3 hydrolyzed with the same } \\
\text { enzymes }\end{array}$ & $\begin{array}{l}\text { expression vector with } P_{n p t I I} \text { arg2-V1- } \\
\text { BsaI- } t_{D I} \text { transcription unit, } \\
\text { p15A ori, } \text { kan }^{R}, \text { tet }^{R}\end{array}$ \\
\hline pArg23-V1-BsaI & $\begin{array}{l}17923 \text { bp SphI-arg3-V1-BsaI-BglII } \\
\text { fragment from pGH-arg3-V1 ligated into } \\
\text { pArg2-V1-BsaI hydrolyzed with the same } \\
\text { enzymes }\end{array}$ & $\begin{array}{l}\text { expression vector with } P_{n p t I I} \text {-arg2-arg3- } \\
\text { V1-BsaI- } t_{D I} \text { transcription unit, } \\
\text { p15A ori, } \text { kan }^{R}, \text { tet }^{R}\end{array}$ \\
\hline pArg234-V1-BsaI & $\begin{array}{l}1047 \text { bp NsiI-arg4-V1-BsaI-BglII fragment } \\
\text { from pGH-arg4-V1-BsaI ligated into } \\
\text { pArg23-V1-BsaI hydrolyzed with the same } \\
\text { enzymes }\end{array}$ & $\begin{array}{l}\text { expression vector with } P_{n p t I}-\arg 2-\arg 3- \\
\text { arg4-V1-BsaI- } t_{D I} \text { transcription unit, } \\
\text { p15A ori, } \text { kan }^{R}, \text { tet }^{R}\end{array}$ \\
\hline pArg2345-V1-BsaI & $\begin{array}{l}1222 \text { bp NcoI-arg5-V1-BsaI-BglII } \\
\text { fragment from pGH-arg5-V1-BsaI ligated } \\
\text { into pArg234-V1-BsaI hydrolyzed with the } \\
\text { same enzymes }\end{array}$ & $\begin{array}{l}\text { expression vector with } P_{n p t I I} \text {-arg2-arg3- } \\
\text { arg4-arg5-V1-BsaI- } t_{D I} \text { transcription unit, } \\
\text { p15A ori, } \text { kan }^{R}, \text { tet }^{R}\end{array}$ \\
\hline
\end{tabular}


Table S6. NMR spectroscopic data of argyrin I.

\begin{tabular}{|c|c|c|c|c|}
\hline Res & $\Delta^{13} C^{a, c}$ & $\Delta^{1} \mathbf{H}^{b}$ & Mult & $\mathbf{J}(\mathbf{H z})$ \\
\hline Thiaz NH & & 8.81 & $\mathrm{~d}$ & 8.6 \\
\hline 1 & 159.8 & & & \\
\hline 2 & 150.1 & & & \\
\hline 3 & 122.9 & 8.03 & $\mathrm{~s}$ & \\
\hline 4 & 170.8 & & & \\
\hline 5 & 45.5 & 5.48 & $\mathrm{~d}, \mathrm{q}$ & $7.1,7.6$ \\
\hline 6 & 20.7 & 1.71 & $\mathrm{~d}$ & 7.2 \\
\hline Trp1 NH & & 8.56 & $\mathrm{~d}$ & 7.3 \\
\hline 1 & 172.7 & & & \\
\hline 2 & 52.2 & 5.10 & $\mathrm{~m}$ & \\
\hline \multirow[t]{2}{*}{3} & 27.0 & 3.49 & $\mathrm{~d}, \mathrm{~d}$ & $15.5,3.3$ \\
\hline & & 2.88 & $\mathrm{~d}, \mathrm{~d}$ & $15.3,3.4$ \\
\hline $1^{\prime} \mathrm{NH}$ & & 10.66 & $\mathrm{~s}$ & \\
\hline $2^{\prime}$ & 125.9 & $6.99^{d}$ & $\mathrm{~d}$ & 2.6 \\
\hline $3^{\prime}$ & 105.5 & & & \\
\hline $4^{\prime}$ & 115.9 & 6.22 & $\mathrm{~d}$ & 7.8 \\
\hline $5^{\prime}$ & 119.8 & 6.52 & $\mathrm{~d}, \mathrm{~d}$ & $7.4,7.4$ \\
\hline $6^{\prime}$ & 121.5 & $6.98^{d}$ & $\mathrm{~d}, \mathrm{~d}$ & $7.6,7.6$ \\
\hline $7^{\prime}$ & 111.8 & 7.14 & $\mathrm{~d}$ & 7.9 \\
\hline $8^{\prime}$ & 134.9 & & & \\
\hline $9^{\prime}$ & 126.5 & & & \\
\hline Trp2 NH & & 6.61 & $\mathrm{~m}$ & \\
\hline 1 & 169.9 & & & \\
\hline 2 & 56.4 & 4.28 & $\mathrm{~m}$ & \\
\hline \multirow[t]{2}{*}{3} & 26.6 & 3.37 & $\mathrm{~d}, \mathrm{~d}$ & $15.3,5.2$ \\
\hline & & 3.31 & $\mathrm{~d}, \mathrm{~d}$ & $15.2,4.9$ \\
\hline $1^{\prime} \mathrm{NH}$ & & 8.41 & $\mathrm{~s}$ & \\
\hline $2^{\prime}$ & 123.4 & 7.21 & $\mathrm{~d}$ & 2.1 \\
\hline $3^{\prime}$ & 109.1 & & & \\
\hline $4^{\prime}$ & 117.9 & 7.62 & $\mathrm{~d}$ & 7.8 \\
\hline $5^{\prime}$ & 121.1 & 7.29 & $\mathrm{~d}, \mathrm{~d}$ & $7.6,7.6$ \\
\hline $6^{\prime}$ & 123.5 & 7.39 & $\mathrm{~d}, \mathrm{~d}$ & $8.0,7.7$ \\
\hline $7^{\prime}$ & 112.1 & 7.60 & $\mathrm{~d}$ & 8.1 \\
\hline $8^{\prime}$ & 136.6 & & & \\
\hline $9^{\prime}$ & 127.3 & & & \\
\hline Gly NH & & 4.75 & $\mathrm{~m}$ & \\
\hline 1 & 171.1 & & & \\
\hline \multirow[t]{2}{*}{2} & 41.2 & 3.62 & $\mathrm{~d}, \mathrm{~d}$ & $17.1,7.8$ \\
\hline & & 1.29 & $\mathrm{~m}$ & \\
\hline Abu NH & & 6.67 & $\mathrm{~d}$ & 6.5 \\
\hline 1 & 169.2 & & & \\
\hline 2 & 54.5 & 4.01 & $\mathrm{t}, \mathrm{d}$ & $8.8,6.3$ \\
\hline \multirow[t]{2}{*}{3} & 21.3 & 1.99 & $\mathrm{~m}$ & \\
\hline & & 1.86 & $\mathrm{~m}$ & \\
\hline 4 & 10.7 & 0.89 & $\mathrm{t}$ & 7.3 \\
\hline DeAla NH & & 9.36 & & \\
\hline 1 & 168.2 & & & \\
\hline 2 & 136.8 & & & \\
\hline \multirow[t]{2}{*}{3} & 99.7 & 5.03 & $\mathrm{~d}$ & 1.5 \\
\hline & & 4.74 & $\mathrm{~m}$ & \\
\hline \multicolumn{5}{|l|}{ Sarc } \\
\hline 1 & 166.8 & & & \\
\hline \multirow[t]{2}{*}{2} & 51.2 & 4.99 & $\mathrm{~d}$ & 17.0 \\
\hline & & 3.41 & $\mathrm{~d}$ & 16.9 \\
\hline $\mathrm{CH}_{3}-\mathrm{N}$ & 37.4 & 3.11 & $\mathrm{~s}$ & \\
\hline
\end{tabular}

${ }^{a}$ acquired at $175 \mathrm{MHz}$ and assigned from 2D NMR spectra, referenced to solvent signal $\mathrm{CDCl}_{3}$ at $\delta 77.16 \mathrm{ppm}$.

${ }^{b}$ acquired at $700 \mathrm{MHz}$, referenced to solvent signal $\mathrm{CDCl}_{3}$ at $\delta 7.26 \mathrm{ppm}$.

${ }^{c}$ proton showing HMBC correlations to indicated carbons.

${ }^{d}$ overlapped signals. 
Table S7. NMR spectroscopic data of argyrin J.

\begin{tabular}{|c|c|c|c|c|}
\hline Res & $\Delta^{13} C^{a, c}$ & $\Delta^{1} \mathbf{H}^{b}$ & Mult & $\mathbf{J}(\mathbf{H z})$ \\
\hline Thiaz NH & & 9.08 & $\mathrm{~d}, \mathrm{~d}$ & $8.0,4.4$ \\
\hline 1 & 159.6 & & & \\
\hline 2 & 150.3 & & & \\
\hline 3 & 123.9 & 8.08 & $\mathrm{~s}$ & \\
\hline 4 & 165.6 & & & \\
\hline 5 & 39.4 & 5.14 & $\mathrm{~d}, \mathrm{~d}$ & $8.2,14.4$ \\
\hline Trp1 NH & & 8.64 & $\mathrm{~d}$ & 7.3 \\
\hline 1 & 172.9 & & & \\
\hline 2 & 52.3 & 5.04 & $\mathrm{~m}$ & \\
\hline \multirow[t]{2}{*}{3} & 26.8 & 3.55 & $\mathrm{~d}, \mathrm{~d}$ & $15.2,3.7$ \\
\hline & & 2.84 & $\mathrm{~d}, \mathrm{~d}$ & $15.4,3.1$ \\
\hline $1^{\prime} \mathrm{NH}$ & & 10.6 & $\mathrm{~s}$ & \\
\hline $2^{\prime}$ & 125.6 & 6.99 & $\mathrm{~d}$ & 2.6 \\
\hline $3^{\prime}$ & 105.7 & & & \\
\hline $4^{\prime}$ & 116.1 & 5.43 & $\mathrm{~d}$ & 7.8 \\
\hline $5^{\prime}$ & 119.2 & 6.34 & $\mathrm{~d}, \mathrm{~d}$ & $8.0,8.0$ \\
\hline $6^{\prime}$ & 121.4 & 6.88 & $\mathrm{~d}, \mathrm{~d}$ & $6.9,6.9$ \\
\hline $7^{\prime}$ & 111.5 & 7.04 & $\mathrm{~d}$ & 8.1 \\
\hline $8^{\prime}$ & 134.8 & & & \\
\hline $9^{\prime}$ & 126.5 & & & \\
\hline Trp2 NH & & 8.77 & $\mathrm{~m}$ & \\
\hline 1 & 169.9 & & & \\
\hline 2 & 57.9 & 4.21 & $\mathrm{~m}$ & \\
\hline \multirow[t]{2}{*}{3} & 27.2 & 3.49 & $\mathrm{~m}$ & \\
\hline & & 3.32 & $\mathrm{~d}, \mathrm{~d}$ & $14.9,3.9$ \\
\hline $1^{\prime} \mathrm{NH}$ & & 8.29 & $\mathrm{~s}$ & \\
\hline $2^{\prime}$ & 123.8 & 6.84 & $\mathrm{~d}$ & 2.2 \\
\hline $3^{\prime}$ & 108.3 & & & \\
\hline $4^{\prime}$ & 152.3 & & & \\
\hline $5^{\prime}$ & 101.5 & 6.92 & $\mathrm{~m}$ & \\
\hline $6^{\prime}$ & 123.8 & $7.34^{d}$ & $\mathrm{~m}$ & \\
\hline $7^{\prime}$ & 106.7 & $7.34^{d}$ & $\mathrm{~m}$ & \\
\hline $8^{\prime}$ & 138.3 & & & \\
\hline $9^{\prime}$ & 117.4 & & & \\
\hline 4'O-Me & 56.4 & 4.34 & $\mathrm{~s}$ & \\
\hline Gly NH & & 4.53 & $\mathrm{~m}$ & \\
\hline 1 & 171.5 & & & \\
\hline \multirow[t]{2}{*}{2} & 40.8 & 3.49 & $\mathrm{~m}$ & \\
\hline & & 1.05 & $\mathrm{~d}, \mathrm{~d}$ & $17.1,5.2$ \\
\hline Abu NH & & 6.76 & $\mathrm{~d}$ & 6.5 \\
\hline 1 & 169.5 & & & \\
\hline 2 & 54.7 & 3.97 & $\mathrm{t}, \mathrm{d}$ & $8.9,6.2$ \\
\hline \multirow[t]{2}{*}{3} & 21.2 & 2.00 & $\mathrm{~m}$ & \\
\hline & & 1.87 & $\mathrm{~m}$ & \\
\hline 4 & 10.6 & 0.88 & $\mathrm{t}$ & 7.5 \\
\hline DeAla NH & & 9.44 & & \\
\hline 1 & 168.3 & & & \\
\hline 2 & 136.8 & & & \\
\hline \multirow[t]{2}{*}{3} & 100.1 & 5.02 & $\mathrm{~d}$ & 1.4 \\
\hline & & 4.73 & $\mathrm{~m}$ & \\
\hline \multicolumn{5}{|l|}{ Sarc } \\
\hline 1 & 167.7 & & & \\
\hline \multirow[t]{2}{*}{2} & 51.4 & 4.96 & $\mathrm{~d}$ & 16.8 \\
\hline & & 3.41 & $\mathrm{~d}$ & 16.8 \\
\hline $\mathrm{CH}_{3}-\mathrm{N}$ & 37.7 & 3.10 & $\mathrm{~s}$ & \\
\hline
\end{tabular}

${ }^{a}$ acquired at $175 \mathrm{MHz}$ and assigned from 2D NMR spectra, referenced to solvent signal $\mathrm{CDCl}_{3}$ at $\delta 77.16 \mathrm{ppm}$.

${ }^{b}$ acquired at $700 \mathrm{MHz}$, referenced to solvent signal $\mathrm{CDCl}_{3}$ at $\delta 7.26 \mathrm{ppm}$.

${ }^{c}$ proton showing HMBC correlations to indicated carbons.

${ }^{d}$ overlapped signals. 
Table S8. Restriction sites (R-sites) engineered within the arg BGC and pSynBio3 sequence. R-sites introduced into coding sequences (CDS) are shown in bold. In total, 22 different restriction enzymes were selected for engineering including EcoRI as backup for future approaches. Introduced R-sites are unique within the $\arg$ BGC and pSynBio3, respectively. Interfering R-sites in other positions were eliminated during sequence modulation.

\begin{tabular}{|l|l|l|}
\hline arg BGC & Position ${ }^{\star}$ & R-site \\
\hline 5' end arg BGC & 3 & NdeI \\
\hline 5' end arg2 & 14 & AvrII \\
\hline 5' end arg2 & 181 & StuI \\
\hline M1/M2 linker arg2 & 3116 & SbfI \\
\hline M2/M3 linker arg2 & 6455 & MluI \\
\hline 3'end arg2 / 5' end arg3 & 10746 & SphI \\
\hline M4/M5 linker arg3 & 13954 & KpnI \\
\hline M5/M6 linker arg3 & 18365 & AscI \\
\hline M6/M7 linker arg3 & 21501 & NotI \\
\hline M7/M8 linker arg3 & 24642 & MfeI \\
\hline 3'end arg3 / 5' end arg4 & 28641 & NsiI \\
\hline 3'end arg4 / 5' end arg5 & 29668 & NcoI \\
\hline 3' end arg5 / arg BGC & 30886 & BglII \\
\hline
\end{tabular}

\$ with $\mathrm{NdeI}=$ start of artificial $\arg$ BGC sequence

\begin{tabular}{|l|l|l|}
\hline pSynBio3 & Position & R-site \\
\hline upstream $P_{n p t I I}$ & 5 & PciI \\
\hline 5' end MCS & 151 & NdeI \\
\hline MCS & 162 & AvrII \\
\hline MCS & 179 & SbfI \\
\hline MCS & 188 & MluI \\
\hline MCS & 204 & SphI \\
\hline MCS & 216 & KpnI \\
\hline MCS & 225 & AscI \\
\hline MCS & 239 & NotI \\
\hline MCS & 252 & MfeI \\
\hline MCS & 268 & NsiI \\
\hline MCS & 276 & NcoI \\
\hline 3' end MCS & 288 & BglII \\
\hline downstream $t_{D 1}$ & 587 & PmeI \\
\hline upstream p15A ori & 589 & AflII \\
\hline downstream p15A ori & 1571 & SspI \\
\hline 5' end kan $^{R}$ & 1589 & SpeI \\
\hline 3' end kan $^{R}$ & 2645 & EcoRV \\
\hline 5' end tet $^{R}$ & 2659 & PacI \\
\hline 3' end tet $^{R}$ & 4044 & SwaI \\
\hline
\end{tabular}

\begin{tabular}{|l|}
\hline $\begin{array}{l}\text { Selected enzymes } \\
\text { (alphabetically) }\end{array}$ \\
\hline$A f l \mathrm{II}$ \\
\hline$A s c \mathrm{I}$ \\
\hline$A v r \mathrm{II}$ \\
\hline$B g l \mathrm{II}$ \\
\hline EcoRI \\
\hline$E c o \mathrm{RV}$ \\
\hline$K p n \mathrm{I}$ \\
\hline$M f e \mathrm{I}$ \\
\hline$M l u \mathrm{I}$ \\
\hline NcoI \\
\hline NdeI \\
\hline NotI \\
\hline$N s i \mathrm{I}$ \\
\hline$P a c \mathrm{I}$ \\
\hline$P c i \mathrm{I}$ \\
\hline$P m e \mathrm{I}$ \\
\hline$S b f \mathrm{I}$ \\
\hline$S p e \mathrm{I}$ \\
\hline$S p h \mathrm{I}$ \\
\hline$S s p \mathrm{I}$ \\
\hline$S t u \mathrm{I}$ \\
\hline$S w a \mathrm{I}$ \\
\hline
\end{tabular}

Table S9. Sequence features of synthetic arg BGC versions compared to the native sequence. The coding sequences (CDS) are compared regarding three features: GC content (GC), codon adaptation index (CAI) and the degree of modification (Mod), which denotes the number of modified codons relative to the native sequence (percent change in parentheses).

\begin{tabular}{|l|c|c|c|c|c|c|c|c|c|c|c|c|}
\hline Gene & \multicolumn{2}{|c|}{ arg2(3539 Codons) } & \multicolumn{2}{c|}{ arg3(5947 Codons) } & \multicolumn{3}{c|}{ arg4(337 Codons) } & \multicolumn{3}{|c|}{ arg5(384 Codons) } \\
\hline Feature & GC & CAI & Mod & GC & CAI & Mod & GC & CAI & Mod & GC & CAI & Mod \\
\hline native & 64.8 & 0.617 & 0 & 66.0 & 0.655 & 0 & 63.7 & 0.618 & 0 & 63.5 & 0.630 & 0 \\
\hline V1 & 64.9 & 0.619 & $\begin{array}{c}24 \\
(0.7 \%)\end{array}$ & 66.1 & 0.655 & $\begin{array}{c}40 \\
(0.7 \%)\end{array}$ & 64.1 & 0.629 & $\begin{array}{c}4 \\
(1.2 \%)\end{array}$ & 63.5 & 0.629 & $\begin{array}{c}4 \\
(1.0 \%)\end{array}$ \\
\hline V2 & 66.9 & 0.716 & $\begin{array}{c}1745 \\
(49.3 \%)\end{array}$ & 66.9 & 0.704 & $\begin{array}{c}2946 \\
(49.5 \%)\end{array}$ & 65.2 & 0.702 & $\begin{array}{c}167 \\
(49.6 \%)\end{array}$ & 65.5 & 0.732 & $\begin{array}{c}185 \\
(48.2 \%)\end{array}$ \\
\hline V1-BsaI & 64.9 & 0.621 & $\begin{array}{c}36 \\
(1.0 \%)\end{array}$ & 66.1 & 0.657 & $\begin{array}{c}56 \\
(0.9 \%)\end{array}$ & 64.1 & 0.632 & $\begin{array}{c}7 \\
(2.1 \%)\end{array}$ & 63.5 & 0.630 & $\begin{array}{c}5 \\
(1.3 \%)\end{array}$ \\
\hline
\end{tabular}


Table S10. HPLC-MS data of argyrin derivatives detected in the heterologous expression strains.

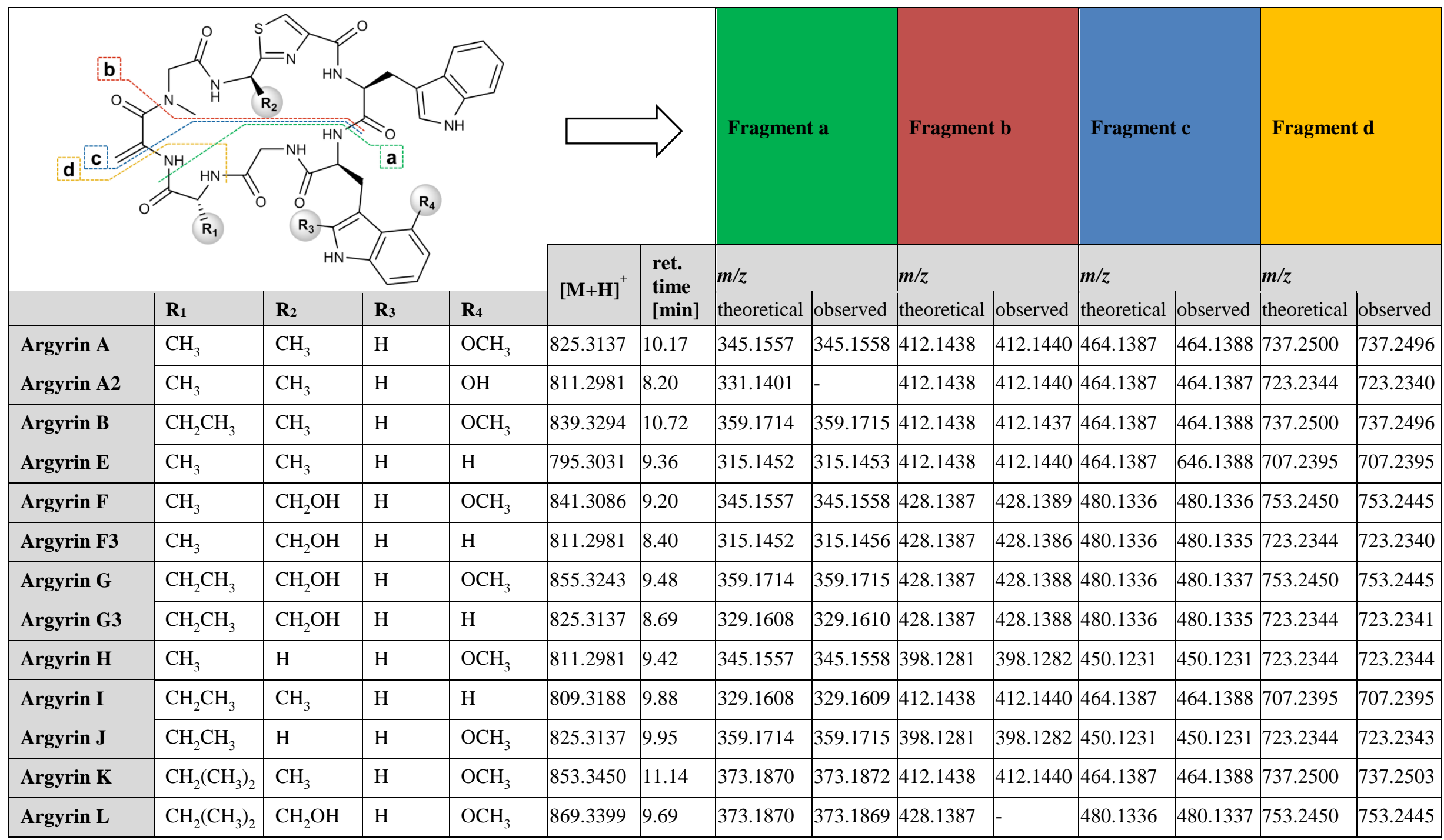


Table S11. Nonribosomal codes of A domains. Nonribosomal codes of A domains from different BGC, aligned with native argyrin A1 code (Arg-A1) and 14 engineered A1 domain codes (modified residues are highlighted in bold). Residue numbering is adapted according to GrsA. ${ }^{15}$

\begin{tabular}{|c|c|c|c|c|c|c|c|c|c|c|}
\hline A domain & 235 & 236 & 239 & 278 & 299 & 301 & 322 & 330 & 331 & 517 \\
\hline Arg-A1 & $\mathrm{D}$ & $\mathrm{V}$ & $\mathrm{L}$ & $\mathrm{F}$ & $\mathrm{L}$ & $\mathrm{G}$ & $\mathrm{V}$ & $\mathrm{V}$ & $\mathrm{A}$ & $\mathrm{K}$ \\
\hline $\operatorname{Mch}_{\mathrm{A}}-\mathrm{A} 2^{1}$ (Ala) & $\mathrm{D}$ & V & $\mathrm{W}$ & V & I & A & A & $\mathrm{V}$ & I & $\mathrm{K}$ \\
\hline A1-mod1 & $\mathrm{D}$ & $\mathbf{V}$ & $\mathbf{W}$ & $\mathbf{V}$ & $\mathbf{I}$ & $\mathbf{A}$ & $\mathbf{A}$ & $\mathbf{V}$ & $\mathbf{A}$ & $\mathrm{K}$ \\
\hline $\mathrm{Mch}_{\mathrm{A}}-\mathrm{A} 5^{2}$ (Ala) & $\mathrm{D}$ & $\mathrm{V}$ & $\mathrm{W}$ & $\mathrm{V}$ & $\mathrm{T}$ & A & A & I & I & $\mathrm{K}$ \\
\hline A $1-\bmod 2$ & $\mathrm{D}$ & $\mathbf{V}$ & $\mathbf{W}$ & $\mathbf{V}$ & $\mathbf{T}$ & $\mathbf{A}$ & $\mathbf{A}$ & I & $\mathbf{A}$ & $\mathrm{K}$ \\
\hline $\mathrm{Mch}_{\mathrm{S}}-\mathrm{A} 3^{3}(\mathrm{Ala})$ & $\mathrm{D}$ & $\mathrm{V}$ & M & $\mathrm{F}$ & I & $\mathrm{G}$ & I & $\mathrm{V}$ & A & $\mathrm{K}$ \\
\hline A1-mod3 & $\mathrm{D}$ & $\mathbf{V}$ & $\mathbf{M}$ & $\mathrm{F}$ & $\mathbf{I}$ & $\mathbf{G}$ & I & $\mathbf{V}$ & $\mathbf{A}$ & $\mathrm{K}$ \\
\hline $\mathrm{Mch}_{\mathrm{S}}-\mathrm{A} 5^{4}$ (Ala) & $\mathrm{D}$ & V & $\mathrm{W}$ & V & $\mathrm{L}$ & A & A & I & I & $\mathrm{K}$ \\
\hline A1-mod4 & $\mathrm{D}$ & $\mathbf{V}$ & $\mathbf{W}$ & $\mathbf{V}$ & $\mathrm{L}$ & $\mathbf{A}$ & $\mathbf{A}$ & I & $\mathbf{A}$ & $\mathrm{K}$ \\
\hline Arg-A4 (Ser/Gly) & $\mathrm{D}$ & $\mathrm{L}$ & $\mathrm{W}$ & $\mathrm{N}$ & $\mathrm{M}$ & G & $\mathrm{E}$ & $\mathrm{V}$ & W & $\mathrm{K}$ \\
\hline A1-mod5 & $\mathrm{D}$ & $\mathbf{L}$ & $\mathbf{W}$ & $\mathbf{N}$ & $\mathbf{M}$ & $\mathbf{G}$ & $\mathbf{E}$ & $\mathbf{V}$ & $\mathbf{A}$ & $\mathrm{K}$ \\
\hline A1-mod6 & $\mathrm{D}$ & $\mathbf{L}$ & $\mathbf{W}$ & $\mathbf{V}$ & $\mathbf{M}$ & $\mathbf{G}$ & $\mathbf{E}$ & $\mathbf{V}$ & $\mathbf{A}$ & $\mathrm{K}$ \\
\hline A1-mod7 & $\mathrm{D}$ & $\mathbf{L}$ & $\mathbf{W}$ & $\mathbf{N}$ & $\mathrm{L}$ & $\mathbf{G}$ & $\mathbf{E}$ & $\mathbf{V}$ & $\mathbf{A}$ & $\mathrm{K}$ \\
\hline A1-mod8 & $\mathrm{D}$ & $\mathbf{L}$ & $\mathbf{W}$ & $\mathbf{N}$ & $\mathbf{M}$ & $\mathbf{G}$ & $\mathbf{A}$ & $\mathbf{V}$ & $\mathbf{A}$ & $\mathrm{K}$ \\
\hline Sare $0718^{5}$ (Ala) & $\mathrm{D}$ & M & $\mathrm{W}$ & I & A & A & A & I & $\mathrm{V}$ & $\mathrm{K}$ \\
\hline A1-mod 9 & $\mathrm{D}$ & $\mathbf{M}$ & $\mathbf{W}$ & I & $\mathbf{A}$ & $\mathbf{A}$ & $\mathbf{A}$ & I & $\mathbf{A}$ & $\mathrm{K}$ \\
\hline Cyc-A6 $6^{6}(\mathrm{Abu})$ & $\mathrm{D}$ & A & $\mathrm{W}$ & $\mathrm{F}$ & $\mathrm{H}$ & A & $\mathrm{V}$ & A & $\mathrm{Y}$ & - \\
\hline A1-mod 10 & $\mathrm{D}$ & $\mathbf{A}$ & $\mathbf{W}$ & $\mathrm{F}$ & $\mathbf{H}$ & $\mathbf{A}$ & $\mathbf{V}$ & $\mathbf{A}$ & $\mathbf{A}$ & $\mathrm{K}$ \\
\hline A1-mod11 & $\mathrm{D}$ & $\mathbf{V}$ & $\mathbf{W}$ & $\mathrm{F}$ & $\mathbf{H}$ & G & $\mathbf{V}$ & $\mathbf{V}$ & $\mathbf{A}$ & $\mathrm{K}$ \\
\hline Tub-A37 (Val) & $\mathrm{D}$ & A & $\mathrm{F}$ & $\mathrm{W}$ & $\mathrm{L}$ & G & G & $\mathrm{T}$ & $\mathrm{F}$ & - \\
\hline A1-mod 12 & $\mathrm{D}$ & $\mathbf{A}$ & $\mathbf{F}$ & $\mathbf{W}$ & $\mathrm{L}$ & $\mathbf{G}$ & $\mathbf{G}$ & $\mathbf{T}$ & $\mathbf{A}$ & $\mathrm{K}$ \\
\hline A1-mod13 & $\mathrm{D}$ & $\mathbf{A}$ & $\mathbf{F}$ & $\mathbf{W}$ & $\mathrm{L}$ & $\mathbf{G}$ & $\mathbf{G}$ & $\mathbf{V}$ & $\mathbf{A}$ & $\mathrm{K}$ \\
\hline A1-mod14 & $\mathrm{D}$ & $\mathbf{A}$ & $\mathbf{F}$ & $\mathbf{W}$ & $\mathrm{L}$ & $\mathbf{G}$ & $\mathbf{V}$ & $\mathbf{T}$ & $\mathbf{A}$ & $\mathrm{K}$ \\
\hline
\end{tabular}

${ }^{1}$ A2 domain from the myxochromide A assembly line of M. xanthus DK1622 (YP_632256, aa 2028-2478) ${ }^{11}$

${ }^{2}$ A5 domain from the myxochromide A assembly line of $M$. xanthus DK1622 (YP_632257, aa 2575-3030) ${ }^{11}$

${ }^{3}$ A3 domain from the myxochromide S assembly line of $S$. aurantiaca DW4/3-1 (CAG29032, aa 475-949) ${ }^{21}$

${ }^{4}$ A5 domain from the myxochromide $S$ assembly line of $S$. aurantiaca DW4/3-1 (CAG29032, aa 2566-3036) ${ }^{21}$

${ }^{5}$ Alanine-activating A domain from Salinispora arenicola CNS-205 ( CP000850) $)^{22}$

${ }^{6} \mathrm{~A} 6$ domain from the cyclosporin assembly line of Tolypocladium inflatum (CAA82227, aa 7572-7976) ${ }^{23}$

${ }^{7}$ A3 domain from the tubulysin assembly line of Angiococcus disciformis An d48 (CAF05648, aa 1593-1993) ${ }^{24}$ 


\section{References}

(1) Ullrich, A., Chai, Y., Pistorius, D., Elnakady, Y. A., Herrmann, J. E., Weissman, K. J., Kazmaier, U., and Müller, R. (2009) Pretubulysin, a potent and chemically accessible tubulysin precursor from Angiococcus disciformis, Angew. Chem. Int. Ed. 48, 4422-4425.

(2) Sharma, S. B., and Signer, E. R. (1990) Temporal and spatial regulation of the symbiotic genes of Rhizobium meliloti in planta revealed by transposon Tn5-gusA, Genes. Dev. 4, 344-356.

(3) Tokarski, Z., Klei, H. E., and Berg, C. M. (1988) Novel biotechnology process for the production of (+)-2aminobutyrate, Biotechnol. Lett. 10, 7-10.

(4) Sasse, F., Steinmetz, H., Schupp, T., Petersen, F., Memmert, K., Hofmann, H., Heusser, C., Brinkmann, V., Matt, P. von, Hofle, G., and Reichenbach, H. (2002) Argyrins, immunosuppressive cyclic peptides from myxobacteria. I. Production, isolation, physico-chemical and biological properties, J. Antibiot. 55, 543-551.

(5) Oßwald, C., Zipf, G., Schmidt, G., Maier, J., Bernauer, H. S., Müller, R., and Wenzel, S. C. (2014) Modular Construction of a Functional Artificial Epothilone Polyketide Pathway, ACS Synth. Biol. 3, 759-772.

(6) Sharp, P. M., and Li, W.-H. (1987) The codon adaptation index-a measure of directional synonymous codon usage bias, and its potential applications, Nucleic Acids Res. 15, 1281-1295.

(7) Li, G. W., Oh, E., and Weissman, J. S. (2012) The anti-Shine-Dalgarno sequence drives translational pausing and codon choice in bacteria, Nature. 484, 538-541.

(8) Widmann, M., Clairo, M., Dippon, J., and Pleiss, J. (2008) Analysis of the distribution of functionally relevant rare codons, BMC Gen. 9, 1-8.

(9) Křížek, M., and Křížek, P. (2012) Why has nature invented three stop codons of DNA and only one start codon?, J. Theor. Biol. 304, 183-187.

(10) Seligmann, H., and Pollock, D. D. (2004) The ambush hypothesis. Hidden stop codons prevent off-frame gene reading, DNA Cell Biol. 23, 701-705.

(11) Wenzel, S. C., Meiser, P., Binz, T. M., Mahmud, T., and Müller, R. (2006) Nonribosomal Peptide Biosynthesis: Point Mutations and Module Skipping Lead to Chemical Diversity, Angew. Chem. Int. Ed. 45, 2296-2301.

(12) Wu, S. S., and Kaiser, D. (1996) Markerless deletions of pil genes in Myxococcus xanthus generated by counterselection with the Bacillus subtilis sacB gene, J. Bacteriol. 178, 5817-5821.

(13) Kashefi, K., and Hartzell, P. L. (1995) Genetic suppression and phenotypic masking of a Myxococcus xanthus frzF-defect, Mol. Microbiol. 15, 483-494.

(14) Yan, F., Burgard, C., Popoff, A., Zaburannyi, N., Zipf, G., Maier, J., Bernauer, H. S., Wenzel, S. C., and Müller, R. (2018) Synthetic biology approaches and combinatorial biosynthesis towards heterologous lipopeptide production, Chem. Sci. 9, 7510-7519.

(15) Stachelhaus, T., Mootz, H. D., and Marahiel, M. A. (1999) The specificity-conferring code of adenylation domains in nonribosomal peptide synthetases, Chem. Biol. 6, 493-505.

(16) Fu, J., Wenzel, S. C., Perlova, O., Wang, J., Gross, F., Tang, Z., Yin, Y., Stewart, A. F., Müller, R., and Zhang, Y. (2008) Efficient transfer of two large secondary metabolite pathway gene clusters into heterologous hosts by transposition, Nucleic Acids Res. 36, e113.

(17) Rausch, C., Hoof, I., Weber, T., Wohlleben, W., and Huson, D. H. (2007) Phylogenetic analysis of condensation domains in NRPS sheds light on their functional evolution, BMC Evol. Biol. 7, 78-92.

(18) Weber, T., Blin, K., Duddela, S., Krug, D., Kim, H. U., Bruccoleri, R., Lee, S. Y., Fischbach, M. A., Müller, R., Wohlleben, W., Breitling, R., Takano, E., and Medema, M. H. (2015) antiSMASH 3.0-a comprehensive resource for the genome mining of biosynthetic gene clusters, Nucleic Acids Res. 43, W237W243.

(19) Röttig, M., Medema, M. H., Blin, K., Weber, T., Rausch, C., and Kohlbacher, O. (2011) NRPSpredictor2 a web server for predicting NRPS adenylation domain specificity, Nucleic Acids Res. 39, W362-W367.

(20) Minowa, Y., Araki, M., and Kanehisa, M. (2007) Comprehensive Analysis of Distinctive Polyketide and Nonribosomal Peptide Structural Motifs Encoded in Microbial Genomes, J. Mol. Biol. 368, 1500-1517. 
(21) Wenzel, S. C., Kunze, B., Höfle, G., Silakowski, B., Scharfe, M., Blöcker, H., and Müller, R. (2005) Structure and Biosynthesis of Myxochromides $S_{1-3}$ in Stigmatella aurantiaca: Evidence for An Iterative Bacterial Type I Polyketide Synthase and for Module Skipping in Nonribosomal Peptide Biosynthesis, ChemBioChem 6, 375-385.

(22) Xia, S., Ma, Y., Zhang, W., Yang, Y., Wu, S., Zhu, M., Deng, L., Li, B., Liu, Z., and Qi, C. (2012) Identification of Sare0718 As an Alanine-Activating Adenylation Domain in Marine Actinomycete Salinispora arenicola CNS-205, PLoS ONE Epub 2012. DOI: 10.1371/journal.pone.0037487.

(23) Weber, G., and Leitner, E. (1994) Disruption of the cyclosporin synthetase gene of Tolypocladium niveum, Curr. Genet. 26, 461-467.

(24) Sandmann, A., Sasse, F., and Müller, R. (2004) Identification and analysis of the core biosynthetic machinery of tubulysin, a potent cytotoxin with potential anticancer activity, Chem. Biol. 11, 1071-1079. 